\title{
UNTERSUCHUNGEN \\ UEBER DAS MHD. GEDICHT VON DER MINNEBURG.
}

Von den minneallegorien des 14. jh.'s war nach Hadamars Jagd die von der Minneburg die beliebteste, sie fand eine ziemliche verbreitung und ist in einer verhältnismässig reichlichen anzahl von handschriften überliefert. Bis jetzt wurde sie von der forschung wenig beachtet. Ihr wert als selbständiges kunstwerk ist auch erstaunlich gering, sie bildet fast das letzt erreichbare ziel einer für andere zeiten und menschen ungeniessbaren manier. Doch ist sie als typus unter einer gruppe von erscheinungen für die geschichte der literatur und cultur wol nicht ohne interesse. Auch für sprachliche beobachtungen ist sie ein nicht ungeeignetes object, wie sie denn hinsichtlich des wortschatzes schon früher von A. Schönbach erfolgreich benutzt worden ist.

\section{I. \\ Die überlieferung.}

1. Die einzelnen handschriften.

Die handschriften der Minneburg sind angegeben von Raab, Ueber vier allegorische motive in der lateinischen und deutschen literatur des mittelalters s. 36 anm. 69 (ansser 1) und von Bartsch, Die altdeutschen hss. der universitäts-bibliothek in Heidelberg no. 208 (ausser 1 und c).

$P$, die Heidelberger pergamenths. (od. pal. germ. 455, 15. jh.. beschrieben von Bartsch a. a. o. no. 246, vgl. auch Ntejjskal. \%s. fda. $22,281 \mathrm{f}$. Jas gedicht steht anf bl. $86 \mathrm{a} .2_{20} 2^{\mathrm{l}}$. ist aher nicht vollstandig überliefert; ausserdem ist die let\%te seite (202v) abgerieben. Voraus gehen eine prosuisehe inhalts- 
alnalu, bl. 8.", darauf bis bl. 85," drei in sehr gekünstelter roimverschlingung abgefasste gedichte religiösen inhalts (s. IIII) ('II).

Dic mundart von $P$ ist ostfiänkisch: es fellen die speciell altmammischen und bairischen kennzeichen ebenso wie die rhein- und mittelfränkischen und die thüringisch-ostdeutschen; umgekehrt finden sich einige erscheinungen, die zusammengefasst den ostfränkischen dialekt ergeben, keine, die ihm direct widersprechen.

Z/um vocalismus ist $\mathrm{zu}$ bemerken: $\hat{a}$ ist häufig zu $\hat{o}$ geworden, besonders in zuor, mo/ze, kro, klo, dagegen meist an $=$ âne. Der umlaut ron $\hat{a}$ ist $\hat{e}$. Für $i e$ steht oft $i$, besonders in -ir, -iren : tir, schir, zirde, infinitiv -iren, und in dinen; immer in ging, hing. ei gilt für altes $e i$ und für die contraction aus egi. $u$ bezeichnet sowol $u, \hat{u}$ und $u o$ als auch häufig $\ddot{i}$, iu, iie. Mhd. ou ist au, $\sigma$ in flog, betrog. Mhd. öu ist eu, der umlaut ist auch eingetreten in lueubt, geleuben, bereuben. I)ie diphthongierung von $\hat{\imath} \mathrm{zu} e \hat{i}, \hat{\imath} \mathrm{zu} a \iota$, $\imath \imath \iota \mathrm{zu}$ eu ist nicht durchgedrungen, es finden sich nur etwa anderthalb dutzend fälle, worunter mehrmals kaum.

Der consonantismus steht ganz auf gemeinmhd. stufe, die verschiebungen sind durchgeführt, auch $d$ zu $t$. Das mhd. auslautsgesetz vom wechsel zwischen lenis und fortis ist nicht mehr streng beobachtet, aber es zeigt sich noch in einzelheiten, so ist \%.b. mit einer gewissen regelmässigkeit nom. acc. burk gegen gen. dat. burge (= bürge) bez. mit apokope burg geschrieben. - sl, sm, sn, sw sind noch nicht schl u.s.w., auch $t w$ ist erhalten, ebenso qu in quecklich, quam, quemen (neben liam, kemen); dagegen ist $r v \mathrm{zu} r b$ geworden; auch $m b \mathrm{zu} m m$ (oft einfach $m$ geschrieben), jedoch immer $u m b$; im auslaut hält sich $m b$ bez. mp länger, vgl. Riickert, Entwurf einer systemat. darstellung der schlesischen ma. hg. von Pietsch s. 177. Behaghel, Pauls Grundr. 1,592. v. Bahder, Zs. fdph.12, 485 und Germ. 23, 199 (die hier angeführte schreibung umbe ist archaistisch: regelrecht ist $u m b, e$ ist abgefallen ehe $m b \mathbf{z u} m m$ wurde; die form mit assimilation, um aus umbe, ist satzdoublette $\mathrm{zu} u m b) ; w$ tritt an stelle von $j$ in gebluwct, muwet, gluwende, vgl. Braune, Ahd. gramm. $§ 110$ anm. 2 und $\S 359$ anm. 3. v. Bahder, Germ. 23, 199. 
Im einzelnen ist hervoryuheben:

1. Die dem dialekt des gedichtes entsprechenden infinitive ohne $n$ (s. unten) sind in den reimen immer bewahrt und finden sich vereinzelt auch im innern der verse, sie waren also dem schreiber von $\mathbf{P}$ mundgerecht.

2. Schwacher conj. praet. mit umlaut begegnet in sente, uente, mechst $=$ mechtest.

3. kumen hat als wurzelvocal $u$, nie $o$, auch im part. perf., dagegen steht $o$ entgegen der ma. im part. perf. ge-, ver-nomen.

4. Immer sulch, sulcher.

5. Die verba gên, stên haben $\hat{e}, \hat{a}$ nur in reimen wie $h \hat{a} n$ : gân, tât : stât.

6. Zu den verba praeteritopraes.: praes. ind. sg.: sul, pl. sullen, sollen, conj. sulle, praet. solcle; mag - mugen - mohte; darf - dur:fen - dorfte; lian - kunnen - kunde. 'wollen' flectiert wil-wollen - wolte.

7. Schwacher gen. plur. ist häufig bei kï̈nsten, der künsten spîse, der künsten sterke, künsten fruhtic, ähnlich der sinnen durf, witzenkünstenlôs, witzenhaft u. a., vgl. Jänicke, Zs. fda. 17, 507. Bech, Germ. 26, 258; zu sinnen vgl. Roethe, Reinmar s. 13 anm. 31 .

8. Für präfix er- stelıt sehr oft das dem ostfränkischen ganz geläufige der-. Die zwei ältesten belege für der-stammen aus dem 12. jh., worunter der eine aus dem ostfränk., nämlich aus der hs. von Himmel und hölle, vgl. MSD. 23, 158. Das anlautende $d$ ist aus dem satzzusammenhang zu erklären, z. b. im übergang von er hât erslagen entstand in or hât derslagen eine dem im ahd. und mhd. häufig begegnenden $t d$ entsprechende articulation, deren physiologische beschaffenheit Paul, Beitr. 7, 129 erörtert hat.

9. $z u$ gilt für präposition und präfix, nie $z c$; aber $z c r-$, nicht zur-.

10. entwurt subst., cntwurten verb. sind in Ostfranken gebräuchlich für antwurt, antu:urten, vgl. 13ayejns ma. 1. 385. Rückert-Pietsch s. 29; das $e$ ist umlaut, entstanden in formen wie antuierte, antwiorten.

11. Für wrïeste subst. begegnet einmal (uf rim) wurlisten. eine sonst nur im bairischen ofter belegte form (Nohnellor-lir. 2, 842. Weinhold, Bais. gramm. \$ 18.1). Ferner der hirtä, vel. 
I)Wh. 4, 2.15(i:3 f.; und immer wille fïr wîle, eine in hss. ver'inzelt, begegnende schreibereigenheit, die keine lautliche bedeutung laat.

Der ostfräinkische dialekt findet unten eingehendere behamdlung. Hier sei aus dem obigen nur so viel herausgehoben, als zu einer näheren grenzbestinımung der hs. P innerhalb Ostfirankens dienen kann:

1. heubt, geleuben, bereuben. Nach Brenner, Mundarten und schriftsprache in Bayern s. 24 'geht ein streifen landes von der Pfalz herüber ins diesseitige Franken, wo sich die form keufen (mit unlaut) festgesetzt hat, mitten durch das reich der unumgelauteten form kaufen'. Ferner s. Schmeller, Die mundarten Bayerns $\S 177$ und 178 (glèb, kèff, rèff, tèff am Mittelmain, glëïb u.s.w. auf der Rhön). Bavaria 3, 1, 213: 'nirgends im Bambergischen, aber sehr häufig im Würzburgischen und der Rhön: ech kä̈fft, ech gläb u.s.w.', s. auch ss. 211. 245. 258. Firmenich 2, 407 a. Bayerns ma. 1, 283 und 285. Als engere abgrenzung der mundart von $\mathbf{P}$ ergibt sich also der westliche teil des ostfränkischen dialekts, während der östliche, das hochstift Bamberg, ausgeschlossen bleibt.

2. Gegen Bamberg spricht ferner, dass die diphthongierung von $\hat{\imath} \mathrm{zu}$ ei u.s.w. nur sehr selten in der hs. vorkommt. In Bamberg aber ist der neue vocalismus schon gegen die mitte des 14. jh.'s durchgedrungen, in Würzburg eigentlich erst um die mitte des 15. jh.'s.

Eine weitere specialisierung ergibt sich durch die ausscheidung des Hennebergisch-ostfränkischen: es findet sich nie das in den Henneberger urkunden sehr geläufige sal für sol; ebenso nie die allerdings auch in den genannten urkunden gemiedenen he neben er, forte für forhte (vgl. Frommanns ma. 4, 238 und 459), dat. sg. mi, di (ebda. s. 459).

Als mundart von $\mathbf{P}$ ergibt sich demnach der westliche teil des ostfränkischen, also Würzburg, bez. dessen engeres dialektgebiet.

$\delta, 2$ blätter einer papierhs. des 14. jh.'s in der fürstlich Fürstenbergischen hofbibliothek zu Donaueschingen (no. 108), vgl. Barack s. 104.f.; enthält v. 2860-2931 und v. 3075-3147. Die dialektischen merkmale: $e$ für mhd, $a$, $e i$ für $\hat{\imath}$ und $e i$, 
$a u$ für $\hat{u}$ und ou, eu für iu, $i$ für $i e$ (für $u o$ als monophthong liefert die schreibung keinen anhalt; es wird geschrieben $u$, i̊, $\imath$ ), ferner einige male ch für $k$ (chvmen, minnenburch), einmal anlautend $p$ für $b$ ( $p i n$ ), dann noch sülcher — weisen auf Böhmen als heimat der hs. (vgl. Knieschek, Ackermann aus Böhmen s. 86 f. Benedict, Das leben des heil. Hieronymus s. xuII ff.).

1. Das im liederbuch der Hätzlerin abgeschriebene gedicht Wie ainer lein fräd wolt begraben, Haltaus II, no. 25, s. 180 ff. ist der Minneburg entnommen und bildet daselbst v. 2399-2664.

c, hs. des historischen archivs der stadt Cöln no.360, papier, folio, 15. jh., einspaltig. Die Minneburg steht auf bl. 1a-41b, sie bildet den einzigen inhalt der hs. Laut aufschrift auf der innenseite des deckblattes gehörte die hs. einst zu Wallrafs bibliothek (Ferd. Wallraf Prof. Colon.). Zum einband ist als falz ein pergamentstreifen einer urkunde verwendet, worauf der name der fürst-äbtissin [des stiftes Essen] Elzabeta zu Manderscheidt-Blankenheim zu lesen (über diese, die 1575-1578 dem stifte vorstand, s. Grevel in den Beiträgen zur gesch. von stadt und stift Essen, heft 13, 3-96). Es ist nicht unwahrscheinlich, dass die hs. einst zu der berühmten bibliothek der grafen von Manderscheidt-Blankenheim gehörte, aus welcher viele hss. in Wallrafs besitz übergiengen (Ennen, Zeitbilder aus der neueren gesch. der stadt Köln s. 345. Suchier, Zs. fdph. 13, 257 f.).

Eine zweite bemerkung auf der rückseite des deckblattes lautet: $N$. B. 'Dies Ms. ist im 7ber 1816 abgeschrieben uorden'. worauf ein ohne nähere anhaltspunkte unleserlicher namenszug folgt. Die notiz rührt ohne zweifel von F. W. Carové her. wie sich aus einem briefe E. v. Grootes an Jakob (irimm rom 18. märz 1817 ergibt (abgedruckt von Reifferscheid in Picks Monatsschrift für rheinisch-westfäl. geschichtsforschung 1, 15(if.). Groote schreibt hier: "seither habe ich nun noch eine hïhsche hs. 4.1 blätter $\mathrm{kl}$. folio anf papier, jede seite $42.4 \mathrm{zejlen.} \mathrm{N-}$ halten, von welcher Ihmen vielleicht Carové sohon geschrielon. der sie 1816 al)geschieben hat. Ten verfassey woiss ioh nicht: das ganze aber ist ain grosses, moist allegorisches fudichl über die minne, in welchem anspielungen anf dic: Nicloclungen, 
auf den (iral, den 'l'ristan, Wiglisz (Wigolais), Blantschiflor, l alurin und latncelot vorkommen. ... Wenn es Ihnen der mühe wert scheint, so teile ich llinen nächstens eine probe daraus mit.' Alle angaben stimmen auf die Cölner hs. der Minneburg, atch die torm Wrglisz (v. 3157; Lauvin liat Groote aus dem unsiunigen und unmöglich zu entziffernden Laurmtipe v. 3158 der hs. erschlossen, aber sicher mit unrecht). Dadurch wird auch der namenszug verständlich: er bedeutet $W C=W$. $C a$ roré. Aus dieser abschrift C'arovés stammt dann jedenfalls die. von IV. Grimm, Heldensage? 283 f. mitgeteilte stelle. - Eine undatierte abschrift von c aus v. d. Hagens nachlass (identisch mit der (arovés?) befindet sich in der kgl. bibliothek zu Berlin (Ms. (yerm. oct. 269).

Dialekt von c. Tocale: $\hat{a}$ und $a$ sind oft von nachschlagendem $i$ begleitet, und zwar ist $\hat{a}$ etwa 80 mal, $a$ etwa 50 mal ai. Dasselbe findet sich ebenfalls, aber seltener, nach $\hat{o}$ und $o$, für $\hat{o}$ besonders in groifz, vereinzelt bloifz, (be)sloif $z$, floifz, schoifz, genoifz, troist, doit, noit, hoich; für o bes. in uoil, seltner hoiffe, goitt, spoitt, besloifzen. Nach u kommt dieses $i$ besonders vor in suifz (= sïeze), etwa 25 mal, gegen ebenso viele sufz, suifz; vereinzelt in huifz $z=h \hat{u} s)$, guiz (= giuz[e]), gruifz (= gruoz), durchstuicket (=durchstücket).

Für umlauts-e steht $i$ in mirclilich, stircke, stirckte, gegenu'irtelieyt, uirt (= werte 'er wehrte'), michtig, geslicht, gliter, ie $n$ riede sb., rieden $\mathrm{vb}$; für $\ddot{e}$ steht $i$ in entwider, wo anch nhd. geschlossenes $e$; ungekehrt $e$ für $i$ in erdisch, errend, vedder ('wider'), derbedent; ausserdem ist $i$ auch durch ie vertreten besonder's in dieser, wieder, liedic, friedc, hiemel, siech ('siehe'). Ursprïngliches $i$ ist erhalten in $i z$, wilch (= got. loileiks, as. huilik). Alle diese schreibungen sind jedoch nicht regelmässig durchgefïhrt.

Der umlaut von $\hat{a}$ ist $e$, auch in fregende, frege sb.

$o$ ist durch $a$ ausgedrückt in den seltenen $a b$, wanen und durchweg in zabel 'zobel', welche md. form auf mlat. sabclum, frz. sablc aus lit. sabalas zurückgeht, während zobel direct aus russ. sobol', poln. sobol stammt.

$o$ ist $u$ in uffen, uffenliche.

$\imath$, auch mit index $\imath$, $\imath$ (über $\imath i$ s. oben) gilt unterschiedslos für $u$, $\hat{\imath}, \ddot{\imath}, \quad i \imath$, $u o$ und $\ddot{i} e ; z u o$ ist $u$ geworden vor $n$ : 
wonder, wonde, uberwonden, sonne, konne u. a.; vor $r$ dorch, borg, worzel, korcze u. a.; desgleichen $\ddot{i} \mathrm{zu} o$ in wonsch, koning, fonf u. a., worde, verlore, dorre, worffel, geborte u. a.

Die diphthongierung von $\hat{\imath}, \hat{\imath}$ ist sehr selten eingetreten, bei $\hat{\imath}$ einige male im auslaut und vor vocal (sey, Arazey, treseney, arzeney, gekreyet, gefreyet), bei $\hat{\imath}$ in gepauen, truwen.

$e i$ ist $e i$ und ebenso ege $>e i$; ou ist au (aii), öu ist $e u$ (eii), auch in gleuben, heupt, erleupt, verleuffen; ie bleibt ie und wird selten $\mathrm{zu} i$, dann meist in -iren und $z i r$.

Consonanten: die gemein-mhd. lautverschiebungen sind durchgeführt, auch $r d \mathbf{z u} r t$, doch neben anlautendem $t$ aus $d$ findet sich nicht selten $d$ und vereinzelt begegnen unverschobene $p, p p$ in plag, hoppen : droppen, unerschopplich, scharpes. Dem mhd. auslautsgesetz gemäss steht auslautend $p$ für $b$ und $t$ für $d$, aber $g$ bleibt und tritt oft sogar für ursprüngliches $k$ ein, besonders in stary. - hs zu ss in vassen, sez; für lit ist neben häufigerem vorhte zweimal vorthe geschrieben, wol deshalb, weil vorhte dem schreiber nicht die geläufige form war: sondern vorte $\left.{ }^{1}\right) ; h$ schwindet einige male in hô, hoesten, gesch $\hat{x}$.

Einzelheiten: neben gewöhnlichem sol, solt el:scheint auch sal, salt, neben brennende auch burnde, burnède; für zu'ischen wechseln thuschen, zwuschen, zuschen; vor vertritt für als adverb, präposition und präfix.

Zur flexion sind $\mathrm{zu}$ notieren vereinzelte dative sg. masc. auf -en beim starken adj., gen. und dat. sg. fem. auf -'r beim schwachen; zur wortbildung fem. abstracta wie stirclit = sterlic'. lurczt, glimpfft, gesmekt. Endlich durchgehends antzlitz. und lêren für lernen.

Die orthographie von c ist keine einheitliche, neben den im allgemeinen geltenden regeln der büchersprache (über ostfränkische spuren s. unten beim hss.-verhältnis) gehen die ang(fiihrten mundartlichen besonderheiten des schreibers. Jiese weisen anf das rheinfränkische gebiet. Gegen siuden ist die grenze best immt durch wassen, das heutzutage nach Wrede. Anz. fda. 21,261 ...21i:3

1) Der schwund des $h$ in der lant verhindunge hlt heruht daranf. dass $"$ ack-lant war und somit dem $r$, dem es in der articulation solhr nahe st:all.

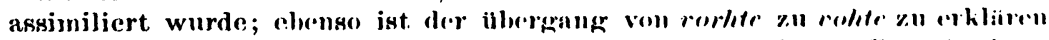

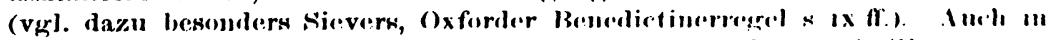

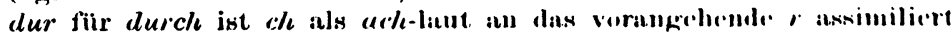


bis nördlich von Fms, Homburg, Hanau, Gelnhausen reicht. Von dem ïberbleibenden nördlichen teile sind auszuschliessen lie eigentlich hessische mundart und das nassauische, denn es fehlen die pron. her he, dit, unse, sowie die contractionen sien, y'schie'n gänzlich (vgl. Sievers, Benedictinerregel s. xIv und s. xI). Fis ergibt sich also etwa die Wetterau als die für den dialekt zu bestimmende landschaft,

Im eingangs - und ausgangsstück fallen einige von dem sonstigen schriftgebrauch abweichende schreibungen auf: neben niehrfachem freude etwa zelınmal freide, dazu frode, frede, frodriches und erzoget; ferner schopfer, ie für ïe in giete (dreimal) und gestiel, briefer (je einmal), endlich th im anlaut bei thuon (elfmal), than (tannwald), thosen, und im reime bal = bald (:al), gesynne = gesinde (:mynne). Die teile, welche diese spuren aufweisen, nehmen auch sonst eine sonderstellung ein (s. unten).

w, hs. der k. k. hofbibliothek zu Wien no. 2890, papier, folio, 15. jh., einspaltig, vgl. Hoffmanns Verzeichnis no. LIII. Tabulae codd. mss. praeter graecos et orientales in bibl. pal. Vind. asservat. 2, 151. Die hs. enthält nur die Minneburg, und zwar auf bl. 1b bis 53 a.

Die mundart des schreibers ist schwäbisch. In der orthographie zeigt er ein lobenswertes bestreben, bestimmte regeln einzuhalten. Bei der verhältnismässig sorgfältigen schreibweise ist die hs. ein muster des schwäbischen dialekts.

Vocale: umgelautetes $a$ wird bezeichnet 1 . durch $e$; 2. seltener und fast nur in fällen jüngeren umlauts durch $\dot{a}, \ddot{a}$, wie in almåchtig : drìtrachtig, geschlåcht, widerwärtige, erbårmde, gegenwårtigkeit, pfärd, einfältig, gewåltig, tåglich, cläfferin, mánlich, schnábelin, frånckisch (dies hat auch nach Seb. Helber, Syllabierbüchlein ed. Roethe s. 19, 12 offenes $e$ ), einmal $\stackrel{a}{e}$ in $\stackrel{a}{e} c h t e n ; 3$. der ältere umlaut durch $\delta$, $\ddot{o}$ in schopffer,

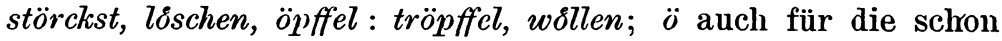
mhd. geschlossenen $e$ in lowe (daneben leowe mit auch sonst belegter, vom lateinischen beeinflusster schreibung) und dört= dert 'dort', vgl. Kauffmann, Gesch. der schwäb. ma. $\$ 65 \mathrm{~b}$ und $\S 84$ anm. 1. v. Bahder, Grundlagen des nhd. lautsystems s. 170. Doppelformen sind manges, mangen (aus manag) neben menger; 
mengen (aus manig) und einmal månig (vgl. Bohnenberger, Zur gesch. der schwäb. ma. im 15. jh. s. 35).

Für $\hat{a}$ ist ausser dem meist gebräuchlichen $a$ auch $\check{a}$ eingetreten, vor nasalen $o: o n[e]$ (immer), hon, lon, ston, geton, somen u. a., seltner han, lan u.s.w.; au in laussen, autem, aubentrir.

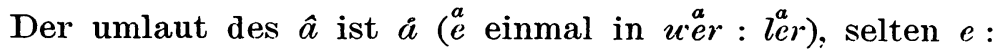
widerspenig, wech (= woche), spech (= spache), seld (= scelde) u. a., vgl. Bohnenberger s. $47-51$.

Mhd. $\hat{e}$ ist $\delta$ in srvig.

$\mathrm{Zu}$ bemerken ist die schreibung fienster 'fenster'. die dreimal vorkommt (daneben zweimal venster, einmal vinster); vienster hat auch die schwäbische Schildbergerhs. in Heidelberg, bl. 58 . vgl. Germ. 7,376 und Langmantels ausgabe s. 132, anm. zu s.82, 14. 'Mhd. $e$ ist wie $\bar{e}$ behandelt in faest $r$ ' u.s.w., Kauffmann $\$ 72$ anm. 4.

Für $i$ und $\hat{\imath}$ werden in den hss. des 14. und 15. jh. $s i$ und $y$ verwendet, und zwar meist ohne bestimmte regel. T'eber die anwendung des $y$ haben besonders Rückert, Entwurf ho. v. Pietsch s. 33 und Pietsch, Trebnitzer Psalter s. xxxvm fördernde beobachtungen niedergelegt, dagegen ist v.Liliencrons annahme. es werde durch $y$ in manchen fällen eine abweichende anssprache bezeichnet (J. Rothes I)üringische chronik s. 712). unhaltbar. I)as $y$ hat seine eigene geschichte, die ron Otfrid bis auf .T. H. Voss reicht. Für das 14 . und 15. jh. hat $y$ seine eigentliche stellung in folgenden fällen:

1. Vor oder nach $n, n n, m, m m$, aus rein äusserlichen gründen, weil das $i$ als einfacher strich hiex mit den $n$ - und $m$-strichen zusammen ein unleserliches gel)ilde ergiht (wohel die häufigen verwechslungen in mhd. hss. zwischen diu und din. nu und im u. a., vgl. z. b. O. Zingerle, I'eber pine hs. des Passionals, Wiener SH. 105, 13-15).

2. $y$ ist $\hat{\imath}$, insofern es aus $i+j=-i+i$ hestelht. vol. nl. ij. weshalb es bej den grammatikern des 16. jh.'s drs. seyfardhe und lange $y$ heisst gegenüher dem kurzell und rinfache'l i. vel.

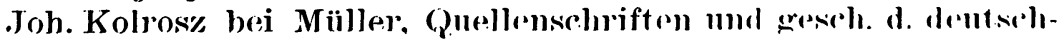

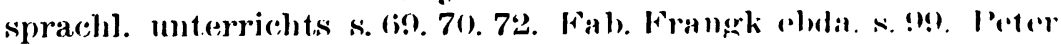

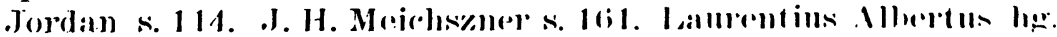
von Müller-fyaurenth s. 27; ferney s. lianfmam $\$ 7.1$ amm. 
Bohmenbergrer s. 61 und 68. Nohl, I)ie sprache des Niclaus von IVyle s. 40.

:3. ! steht in diphthongen vor folgendem vocal $(y=i j)$ und im wortauslaut, vgl. Joh. Kolrosz: so das lang y. zwüschen zween stimbirhstaben grsetzt wïrt, so thit es ein $i$. vnd ein halb $g$. H'rmplum. Meyer, Beyer, ayer, näyen, säyen ... Müller, Quellenschriften s. 75, vgl. auch Kauffmann $\$ 182$ anm. Fabian Frangk: i: wird ans end eines worts, nicht gestellet, sondern das y, als lrey, clabey etc., Müller s. 99; s. auch Laurentius Albertus s. 33. Joh. ('lajus hg. von Weidling s. 12 f. Joh. Becherer, Zs. f. d. d. unterricht 9, 708.

4. Endlich steht $y$ im wortanlaut in $y e$ und in den damit zusammengesetzten wörtern wie yeman, yeglich, yezunt etc., offenbar um anzuzeigen, dass der diphthong ie auf dem $i \mathbf{z u}$ betonen ist, zum unterschied vom steigenden diphthongen, wo $i$ oder $j$ statt hat, wie jagen, jugent. So schreibt Joh. Kolrosz (Müller s. 69 und 75 f.) Jesus, ieger und stellt dagegen ye vnd ye, yederman, yedes unter diejenigen wörter, die das $i$ betonen.

Der schreiber von w hat sichtbar das bestreben, einen unterschied zwischen $i$ und $y$ zu machen, und zwar gemäss den angegebenen vier grundsätzen. Für kurzes $i$ ist $y$ überhaupt nicht sehr oft gebraucht, dann aber mit ganz wenigen ausnahmen wie ryscn, rysel und in einigen fremdwörtern, der regel 1 entsprechend neben $n$ und m: mynne, synn, nym, ynneclich, yngcsinde und besonders in yner, nymer. Seine hauptsächlichste verwendung findet $y$ für die länge (regel 2), woneben viel seltener $i$, dieses jedoch immer in min, din, sin. Beispiele fïr legel 3: dat. pl. zwayen, aber zwein, mayen (acc.sg.), weye, imp. zu mhd. wajen mit echt schwäbischem ey für $\propto j, \mathrm{vgl}$. Kauffmann $\$ 66$ anm. 3. Bohnenberger s. 47-51. H. Fischer, Geographie der schwäb. ma. s. 33 anm. 7. Nohl s. 64; zvvay, dehainerlay, schray, ey (interjection) und die fremdwörter Aglcye, Troy. Für regel 4: ye, yeglich, yemunt, yetzunt gegen jagen,jumer, jar, jugent, jung. - In den beiden schon besprochenen hss. $\mathbf{P}$ und $\mathbf{c}$ sind diese regeln über die verteilung von $i$ und $y$ bei weitem nicht so correct durchgeführt wie in w, aber trotz der verwirrung noch bemerkbar und zwar in $\mathbf{P}$ deutlicher als in c (hier eigentlich nur regel 1 und 2).

$i$ wird sehr oft $z u$ nach $w$, besonders in der lautgruppe 
wir-, vereinzelt auch vor $r$ ohne vorangehendes $w$, hier jedoch sichtlich meist nur des reimes wegen: ich vvird, du wúvst, er wuirt, diu wirde, wúrde : gúrde (= givde sb.), der wúrt, wuirs, wuirff, cruírbt : stúrbt, wúrcken, wúrcket : zúrcket, zúrckel, gewúrckt : búrgkt, ich wúrb : ich stúrb (ind. praes.), zwviret, zwiischent, fürne, ferner ich uiust, súben, túschelin, imer neben ymer, aber nie im pronomen wir; vgl. Kauffmann $§ 86$ anm. Bohnenberger s. 58-61. v. Bahder, Grundlagen s. 181.

Die diphthongierung von $\hat{\imath}, \hat{\imath}, \hat{\imath} \iota$ ist, dem schwäbischen des 15. jh.'s entsprecliend, nicht durchgeführt; vereinzelt ist ge(z)weyot: gefreyot zu zwîen, frîen.

Die umgelauteten vocale sind von den nicht umgelauteten reinlich geschieden, $o=o$ und $\hat{o}$, dagegen $\delta, \ddot{o}=\ddot{o}, x ; u=u$ (im anlaut $v$ ) und $\hat{\imath}$, dagegen $u, u=\ddot{\imath}$ und $i u$ (sowol ursprüngl. diphthong als umlaut von $\hat{\imath}$ bez. $i u), \imath=\imath$, dagegen $\dot{u}=\ddot{\imath}$. Damit lässt sich feststellen, dass keinen umlaut haben die intensiven verba rucken, drucken, zurken, durchstucken. geburlict, geschmuckt, gelinuclit (aber erkïich), ferner bruck 'brücke', r'vlupt 'vergiftet', luppendig, nutzlich, guldin, gpenuchtig : suchti!! (v. 2627, aber süchtig : brïchtig v. 1657), sî̀l, vgl. Kauffmann $\$ 124$. H. Fischer, Geogr. s. 74 und Germ. 36, 422. v. Bahder. Grundlagen s. 199 ff.; suffix -nus.

Schwanken der umlautsbezeichnung herscht in der verbin-

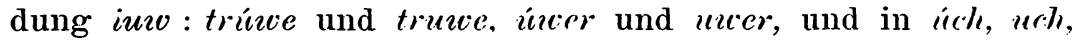
wie auch sonst im schwäbischen des 15. jh.'s, rgl. Bohmenberger s. 116-122; über heutiges $\hat{\imath} w$ s. H. Fischer, Geogr. s. $41-43$.

Mhd. $e i$ ist $a i$; davon ist die contraction ron cgi als ai geschieden, vgl. Kauffmann $\$ 91-93$. H. Fischer, (Yeogr.s. 44-4\$. Bohnenberger s. 104-113: treit, seit, geleit, gein--- daneben die unter schwachem satzton entstandene form gen (iiber schwäh.

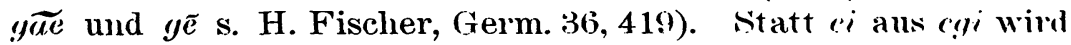
ai nur der reimgenauigkeit wegen geschrieben, wenn die betr. wörter mit einem ai enthaltenen worte gebmonden sind. das ihmen als reim vorausgeht: wyszhait : gesait. restigliait : torit u. a. l'mgekehrs, steht mehrfach oi fïr ai, aber nur in moletonter

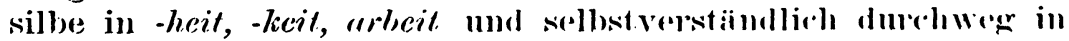

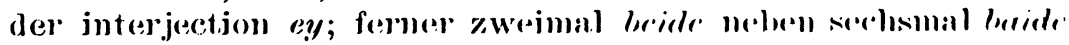

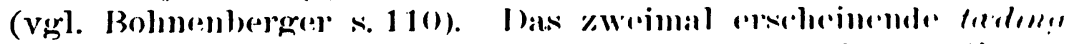

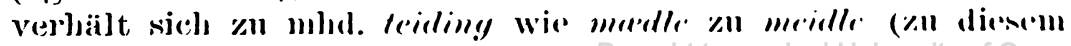


s. v. Bahder, rs. folph. 12, 485. H. Fischer, Geogr. s. 47 f. Germ. :36, 419 und 7 ur gesch. des mhd. s. 66 anm. 3.1) toeding (vgl. Bohutuberger s. 110-113) ist = tagading, teiding $={ }^{*}$ tagiding $>$ tegieling mit assimilation des mittelvocals an das $i$ der schlusssilbe (vgl. Braune, Ahd. gramm. § 68 und $\$ 27$ anm. 4).

Mhd. ie ist ie, ye.

Für "o vor nasal findet sich ganz selten 0 in ton, stond, vgl. Kauffmann $\$$ 97, 2. Bohnenberger s. 132-135. - Präposition und adverb sind durcheinander $z \ddot{u}$ und $z \ddot{i}$ geschrieben, hier also hat der index keine lautliche bedeutung mehr.

Mhd. ou ist ou und o ohne unterschied, z. b. berouben und beroben, gelouben und geloben, ougen und ogen u. a., aber nur $o$ vor $m$ : bom, trom und in frowe und och $=$ ouch; vereinzelt steht gnaw (Kauffmann $§ 94$. H. Fischer, Geogr. s. 40. Bohnenberger s. 122-128).

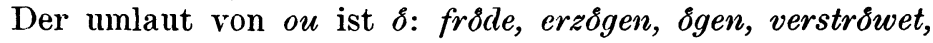
tromen.

Die schwäbische nasalierung findet statt in zweimaligem sinffizen gegen einmaliges súfftzen, s. Kauffmann $\$ 134$. H. Fischer, Geogr. s. 56 f. und Germ. 36, 423. Alemannia 3, 296.

Synkope und apokope der schwach betonten $e$ ist ganz geläufig, erstere u. a. z. b. in gwel, gnaw, gbunden, gsind.

Consonanten: die medien $g$ und $b$ bleiben; für $b$ steht in fremdwörtern anlautend auch $p$ in panier, paner, perlin neben berlin, pensel neben bensel, sonst nur etwa zweimal (plickte, plócligliait). Oefter tritt auf anlautend $t$ für $d$ : tach (Kauffmann $\$ 166$, s. 219 unten), tachs, tiessen, getagen, tïrres, tringen; selten th: thin, thorhus, vnderthainig (Kauffmann $\$ 158$ anm. 3); mehrfach $d t$ für mhd. $d$ und $t$; bt zu pt: blipt, lepten, gehapt u.a.; mt zu mpt: zimpt, nempt u. a. Gutturaltenuis ist $c$ oder $k$, nie $c h$. Verdoppelung des $m$ ist oft vereinfacht: tumer, verstumet. $u$ wird auslautend nicht $\mathrm{zu} b$ : farw, und steht nach langem rocal in blaw, gravo; im inlaut wechseln $r w$ und $r b$, $l w$ und $l b$. Für qu erscheinen die $k$-formen erkúcken, kecklich neben queck (vgl. Kauffmann $\$ 156$ anm.). sl, sm, sn, sw sind zu schl u.s.w. geworden, tw zu zw. $g$ für $j$ in blügender (vgl. Kauffmann $\S 180 \mathrm{~s} .255), v$ als übergangslaut in fïwr vor sonantischem $r$,

1) Vgl. auch magan zu mân, meginŁzu mein 'kraft'. 
unterbleibt vor consonantischem $r$ : dat. füre, adj. fúrin, fúrig. Wechsel zwischen $h$ im inlaut und $c h$ im auslaut ist eingehalten in wåher - wách u. a., dagegen ist bei hoch die spirans auch in den inlaut gedrungen: hocher, hochem u.s.w.; vorgesetzt ist $h$ in herfúcht, herwandelieren, hernúwet (vgl. Kauffinann $§ 158$ anm. 1).

Zur flexion und wortbildung: verbum: die zweite person plur. endigt neben gewöhnlichem -et auf -ent, besonders im imperativ; part. perf. einmal auf ot: geweyot (entstellt aus gezweyot, s. oben s. 267) : gefreyot. Der conj. des verb. subst. hat neben den gemeinmhd. formen $s \hat{\imath}$ u.s.w. in der 1. 3. sg. sig, 2. sigst, pl. ir sigent (vgl. Kauffmann $§ 182$ s. 254 f.). In dem einmaligen verlor, 3. sg. conj. praet., ist die ablautsstufe des ind. sg. praet. eingedrungen. Der vocal in den seltenen sten, gen - gewöhnlich stan, gan - ist aus der vorlage übernommen. - Oefter begegnen die abstracten fem. auf -in: liebin, giitin (gen. dat. sg., vgl. Kauffmann $\$ 114, \S 116$ und $§ 135$ s. 164), und solche auf -nus; häufig ist dennocht, dannocht (Weinhold, Alem. gramm. s. 141), einmal steht gelernet $=$ gelêret.

Einige der angeführten mundartlichen eigentümlichkeiten gehören speciell in das westliche Schwaben: die beibehaltung der alten $\hat{\imath}, \hat{u}, i u$, wofür ostschwäbisch im 15. jh. ei, au, eu gilt (Kauffmann § 138. H. Fischer, Germ. 36, 423-426. Bohnenberger s. 62-70); auch ei aus egi, wofür ostschwäbisch gern ai auftritt (Bohnenberger s. 113). Noch einem bestimmter abgegrenzten westlichen gebiet gehören $\hat{u} w$ für iuw, súnfftzen und fienster an. s. dazu die nachweise oben s. 267, s. 268 und s. 265, zu fienster auch Kauffmann $\$ 77$ anm. 2.

d, hs. der fürstlich Fürstenbergischen hofbibliothek zu Donaueschingen no. 107, papier in 40, 15. jh. (1468), vgl. liarack s. 102-104, enthält auf bl. 1 a-69 b die Minneburg. und zwar von zwei verschiedenen händen geschrieben: da von bl. $1_{\text {a }}$ - :3:a (v. 1905), d'b von bl. 38b (v. 1906) bis 69b (schluss der Mlly.). J)ie roten anfangsbuchstaben an den absätzen mol meist anch

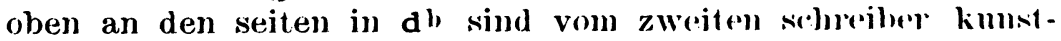
reich und gewant mit blattornamenten, köpfon mol pliantastischen tiergestalten veryiert. Auch die araloesken lil. :3:31 mud 34a in der partie des ersten schureibers sind vom \%writch nath- 
trïglich hinzugezeichnet. I)ie hs. grehörte laut einer aufschrift anf der 'rsten seite vom jahre 1688 (Mn̈rij S. Magnj Fie/sa' 1/SS) einst dem kloster S. Mang in Füssen, kam später an lassberg und aus dessen nachlass in den besitz der Donaueschinger hofbibliothek. Sie ist in den beiden bibliothekskatalogen, die von der einstigen bibliothek in St. Mang erhalten sind, nämlich im Catalogus bibliothecae Sancti Magni de annis 16:8-1686-1695 in der fürstlich Wallersteinschen bibliothek zu Mayhingen und im Clm. 1387, nicht verzeichnet. In seinem briefe an IThland vom 16. august 1821 (Briefwechsel s. 23) berichtet Lassberg, dass er aus einer schweizerischen hs. der Minneburg eine abschrift genommen habe. Es ist möglich, dass diese 'schweizerische' hs. eben diese jetzige Donaueschinger hs. ist. 1) Ueber den verbleib der abschrift konnten mir die verwaltung der fürstl. hofbibliothek sowie die tochter Lassbergs, fräulein Hildegard von Lassberg in Mersburg, keine auskunft geben.

Der dialekt der beiden teile $\mathrm{d}^{\mathrm{a}}$ und $\mathrm{d}^{\mathrm{b}}$ ist ebenfalls schwäbisch, aber in nicht so einheitlicher orthographie, auch nicht phonetisch so genau widergegeben wie in $\mathbf{w}$.

Zum vocalismus: $\hat{a} \mathrm{zu} \hat{o}$ vor $n$, besonders in on[e]. - Für alle $e$ und ebenso für $\hat{e}$ und $a$ haben beide teile $e$, mit ausausnahme von geschl. $e>\ddot{o}$ in hölscher, wöllen, schöpffer, öpffel, löschen und etwa einem dutzend $\alpha$ bez. $\stackrel{a}{e}$ für $a$ in $\mathbf{d}^{\mathbf{b}}$; dazu leove, leuwe für lewe in da. - $i$ wird $\mathrm{zu} \ddot{u}$ unter den nämlichen bedingungen wie in w, aber nur etwa in der hälfte der fälle; zu $e$ in brenge (da), vgl. Kauffmann $\S 75$. Bohnenberger s. 58. In der verwendung von $y$ für $i$ verfolgt $\mathbf{d}$ a ähnliche grundsätze wie $\mathbf{w}$, daneben tritt ie auf in diese, $\left.{ }^{2}\right) \mathrm{db}$ dagegen braucht $y$ fast nur in symn und mymne, wofür auf den letzten blättern jedoch wider $i$ regel wird. - Der unterschied

1) S. unten s. 274.

2) dieser erscheint in hss., bes. mittelfränk., auffallend häufig mit ie, auch in solchen die sonst nicht ie für $i$ brauchen (s. auch oben s. 262). Dies kann einen lautlichen grund haben: ie kann auf *thê zu thie, die starktonige form des pron. demonstr., zurückgehen, wonach dieser in beiden compositionsteilen flectiert ist; vgl. Isidor dheasa (Braune, Ahd. gramm. \$ 288 anm. 3 e. Höfer, Germ. 15, 71). Auf dieselbe weise ist wol das in der Jolande erscheinende dyser (John Meier s. xxvıI) zu erklären, indem $y$ hier für $i e$ stehen kann. 
von mhd. $c i>a i$ und $e g i>e i$ ist durchgeführt. - Der umlaut von ou ist in $\mathrm{d}^{\mathrm{a}} \ddot{\delta}, \delta u$, $e u$, in $\mathrm{d}^{\mathrm{b}}$ nur $\delta$. - ie ist $i e$, $e$ in neman (vgl. Kauffmann $\S 96,2$. Bohnenberger s. 114 f. Weinhold, Alem. gramm. $§ 37, \mathrm{e})$. - Indices über vocalen sind in db im übermass gesetzt, abgesehen von allen umgelauteten vocalen massenhaft beliebig auf andern. Dieses verfahren zeigt so recht, dass diese zeichen keineswegs immer einen umlaut bedeuten, sondern oft nur eben die vocalische natur des betr. buchstabens hervorheben sollen. - Nasaliert sind sünftzen und sünst $\left(\mathrm{d}^{\mathrm{b}}\right)$. - Schwund des schwachen $e$ ist häufig.

Zum consonantismus: für anlautende $b$ und $d$ finden sich mehrfach $p$ und $t$ (tach etc.), für $t$ th in thů queck und kecklich ( $\left.\mathrm{d}^{\mathrm{a}}\right)$, erquicken und erkïcken ( $\mathrm{d}^{\mathrm{b}}$ ) neben einander; prothetisches $h$ erscheint wie in w (s. oben s. 269); $m$ zu $n$ in hain (da), vgl. Kauffmann $\$ 189,4 ;$ gäischlich für geistlich (db), vgl. Kauffmann $\S 153$ anm. 2.

Zur flexion und wortbildung: - ent lautet die flexion der 2. plur. imp., selten -en; der conj. sig für sî ist häufig; übereinstimmend mit w kommt einmal verlor (3. conj. praet.) ror (da), ebenso dannocht, dennocht ( $\mathrm{d}^{\mathrm{a}}$ und $\mathrm{d} \mathrm{b}$ ), gelernet = gelêret (db); die abstracta auf -in (auch -i) begegnen nur in da, die auf $-m u / z$, $-n \ddot{u} / z$ in beiden teilen. Von dem schwäbischen tỵus weicht nur eine form gänzlich ab, das in da etwa siebenmal erscheinende sal für sol. Die form ist ganz unschwäbisch und beruht auf einer nicht mehr zu ergründenden laune des schreibers von $d^{a}$.

In den beiden teilen $\mathrm{d} a$ und $\mathrm{d} b$ sind nicht genau die gleichen schreibgebräuche befolgt, die verschiedenheiten sind aber nicht mundartliche, sondern nur orthograjhische. Jedenfalls liegt beiden ein und dieselbe vorlage $\mathrm{zu}$ grunde, wie sich auch aus der beobachtung des textes ergibt. $d^{a}$ und $d^{b}$ gelten deshalb als eine hs., d.

h, die Heidelberger pajierhs. Cod. jal. germ. :385. 15. jh.. beschrieben von Bartsch no. 208. I)er in den sich nur in dirier hs. befindenden eingangsversen (s. Bartsch a.a. o.) als verfiasior genannte Mraister Nectomerus stammt aus dem inhall dex gerdicluts. Wine abschrift von $h$, gefertigt von dell ptiizisihen pfarrer und historiker .J. (i. I dehmann im jahre 18.17 (verl. lierm. 
22. 120) befindet sich jetzt in der kaiserl. universitäts- und landesbibliothek zu strassburg.

Die mundart in $\mathbf{h}$ ist schwäbisch, jedoch einige in $\mathbf{w}$ und $\mathbf{d}$ bemerkenswerte kemuzeichen fallen hier weg oder treten noch mehr zuriick als in d, wogegen andere aber weniger ausgeprägte netue erscheinen. Der schreiber von $\mathbf{h}$ zeigt das bestreben, sich mehr der allgemeinen geschäftssprache anzupassen, während $\mathbf{w}$ in der starken betonung mundartlicher eigenheiten einen sonderstaatlichen charakter trägt. Auch dem alter nach ist $h$ wol einige jahrzehnte von $w$ getrennt und gegen das ende des 15. jh.'s in die zeit der drucke Steinhöwels und Niclas' von Wyle zu setzen.

Vocalismus: $\hat{a}$ wird $o$ vor nasal, immer in on $[e]$.

Für die $e$-laute werden drei zeichen verwendet, $e, \ddot{e}$ und $\ddot{a}$, und zwar werden im grossen und ganzen damit die geschlossenen und offenen laute unterschieden: $e$ steht für altes $\ddot{e}$, ältern umlaut (wofür auch $\ddot{o}$ : löschen, schöpfer etc.) und $\hat{e} ; \ddot{e}$ für altes $\ddot{e}$ besonders vor $r$ und $l$ (kërn, hër, mël, hëln) und für $\alpha$; $\ddot{a}$ für den jüngern umlaut (täglich, schäntlich, schnäbeln, gefängnus) und ebenfalls für $c$ e. Natürlich ist dieses etwas verwickelte system nicht ganz pünktlich durchgeführt.

Die rundung des $i \mathrm{zu} \ddot{u}$ ist noch seltener als in $\mathbf{d}(z w \ddot{u}-$ schen, sïben, wïrde sb.). Im wechsel zwischen $i$ und $y$ sind die oben gegebenen regeln zwar nicht streng eingehalten, aber grösstenteils noch sichtbar; ausserdem steht ie in dieser, wieder, friede, wiessen u. a.

$u$ bezeichnet das lange $\hat{u}$; für $u, \ddot{u}, i u, u o$, $\ddot{u} e$ steht $\ddot{u}$ (im anlaut $\ddot{v}$ ), für $u o$ auch $i$; aber immer $d u$, vnd; meist $z u$, aber zïr, zïm. - Vor doppeltem nasal und vor nasal + cons. wird u zu o, meist $\ddot{o}$ geschrieben, wie denn das umlautszeichen mehrfach auch über nicht umgelauteten $o$ und $\hat{o}$ steht und andrerseits bei umgelauteten $\ddot{o}$, œ fehlt: sönnder, wönnder, wönnde, sonne, wönne, wönsch, kümmer; $\ddot{u}>\ddot{o}$ in konig, konigin.

$\hat{\imath}$ ist $o$ in $k \ddot{o} m$, vor nasal, vgl. Kauffmann $\S 82,2$. Bohnenberger s. 91-96.1)

1) kîme nimmt auch sonst in hss. eine sonderstellung ein: $\hat{u}$ ist oft auch in solchen hss. diphthongiert, die sonst meist $\hat{\imath}$ bewahren, alemannisch z. b. in der Berner hs. der von Bachmann und Singer herausgegebenen Volksbücher (Lit. ver. 185) s. LXxxv koum oft, und versoumpt, versoumbnu/z, 
Beide ei, das ursprïngliche und das aus egi entstandene, sind $a i$, nur unter schwacher betonung tritt $e i$ ein, daher gein, cinander, wie im bair. hochtonigem ain gegenüber schwachtoniges ein (Bartsch, Germ. 24, 198 f.).

Mhd. ie ist nur in ich ging durch $i$ widergegeben.

Mhd. ou ist ou, aber bom; $\ddot{\partial} u$ ist $\ddot{o}$. Bemerkenswert ist schún (: sun) für schôn (: son). ${ }^{1}$ )

roumpt; s. auch Rosenhagen, Untersuchungen über Daniel vom blühenden tal s. 3. Im bairischen ist $\hat{u} m$ unter den frühest diphthongierten lautverbindungen am stärksten vertreten, vgl. Weinhold, Bair. gramm. \$100. Im heutigen schwäbischen ist $\hat{\imath}$ vor nasal $z u \quad \tilde{u}$ geworden, sonst $z u$ ou (Kanffmann $\$ 82,2)$. S. auch Toischer, Ulr. v. Eschenbach, Alexander s. xIx (kam[e]) und oben s. 258 .

1) Im schwäbischen tritt manchmal vor nasal $\hat{u}$ für $\hat{o}$ ein, s. Bohnenberger s. 75. L. Voss, Ueber Friedrich von Schwaben (dissertation, Muinster 1895) s. 6 (schion, liin, dun, kriin; $i$ soll hier vermutlich ou widergeben, vgl. Kauffmann $\$ 80$ anm. 1). Aber gerade für schôn adv. ist schůn öfter zu belegen, so in der Wiener prosaischen Minneburg (s. unten s. 275), in dem derselben hs. angehörenden gedicht von Friedrich von Schwaben (s. Toss a. a. o.), bei dem von H. Hofmann herausgegebenen 'Nachahmer Hermanns von Sachsenheim' v. 541 und 1159 (im reim anf thin). Dazu erscheint als adjectiv schüen bez. schien bei dem letztern (superl. schienst : dienst $\mathbf{v}$. 305). bei Bohnenberger s. 84. Anz. fda. 5, 224 und in vielen beispielen bei Michels, Studien über die ältesten deutschen fastnachtsspiele s. $115 \mathrm{f}$. Besonders lehrreich für die formen schüen adj. - schuon adv. ist die schreibung in dem gedicht ron der sultanstochter im blumengarten, das Bolte in der Zs. fda. 34, $18 \mathrm{ff}$. aus einer hs. des frauenklosters Inzigkofen bei Sigmaringen herausgegeben hat. Hier werden die umgelauteten vocale von den unumgelauteten durch index pünktlich geschieden: mhd. $u$ ist durch $u$ widergegeben, mhi.

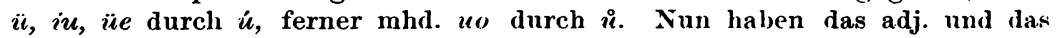
abstracte fem. subst. immer $\dot{u}$, niemals $\imath$, d. h. schun (siebenmal), schumi

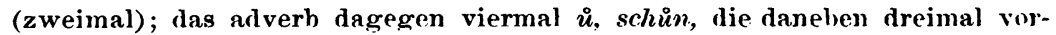
kommenden schún können nicht auffallen, da adj. und adv. nicht mehr streṇ getreunt gehalten wurden. - Es fragt sich, ob schüen - schuon nur mundartliche entwicklungen von schkn - schôn sind oder etymologisch davon verschiedene formen. Michels hat das letztere angenommen. [rni wil mil recht. Denn schüen - schuon haben ein weites verbreitungsgelict, auch iiber mundarten die sich ferne stehen. Auch wiirden als reime beim Nach. ahmer Sachsenheims angesetzt werden missen die streng dialektischen

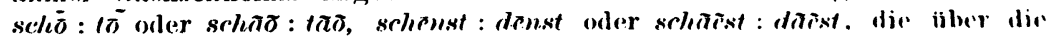

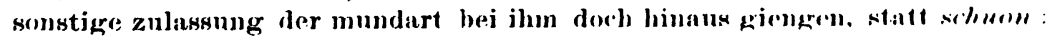

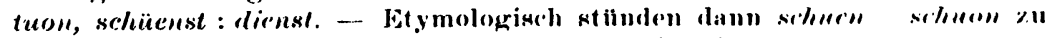

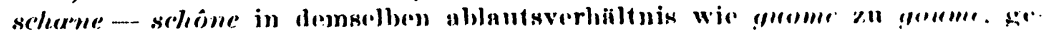
mäss Michels erkliirmug. 
Nasaliert sind gïnst $=$ giuzt und sïnst.

synkope und apokope des schwachen $c$ sind in $h$ viel seltener als in w und $d$, vielmehr wird umgekehrt sehr häufig am wortende ein etymologisch überflüssiges $e$ zugefügt, z. b. drer sturme, den munde, ich vande, warde u.s.w.

Zum consonantismus: neben $d$ kommen anlautend, wie in w und $\mathrm{d}$, einige $t$ vor; für $b$ ist $p$ sehr häufig (plüme, plüt, pringen); $q u$ nicht $l$ in erquicken (kecklich fehlt in der hs.); $h$ statt $j$ in wehe (mhd. waeje); prothet. $h$ in herfúcht, herwandelie'ren; tw zu zu'; sl u.s.w. zu schl u.s.w.

Zur flexion und wortbildung: 1.sg. ind. praes. geht oft auf -en aus, besonders im hiatus, sagen ich, ich wirden ouch; die endung -ent ist in allen zweiten personen des plurals neben -en sehr häufig und findet sich auch in den ersten; das gerundivum hat als flexion -ende; die conjunctivform sig(e) ist selten. - Wie in w und finden sich die abstracta auf -in (auch - $i$ ), liebi, gïttin, und auf -nülz(e), und dannocht, dennocht. Ausserdem sind anzumerken yena, nyena, zwürnot.

Die für $\mathbf{h}$ gegenüber $\mathbf{w}$ und $\mathbf{d}$ charakteristischen mundartlichen bez. orthographischen erscheinungen sind: $u$ zu $o$ vor nasal, ९gi zu ai, anfügung eines überflüssigen $e$, anlautend $p$ für $b$, 1. sg. praes. ind. auf -en, -ent in allen zweiten personen des plurals und auch in der ersten person. Sie kommen alle auch sonst im schwäbischen vor: $o$ für $n$ vor nasal ist echt schwäbisch, vgl. Kauffmann $\S 81,3$. H. Fischer, Geogr. s. 28. Bohnenberger s. $87-91$; ai für egi s. bei Bohnenberger s. 110 -113 und s. 106; die überflüssigen $e$ sind aus den' gleichzeitigen schwäbischen schriften reichlich zu belegen, vgl. Kauffmann $\S 122$ anm. 2. Nohl, Sprache des Niclaus von Wyle s. 65-71; $p$ für $b$ besonders bei Steinhöwel, s. Weinhold, Alem. gramm. s. 114. Karg, Die sprache H. Steinhöwels s. 23; die besprochenen verbalendungen auf -en und -ent bei N. v. Wyle (Nohl s. 73), bei Steinhöwel (Karg s. 38).

Die drei schwäbischen hss. $w, d, h$ stimmen in sehr vielen einzelnen auffallend mundartlichen schreibungen so buchstäblich genau überein, dass an einer gemeinsamen schwäbischen vorlage (über ostfränkische spuren s. unten s. 278) kein zweifel sein kann. Dass sie auf ein und dieselbe quelle zurückgehen, 
wird durch das verhältnis der varianten bestätigt (s. s. 277). w hat die ursprüngliche mundartliche färbung am besten bewahrt, d hat etwas mehr davon abgestreift, $h$ hat sich einem neuen princip zugewendet ohne das alte ganz $\mathrm{zu}$ verwischen.

In dem oben s. 270 angeführten briefe bemerkt Lassberg, dass Conz in Tübingen eine hs. der Minneburg besitze. In der tat bespricht Conz in seinen Kleineren prosaischen schriften 2, 307 und 327 das gedicht in einer weise, aus der hervorgeht, dass ihm eine hs. muss vorgelegen haben (in der ersten fassung jenes aufsatzes in seinen Beyträgen für philosophie s. 82-131 fehlen die beziehungen auf die Minneburg). Leider ist es mir trotz gütiger bemühungen les herrn $d r$. Bohnenberger in 'Tübingen nicht gelungen den gegenwärtigen aufbewahrungsort dieser hs. zu erfahren. In der universitätbibliothek zu Tübingen und in der öffentlichen bibliothek zu Stuttgart sowie in der kgl. hofbibliothek daselbst befindet sie sich nicht, auch konnte mir herr stadtpfarrer Conz in Canstatt, ein nachkomme des Tübinger professors, keine auskunft über sie geben.

Ausser der gereimten Minneburg existiert noch eine umarbeitung in prosa. Diese ist überliefert in der papierhs. der k. k. hofbibliothek zu Wien no. 2984, 15. jh. (1463), auf bl. $246 a-273 b$, vgl. Hofmanns Verzeichnis no. LXXXIX. Tab. codd. mss. 2, 168. Toischer, Aristotilis heimlichkeit s. 1. L. Yoss, Friedr. v. Schwaben (s. oben s. 273) s. 6.

Auch diese hs. ist im schwäbischen dialekt abgefasst, und zwar tritt das mundartliche element stark hervor, z. b. sehr häufige au und $\grave{a}$ für $\hat{a}$, seltner $o$ vor nasal für $\hat{a}$, geschlossenes $e \mathrm{zu} \ddot{o}$ (störker, hörtt, hör 'heer', kröftig u.s.w.), $i$ zu ic vor $r$ (stiern, wiert, gegenwiertigen, hiers; vgl. Kauffmann $\$ 75$ anm. 1. H. Fischer, Geogr. s. 27. Bohnenberger s. 58-62), i zu $\ddot{u}$ (urird, súben, vermúschen), ̈̈u zu $\delta$ (frod etc.), $u \mathrm{zu}$ o vor nasal. entrundung von o zll $e$ (besen), ïc zu ic (griener), cu zu ai (firand). nasalierung in sunffizen, erhaltene schwere flexions- und ablejtungssilben wie superl. ellost, sterkost, part. perf. grlermot. conj. praet. romtin, ä̈llist, adverb himnan, abstrarta auf -in (hertin, lyobin, hochrin), das echt schwäbische nirme'n memen (Kauffmann $\$ 70$ b. Bolmenberger s.41-17), hourl, troust (lianffmann \$80 anın. 1. Bohmenberger s. 75). schian schion (s. olon 
s. 27:3); $m \% " \|$ in hrein -- heim (s. oben s. 271), ch für $h$ (sechen, flichlen, sluchel, Kautfmann $\$ 158$ anm. 2), st für scht in erlast, !reuroust (Kanffimann $\$ 153$ anm. 2). Erwälnt sei noch die syntaktische umschreibung des praeteritums das kind nnd srin ami!! ... dätten sich fröwen.

\section{Das handschriftenverhältnis.}

I)ie hss. des gedichtes verteilen sich zunächst auf zwei klassen, A und B, die sich im wesentlichen durch die abweichende behandlung des eingangs und des schlusses und, damit zusammenhängend, durch ihren umfang unterscheiden; das mittlere stück stimmt in beiden überein. Die auf diese weise sich ergebenden je drei teile, AI AII AIII und BI BII BII, verhalten sich folgendermassen $\mathrm{zu}$ einander: der eingang ist in $\mathbf{A}\left(\mathbf{A}_{\mathrm{I}}=\mathrm{v} .1-80\right)$ gänzlich verschieden von dem in $\mathbf{B}\left(\mathbf{B I}_{\mathrm{I}}=\right.$ v. 1-180 B); darauf folgt der beiden gemeinsame hauptteil $(\mathbf{A I I}=\mathbf{B I I})$; der widerum sondergebildete schluss ist in $\mathbf{B}$ (BIII $=3319-3628$ B) bedeutend kürzer als in $\mathbf{A}$ (AIII = v. $3119-5488$ ). Dabei sind jedoch gewisse stellen im eingangsund schlussteil bei $\mathbf{A}$ und $\mathbf{B}$ inhaltlich gleich und nur in der sprachlichen fassung verschieden; es sind dies die verse $1-80$ sowie 3119-3172 und 3605-3825 in der zählung von A. A zählt in der vor dem schluss abgebrochenen hs. P schon 5488, B nur 3628 verse. Vorausbemerkt sei, dass, wie sich erst aus der beobachtung der reime ergibt (s. unten), $\mathbf{A}$ das ursprüngliche gedicht darstellt und dass die in $\mathbf{B}$ abweichenden eingangs- und schlussstücke (BI und BIII) erst änderungen eines späteren bearbeiters sind.

$\mathbf{A}$ ist vertreten durch die hs. $\mathbf{P}$ und die bruchstücke $\delta$, wozu wahrscheinlich noch das bruchstück 1 kommt.

$\mathbf{P}$ gibt einen lesbareren text als jede andere hs., die zwei blätter von $\delta$ ausgenommen, ist jedoch von flüchtigkeiten nicht frei. Solche sind einige male vom schreiber selbst gebessert. Ausserdem aber hat eine spätere hand mit blasser tinte zahlreiche correcturen angebracht, und zwar meistens unter beiziehung einer auf $\mathbf{x}(=\mathbf{w} \mathbf{d} \mathbf{h})$ zurückgehenden hs., denn mehrere änderungen stimmen mit sonderlesarten jener schwäbischen gruppe überein. Die zur richtigstellung benutzte hs. war eine andere als die uns erhaltenen hss. $\mathbf{w}$ d h. 
Iass $\delta$, welches die verse $2860-2931$ und $3075-3147 \mathrm{um}-$ fasst, zu A gehört, beweist der umstand, dass die letzten 29 in jenen schlussteil, wo $\mathbf{A}$ und $\mathbf{B}$ auseinander gehen, fallenden verse $(3117-3147)$ den text von $P$ bieten. In wortlaut stimmt $\delta$ mit $\mathbf{P}$ fast durchweg überein; wo beide verschieden sind, hat in der mehrzahl der fälle $\delta$ die ursprünglichere lesart, wie sich durch vergleichung mit $\mathbf{B}$ ergibt. Es erhellt aus der beiziehung von $\delta$, dass $\mathbf{P}$, was für die beurteilung ihres textkritischen wertes von wichtigkeit ist, in einzelfällen vielfach von dem grundtext abweicht.

Die stellung von 1, das die verse $2399-2664$, mit auslassung von 2403 f., 2465 f. und $2597-2616$, aufweist, lässt sich gleich durch die ersten verse 2399-2402 näher bestimmen: diese fallen in eine lücke der B-hss., 1 zweigt also jedenfalls nicht von cx ab, auch die abweichungen im wortlaut. die für cx bezeichnend sind, teilt 1 nicht. 1 stimmt in weitaus den meisten fällen mit $\mathbf{P}$, kein einziger spricht dafür, dass 1 mit $\mathbf{B}$ eine gemeinsame vorlage hatte; man wird daher nicht fehl gehen, wenn man dieses bruchstück, obgleich bei seinem geringen umfang eine übereinstimmung mit fehlern von $P$ nicht nachgewiesen werden kamn, dem grösseren gedichte $\mathbf{A}$ zuteilt. - Ier text von 1 ist sehr entstellt und manchmal ganz unverständlich, kann aber doch zur herstellung einiger kleinigkeiten mit nutzen verwendet werden.

Die übrigen hss., $\mathbf{c} \mathbf{w}$ d h, gehören zu der kürzeren fassung, B. w d h weichen im mittelteil (BII) an sehr vielen stellen, worunter zahlreiche gemeinsame fehler, in gleicher weise von c und AII ab, desgleichen im anfangs- und endstiuck (B I und BIII) von c, so dass eine gemeinsame vorlage der drei loss., $x$, leicht ersichtlich ist. Fine solche hat sich schon dur.h die übereinstimmende orthographie in den dialektformen (s.obon $\therefore$ 274) als wahrscheinlich erwiesen. $x$ war. jenen zufolge. in schwäbischer mundart abgefasst. Innerlıalb der grup'pe $\times$ kommen $w$ und d (da und $\mathrm{d}^{\mathrm{b}}$ sind ilurer vorlage gleichmässig grenau gefolgt, gelten also auch in ihrem text.kritischen werte als aillliejt) dem texte All c am nächsten, sind anch in logur anf die widergabe dessellen ziemlich gleichwertig. Wilhrend h morcr allen liss. ausser l von dem original am meistell aliwiolit.

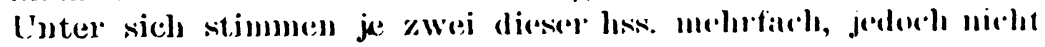


häutin. regeniiber der dritten in fehler überein, am meisten noch w Ind d. Da aber in dicsen fällen die sehr frei verfalırende hs. h durch eigene anderung ursprüngliches widerheregestellt haben komnte, so ist daraus auf ein näheres zusilmmengehen von $w$ und $d$ nicht zu schliessen. Für die herstellung des grundtextes ist eine entscheidung darüber atch nicht ron wichtigkeit, da $h$ dazu entbehrlich ist. $x$ war eine sehr willkürlich ändernde hs.

Viel geringer sind die besonderheiten von c. Die gemeinsame vorlage von $c$ und $x$ war im wortlaute von AII nicht erheblich verschieden. Am meisten treten auslassungen von kleineren und grösseren stellen hervor: es fehlen in cx die verse 133 f. $247-343.405$ f. 1711 f. 2218 . $2391-2402$, die für den zusammenhang meist unentbehrlich sind. Sinnstörend umgestellt sind, mit änderung einzelner verse, v. 1974-2018 linter 1672.

Die beschaffenheit jener gemeinsamen vorlage lässt sich auf folgendem wege näher ergründen: es ist oben (s.261) gezeigt worden, dass der eingang und der schluss von c (cI und cIII) formen enthalten, die einer andern mundart angehören als der mittlere, der hauptteil (cII). Diese wenigen merkmale lassen eine sichere heimatsbestimmung nicht $\mathrm{zu}$, weisen aber auf das schwäbische oder südrheinfränkische. Da nun aber keine ausgeprägt schwäbischen kennzeichen in jenen teilen vorkommen und da ferner, wie sich aus den reimen ergibt (s. unten), der ursprïngliche verfasser jener stïcke (BI und BuI) im südlichen Rheinfranken zu hause war, so ist anzunelimen, dass jene mundartlichen besonderheiten in cI und cIII iiberbleibsel des siidrheinfränkischen originals BI BIII sind (in $x$, das seinen schwäbischen dialekt streng durchführte, sind sie grösstenteils getilgt worden, ball und gesinn sind, weil im reime stehend, erhalten geblieben). Daraus lässt sich nun fermer die zusammensetzung der vorlage von $\mathbf{c x}$ erkennen: das mittlere stück, das in c keine rheinfränkischen sonderheiten enthält (selbstverständlich auch nicht in $\mathbf{x}$ ), wol aber ostfränkische (infinitive ohne $-n$, sowol in $c$ als in $x$, allerdings nur ganz vereinzelt), ist gar nicht durch die feder des siidrheinfränkischen bearbeiters von BI BIII gegangen, sondern unmittelbar aus einer ostfränkischen vorlage herübergenommen 
worden, anfang und ende, die er in seiner heimischen mundart, dem südrheinfränkischen, neu hinzu dichtete, sind von ihm einfach jenem ostfränkischen mittelteile vor- bez. zugesetzt worden. - Ist nun zwischen cx und $\mathbf{B}$ ein mittelglied anzusetzen? Kaum. Ein solches würde, in welcher landschaft es auch entstanden sein mochte, in c jedenfalls mundartliche spuren hinterlassen haben, auch würden bei dem durchgehen durch eine zwischenhandschrift die in cI cIII sich noch findenden südrheinfränkischen eigenheiten mehr verwischt worden sein. Aus dem wortlaut des textes lässt sich für diese frage nichts gewinnen, da dieser schon in seiner ursprünglichen anlage ganz verworren und oft unverständlich war, wie aus den sicheren bestandteilen, den reimen erhellt. Mit dem gänzlichen mangel des bearbeiters an schriftstellerischer begabung lässt es sich auch vereinigen, dass er solche störungen des zusammenhangs, wie sie durch die s. 278 angeführten auslassungen entstanden, ohne anstand bestehen liess.

Das so festgestellte verhältnis der hss. des gedichts lässt sich in folgendem schema veranschaulichen:

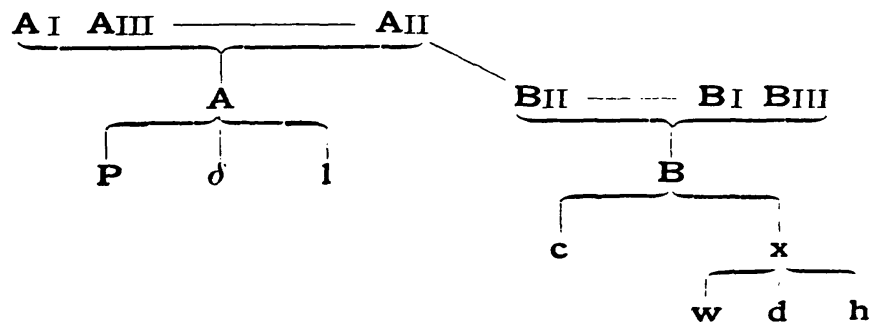

Der prosa liegt das kürzere gedicht $B$ zu grunde. der eingangs- und schlussteil sind in der hauptsache aus $B$ übertragen. Jedoch ist in einzelheiten des wortlants für die albschnitte wo $B$ denselben inhalt hat wie $A$, nur in anderer sprachlicher darstellung, heide male eine hs. von A beigezogren. So sind innerhalb des eingangs mitten unter den B-versen die verse 7:3-78 ans A verwendet. Besonders eigenartig zeigt sich die benutzung von $A$ im schluss. Hier gehen die lesinten von A und B so durcheinander, dass ersichtlich der frosalbearbeiter je eine his. von $A$ und $B$ vor sich hatte und die 
Worte bald atus der einen bald aus der andern nach belieben alswïhlte.') \%. b.:

Prosa bl. 268a.

vul täling selbs mit der frowen das geschach, myñe überwand wes si rrrett vud gebar jn der burg ain kind dz wider myñe hieffz recht als si geborn ward sy warl herr jn derburg vnd dă ward fröde sunder zal in der burg me dañ kain hand geschriben kúnde.

A ( =- P) v. $3146-3161$.

vind teyding selber mit der

frawen

die mynne die rolgt dem rat nach

vnd tet ez gern vid geschach was myune da irret daz vber want

sie vol gebar auch allzuhant in der burg ein edel kint laz waz zum mol gesichtes blint rnd haimlich selb zu tåding ste da by erkenn die burgfrow die minn wnd iren flyfz anschow das geschach die minn bezwang: mit rechter giit dar nach sie rang vinl gebar in der burg ain kind vud hiez auch wider mynne daz kint jn rechtem synne wart geborn in sulher art als mynne vor geborn wart daz ir gehort habt hie vor minne wurden do die burgtor vff geslofzen vber al do hube sich freude ane zal mer dann geschriben mag kein hant.

das was so gar des wunsches find vnd ward die wider minn genant als sie geboren was erkant sie ward da in der burg der her

in aller fród nach wunsches ger me damn volsprechen kan kain mund.

Ferner: prosa bl. 269 a.

lie burg ward von ainem grossen hör beräntt Die fraisslichen stírm̄ten vnd lchussen vnd wurfen. vor irem sturmen künd sy nit besten Ir greschollz was scharpff vid hrantt die jngestïle von zipperes von gestain jn der burg jr bleyden freysslich brachen ärker tïrn vad mänig starck gewelb Alles jr stúrmen was zobell töttlich farb dz veld gar beströwett warl mit rotten fürin zungen.

$$
\text { A }(=\mathbf{P}) \text { v. } 3630-3650 \text {. }
$$

daz die burk vil vefte wart vo eim grofzen her berant

die freislich sturmtē allzuhant vor irem sturme kund niht besten sie wurden vast hin zu gen der slug der schoz yener warf ir geschoz waz also scharf daz ez die edeln gestul verbrant́ die an der burge waren bekant die waren also hubsch vod kurk

1) Es ist dies ein sicheres heispiel für eine sonst im mhl. ungebriuluchliche arbeitsmethode, vgl. Paul, Beitr. 1, 309. Steimmeyer, Gött. gel. anz. 1887, 786 ff. Stosch, Anz. fda. 19, 302 anm. E. Kettuer, Zs. fdpli. 23, 205. 
als yene dort zu mymnenburk die ich vor genennet han daz gestul zum mol verbran turn vnd erker musten lyden lytlich gebrechen von den plyden wann daz must allez samt entzwey ir sturm waz mit grofzem geschreye ir banir velt vil garbe waz von zobel totlich varbe darin waz vil gedrungen rotter vintlicher zungen.

\section{B v. 3190-3201 (nach w).}

ain grosses her die burg beranten stúrmen werffen schiessen geschach da vnuerdriessen das sie deshalb nit wol bestůnden geschofz das scharpff tett sie wunden das in der burg blaib gantz dekain gestül ron Ciprefz vnd gestain blyden gewelb ercker durn brachen von des sturmes zurn der was fraislich totlich zobel das veld durch ain ander strobel was bestrówet mit fúrin zungen.

Die hs. welche der prosa für den mittleren teil, wo $\mathbf{A}$ und $\mathbf{B}$ zusammengehen, vorlag, hatte die einzelabweichungen von $x$ sowie mehrere $c$ und $x$ gemeinsame fehler nicht, ebenso nicht einige fehler von P. - Der text der Wiener prosahs. ist sehr entstellt (er scheint aus einer schwer lesbaren rorlage flüchtig abgeschrieben), im ausgang oft ganz simmlos; offenbar hatte schon der prosaumarbeiter das confuse machwerk von B gar nicht verstanden.

Unter solchen handschriftlichen verhältnissen lässt sich der ursprüngliche text der Nimmeburg annähernd richtig nur im mittleren teile herstellen $\left(\mathbf{A I I}_{\mathrm{II}}=\mathbf{B I I}\right)$. Für $\mathbf{A}_{1}$ und $\mathbf{A}_{11}$ liegt nur die vielfach ändernde, aber doch einen verständlichen text bietende hs. P vor. Bei der kritischen herstellung dej in B ungeänderten partien BI und BIII fehlt alle sicherheit. da der verfasser selbst keinen lesbaren text zu stande gebracht liat.

II.

Metrik. Sprache des originals.

l)ie Minneburg ist in der für die erzählenden mol lohlaften gedichte meist gelorauchten form der par wrisc gurrimten verse, von vier liebungen aligefasst.

\section{Rhythmus.}

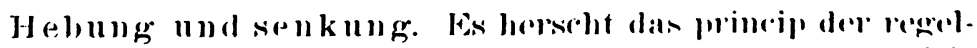

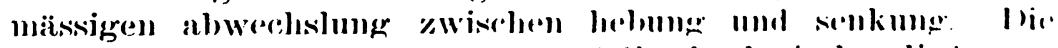

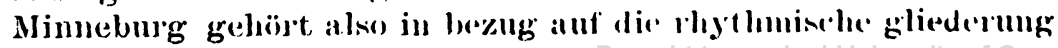


Zו1 der \%writen der von P'aul, Girundr. 2, 945 unter den gedichten des spaiteren mittelalters unterschiedenen gruppen. Die zweisilhigkeit der füsse ist jedoch nicht streng durchgeführt. Nicht selten fehlt eine senkung, am häufigsten zwischen der vorletzten Imi letzten hebung, sowol in ein und demselben worte bei starkem nebenton der zweiten silbe, wie oúgstein, fiurstein, ïrprinc, hérbìrg(e), winbràu(e), ármìot, gefénkniss(e), hélblìnc, kliochìt, evîsheit, billich, dánnòch, veréllèndet u. a., als bei zwei wärtern: stéin brain, buirc líg(e), héim gấn, in die búrc gấn, líep hite, wé tio u. a. Dem gegenüber finden sich öfter auch schwere senkungsfüllungen, z.b. er kiunde kriechisch er kúnd(e) kaldéisch (v. 468), oder vón der fünf sinne kóren (v. 650), wírklich uirkung des uíllen (v. 631) u. a.

In der behandlung der schwachen $e$ folgt der dichter je nach bedarf entweder seiner mundart oder der seit dem 13. jh. iiberlieferten fortdauernden literatursprache, denn er gebraucht sowol die syn- bez. apokopierten formen (wie die reime zeigen), als auch die nicht gekürzten, was daraus hervorgeht, lass dieselben schwachen $e$ senkungen zweisilbiger füsse und klingende ausgänge dreihebiger verse bilden können.1)

I)ie quantität der stammsilbe kommt dabei nicht mehr in betracht. In dieser doppelten behandlung der schwachen $e$ stimmt die Minneburg zu dem allgemein üblichen gebrauche der.jenigen gedichte des 14. 15. jh.'s welche den syn- bez. apokopierenden mundarten angehören. Jedoch ist nicht in jedem einzelnen fall die entscheidung möglich, wie sich der dichter denselben gedacht hat. Da indess im princip einsilbigkeit der senkung gilt, so wird tilgung des schwachen $e$ da vom dichter gemeint sein, wo durch sie dreisilbige füsse auf zweisilbige zurückgeführt werden kömmen.

Das zusammengehen von logischer und rhythmischer betonung ist öfter gestört. Verletzung des natürlichen satztons liegt vor an stellen die zum teil unter den begriff der schwe-

1) Diese zwiefache verwenlung von wörtern mit schwachem $e$ in der schlusssilbe, je nach bedürfnis für klingenden oder stumpfen reim, begegnet schon in der zweiten hälfte des 13. jh.'s, besonders bei den schwierigeren strophenbildungen wie z. b. in Lohengrin (Rückert s. 270 f.). Aus den Lorengel ( $Z$ s. fda. 15, 180 ff.) sei ein auffallendes beispiel erwähnt: in strophe 22 (s. 185) reint $\hat{e} r$ auf $h e r$, in der darauf folgenden strophe $\hat{e r e}$ /auf lêre. 
benden betonung fallen, z. b.: say(e) ich dir daiz so betrüg(e) ich dich (v. 782), swaz er mir ságt(c) solt(e) ich daz ságen (v. 451), der vór dem tág $\hat{u} f$ brichet und sồ diu $\operatorname{súnn}(e) \hat{u} f$ stichet (v. $1943 \mathrm{f}$.) u. a.

In der setzung des auftakts bestehen keine regeln; die auftaktlosen verse bilden jedoch die minderheit, etwa ein achtel der gesammtzahl. Zweisilbiger auftakt ist nicht selten.

Dass der hiatus nicht vermieden wird, beweisen verse wie under den dache ouch duvchifischet (v.212), denn wollte man in solchen fällen elision des $e$ vorziehen, so würden übermässig viele einsilbige füsse entstehen, was dem charakter der rhythmischen gliederung des gedichtes widerspräche.

Versausgang. Bei stumpfem ausgang haben die verse regelrecht vier hebungen, nur ganz vereinzelt begegnen dreihebige. Die klingenden reime von den stumpfen $\mathrm{zu}$ scheiden ist sehr oft nicht möglich, da die ersteren durch apokope oder synkope des schwachen $e$ als stumpfe gelten könmen. Jedoch können unter folgenden zwei gründen sicher klingende ausgänge festgestellt werden: einmal sind als klingend endigend alle diejenigen verse aufzufassen, welche durch tilgung des schwachen $c$ zu stumpf endigenden mit nur drei hebungen würden, da der dichter dreihebige verse mit stumpfem reim meidet. Und zweitens bilden die $z$ weisilbigen wörter mit langer paenultima und $-e l,-c m,-c n,-c r$ in der ableitungsbez. flexionssilbe wie wandel, wunden, yuoter jedenfalls klingende reime, wie in der mhd. blïtezeit. Abgesehen davon, dass solche wörter physiologisch nicht als einsilbig gelten können (I'aul. Beitr. 8, 188), lässt sich aus der metrik des 14. 15. jh.'s. selhst der beweis führen, dass sie als zweisilbig anerkannt und die sie enthaltenden verse als klingend angesehen wurden: Suchenwirt gebraucht sie nie in vierhebigen versen, die bei ihm immer stumpfen ausgang haben, sondern nur in dreihebigen. stets klingend endigenden, während er als stmmp auch solelor zweisilbige wörter mit langer paenultima verwendet. deren letzte silbe auf $c$ oder mit bestimmten einschränkungen (vgl. Kolwer-

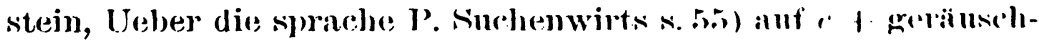

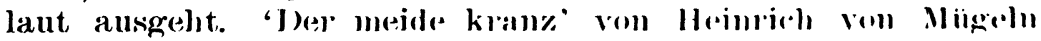

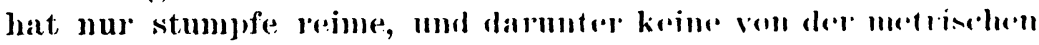

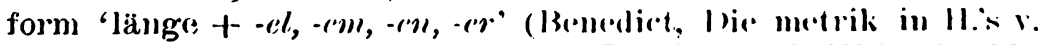


Miigeln 'Der meide cranz' s. 9 f). Hermann von Sachsenheim halt in den :30.40 reimpaaren seiner nur stumpf gereimten Mörin nur sechs solcher wortpaare (Martin s. 39), keine in Jesus der ar\%t (lite (onsonantverbindung $r+f[c] n$ gilt naturgemäss als

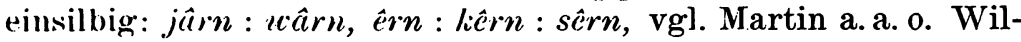
mamms, Walther'2 s. $26^{\circ}$ und 47 und Beiträge zur geschichte der äler'n deutschen lit. 4,96 ff. Paul, Beitr. 9, 118), der ebenfalls nur stumpf reimende 'nachahmer' Sachsenheims hat keine. selbst noch bei den meistersingern waren 'gezwungene reime' wie betragn : sagn verpönt, diese 'sind mit gewalt aus klingenden zu stumpfen gemacht', ebenso die 'schnurrenden reime' mit kürzungen wie feur für feuer (s. Plate, Strassburger studien 3, 216). Teber häufigere verwendung von wörtern des angeführten masses als stumpfe reime im jüngeren Sigenot $\mathbf{s}$. Steinmeyer, Altd. studien s. 85; bei Ulrich Fürtrer s. Hamburger, Intersuchungen über L'lr. Fürtrers dichtung von dem Gral s. 9; im lied rom Hürnen Seyfrid s. Golther s. xvır f. - Diese sicher zweisilbigen wörter werden nun nicht nur in versen mit drei, sondern auch in solchen mit vier hebungen verwendet, und solche klingend endigenden verse mit vier hebungen sind nicht selten, reimen auch mitunter auf dreihebige. Schon des dichters landsmann Hugo v. Trimberg hat sie reichlich gebildet, zum König vom Odenwald s. v. Bahder, Germ. 23, 207.

Ausser diesen durch die angegebenen kriterien als klingend endigend erwiesenen versen besteht noch eine ziemliche anzahl solcher, deren reimgattung schwankt. Es sind dies alle diejenigen vierhebigen verse, deren reimwort in der endung ein schwaches e allein oder vor einem geräuschlaut enthält. Diese können unter verschweigung des $e$ als stumpf oder mit beibelıaltung desselben als klingend schliessende gelesen werden.

Zweisilbige wörter mit ursprïnglich kurzer paenultima + schwachem $e$ treten, in übereinstimmung mit der mhd. metrik, meist in vierhebigen versen auf, seltener, abweichend von dieser, in dreihebigen. In manchen fällen mag schon dehnung der stammsilbe eingetreten sein, aber es bilden den ausgang dreihebiger verse auch solche kurzstämmige wörter, deren stanmvocal niemals verlängert worden ist, z. b. haz flíderhólz gesniten (v. 191), uan úmb lie minne gótes (v. 871). 1)och enthält in dreihebigen versen dann das reimwort in der ableitungssilbe 
meistens sonantisches $l, m, n, r$, selten wie in dem letztangeführten beispiel bloss schwaches $e$ allein oder von geräuschlaut gefolgt. Bei dieser verwendung der kurzstämmigen zweisilbigen wörter in versen mit nur drei hebungen gilt demnach in der Minneburg eine ähnliche, nur nicht so folgerichtig durchgeführte einschränkung wie bei Suchenwirt, nämlich dass nur die wörter mit silbebildendem nasal oder liquida als klingende reime angesehen wurden, während bei den andern wörtern unter tilgung des schwachen $e$ stumpfer reim eintrat.

Das zahlenverhältnis der stumpfen und klingenden reime ist je nach dem inhalt abschnittweise ein verschiedenes. Die klingenden ausgänge werden mit vorliebe angebracht in den lyrischen minnereden (rede), die zwischen die erzählung (materge) eingestreut sind (s. unten). Demnach verteilen sich die beiden reimarten im grossen und ganzen in folgendem verhältnis ${ }^{1}$ ):

Anfang bis v. 1614 materge ca. 33 proc. klingende ausgänge

v. $1615-2034$ rede
v. $2037-2304$ matcrge
v. $2305-2677$ rede
v. $2677-3272$ materge
v. $3273-3596$ rede

v. 3597 bis schluss materge

$\begin{array}{lll}" & 56 & \\ " & 31 & \\ " & 60 & " \\ " & 35 & \\ " & 50 & 29\end{array}$

$\begin{array}{ll}" & \because \\ , & , \\ " & , \\ , & , \\ " & ,\end{array}$

(die in diesem letzten capitel eingestreuten minnereden v. $4267 \mathrm{ff}$. und 5013 ff. haben nicht den hohen procentsatz klingender reime wie die früheren).

In den minnereden ist der lieblingsvers des dichters der dreihebige mit klingendem ausgang, in stil und verskunst sind hier die gedichte Egens von Bamberg sein vorbild (s. unten). Die beiden von diesem erhaltenen minnereden haben ca. 54 bez. 57 proc. weiblicher schlüsse.

Der procentsatz der klingenden ausgänge, der sich sellsst.

1) Als klingend sind gerechnet 1. alle reimwiirter, hei denen dureh ti]gung des schwachen $e$ ein dreihehiger stmmpf ondender vers entstolien wïrle, nud 2. alle langstïmmigen reimwörter mit somantischem l. m. "r.

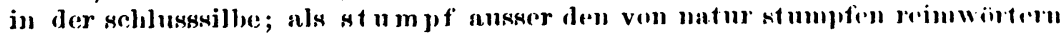
anch diejenigen, die in vierhobigen versen ktehend tilgharex. nicht voll $I$.

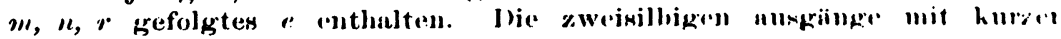
paenultina sind nicht mitgerällt. 
in den allegorisch er\%ählenden abschnitten \%wischen 29 und 3i5 proc: bewegrt, ist also allch hier schon ein grosser gegenüber den meist in den erzihlenden gedichten des 14. jh.'s geltenden zahlenverhältnissen, wie sie von Kochendörffer, Zs. fda. 35, $290 \mathrm{f}$. und ron sichröder, Z Zwei altd. rittermären s. $x$ beobachtet worden sind. Bei den allegorien, lyrischen und didaktischen 'reden' und reimsprüchen treten überhaupt die klingenden ausgänge in allgemeinen weniger zurück. So werden z. b. in den im Liederbuch der Hätzlerin und in Lassbergs Liedersaal abgedruckten minnereden 20 proc. öfter überschritten, ebenso in vielen sprüchen Suchenwirts, in den fünf paarreimigen reden Hugos v. Montfort u. a. Die klingenden reime beim König vom Odenwald halten sich zwischen 20 und 44 proc.

Enjambement. Stärkere verletzungen des sprechtaktes bez. der logischen betonung durch enjambement sind häufig. Getremnt sind durch den versschluss z. b.:

Partikel bez. adverb und verb:

$$
\begin{aligned}
& \text { v. } 851 \text { swaz dînem geminten an } \\
& \text { stêt daz dünkt dich wol getân. } \\
& \text { v. } 1520 \text { und wil ouch iezunt iemer an } \\
& \text { ruofen dinen zarten lîp. } \\
& \text { v. 2247 siufzen swenn ez dir niht wol } \\
& \text { gêt in dîm wirken als ez sol. } \\
& \text { v. } 3685 \text { geschehener schade ist niht ze bringen } \\
& \text { wider zwâr mit keinen dingen. } \\
& \text { v. } 4043 \text { dâvon weiz ich daz du niht an } \\
& \text { mich muotest daz wêr(e) missetân. } \\
& \text { v. } 5002 \text { sô sprach frou Triuwe und heizet reht } \\
& \text { teilen als ez sî für gezelt. }
\end{aligned}
$$

Terbum finitum und dazugehöriges persönliches pronomen :

v. 1300 ez sprach: 'lieber meister wart ich geborn aleine?'

Reflexives verb und dazugehöriges pron. reflexivum:

v. 1866 mîn ougen kunden nie derlnoder(n)

sich der zarten frouwen rein.

Zusammengesetztes tempus oder genus verbi:

$$
\begin{array}{ll}
\text { v. } 1454 & \text { gip mir als vil als du mir hâst } \\
\text { genomen, ich mein dîn herze. } \\
\text { v. 3976 daz ir darumb zefüeret } \\
\text { werd all ir fröud in trûren gar. }
\end{array}
$$


DAS MHD. GEDICHT VON DER MINNEBURG.

v. 4117 sô daz sie im gekündet

habe wie sie angeziindet.

v. 4666 getihtes geist ouch verstarret

ist in mir und verdumpfet.

Hilfsverbum und infinitiv:

v. 3745 daz ich mich vor den bœsen sol verbergen, ach, ez stêt niht wol.

v. 3669 als vil als ir die banier moht begrîfen swâ daz iemer toht.

Copula 'sein' mit prädicatsnomen:

v. 3828 daz minne von natûre ist ein edel erznîe diu dâ heilt.

Artikel und substantiv:

v. 244 dâ sach ich enmitten ein mannes bilde vor mir stân.

v. 5221 und sprach alsô: 'waz meinet die krâ, daz ich ir noch nie ...'

Adjectivisches attribut und substantiv:

v. 820 minne, du hâst dînen werten friunt als dich selber liep.

v. 866 waz ist ân got daz nützest und edelst dink ôf aller erden hie?

v. 1051 dâvon sol ein sôgetân wîp eins mannes rede empfân.

v. 2970 von harmen ist der vierde sinn durchliuhtet und durchziert.

Genitivisches attribut und substantiv:

v. 4570 geloubestu der philosophîen meister schrift und lêre?

Reimbrechung. Diese ist in den 'reden' im princip, wenn auch mit manchen durchbrechungen, durchgeführt, auch in Egens gedichten herscht sie vor, ist jedoch dort nicht so stark ansgeprägt. In den allegorischen teilen ist im allgemeinen die beziehung zwischen satzschluss und reimpaar frei gelassen. in einzelnen teilen überwiegt aber auch hier die reimbrechung das rime samenen.

Der rhythmus ist podisch, der abstand in der hetomung zwischen hebungen und senkungen gering. In den 'reden' lickt ein schwerpunkt nuf den seltsamen reimen, nlso $\mathrm{nm}$ (nde des 
verses. Begrründet ist dieses nicht in logischen verhältnissen des sat:simnes, sondern in ästhetischen liebhabereien (über dic spihlu rime s. unten IV unter 'stil'). I)ie inlaltliche füllung der einzelnen verse ist neist erstaunlich diurftig; oft könnte bei dell schleppenden widerholungen, tautologien, unnötigen umschreibungen, doppelgliedrigen formeln, überflüssigen, nur des reims wegen angebrachten flickwörtern und phrasen, ja ganzen sätzen, das was in mehrere verse gedehnt ist, in wenige worte zusammengezogen werden olıne dass dem gedanken abbruch getan würde. Iie armut des inhalts, die bei der beobachtung des verhältnisses zwischen dem gesammtstoff und der ausdehnung des ganzen gedichtes so auffällig ist (s. unten III) zeigt sich somit schon im einzelnen verse.

\section{Reim.}

a. Reim und sprache.

Tm reine reime zu gewinnen, macht der dichter sehr oft von mundartlichen formen gebrauch. Die untersuchung derselben ergibt zugleich seine heimat: diese ist Ostfranken. Zur feststellung der mundartlichen erscheinungen') sind die ostfränkischen gedichte Hugos von Trimberg (der Renner), des Königs vom Odenwald (v. Bahder, Germ. 23, 193-222 und 292-314), Ruprechts von Würzburg erzählung Von zwein kaufleuten (Zs. fdph.7,65-88), stellenweise auch der spruch vom W'ürzburger städtekrieg (Liliencron 1, 161 ff.) beigezogen.

\section{Vocale.}

Sehr häufig werden silben, die in der mhd. literatursprache als kürzen gelten, gebunden mit längen; so reimen $a: \hat{a}$ häufig z. b. in an : getân : hân : wân, kan : hân : getân : wân, bran : stân : hân, versan : hân; gar : dâr : wâr : zwâr : âne vâr : jâr : -bâr, clâr : nar : (ge)var : (ge)war : schar : tar; nâch : sprach :

1) Der Renner ist zum vergleich genommen als wichtigstes ostfränkisches denkmal des 13./14.jh.'s, Ruprechts erzählung, weil darin möglichste reinheit und dialektfreiheit der reime erstrebt ist; des Königs vom Odenwald gedichte, deren dialekt von $\mathrm{K}$. v. Bahder a. a. o. trefflich behandelt ist, und der Städtekrieg sind es als ausgeprägt mundartliche dichtungen. - Nachträglich verweise ich auf die reichhaltige einleitung M. H. Jellineks zu der psalmenübersetzung des Ostfranken Melissus (Braunes Nendrucke no. 144148), welche nach abschluss vorliegender abhandlung erschienen ist. 
besach : geschuch; gemaht : gedâht; tag(e):wâg(e); hâst : gast : glast : last; tât : bat, hât : blat: mat : stat, rât : stat, stât: bat; underlâa : daz; im klingenden reim: namen : âmen, mâsen : nasen.

Offenes $e: \hat{e}=a e$ : bèr : swêr 3769, swêr : gër 49, wêr : enbër 4749, wërt : vermêrt 1733. 3891, «ềrn : gërn : kërn 2851. 401, brwêrn : gërn 4711, wêrn : ern(e) ') 79, umbeniêrn : enbërn 1053; getêt(e) : Gamuret (vgl. Franck, Zs. fda. 25, 223) 2991; brêch(e) :

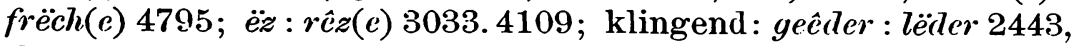
flëdert : êdert 2453, genêhen : sëhen 1141, brëhet : wêhet 2433, lietrehtic : bedêhtic 5337; meldet : unsêldet 1273.

Geschlossenes $e: \hat{e}=a:$ envền : den 2145.

Geschlossenes $e$ : $\hat{e}$ : rede : bêde 4613.

$i: \hat{\imath}:$ hin : sîn 25, smitten : margarîten 2467, mich : fröudenrîch 1557. Die persönlichen feminina wie künigin werden auf wörter mit kurzem und. langem $i$ gebunden, z. b. hin : künigin, auch keiserinne: minne, neben meisterin etc.: schîn : mîn; desgleichen die adjectiva auf -lich: êwiclich : mich : dich : sich : sprich : stich und eigenlich : rîch, ebenso die adverbia auf -lichen: festiclichen : stichen und festiclichen : wîchen, und gelîch : rîch sowie gelîch : dich : eigenlich.

$i$ und $\hat{\imath}: i e$ vor $r$ bez. $h$ : gîे : fier 5097, siht : lieht 3229. Im Renner tier: wir, vgl. v. Bahder, Ueber ein vocal. problem des md. s. 36.

o : ô: vor: Amôr 2821, von : Salomôn 3355, wort : gehôrt (3. pers. sg. praes., ohne umlaut, vgl. Weinhold, Mhd. gramm. ? \$ 111) 2061 .

$\imath: \hat{u}:$ fluz : $\hat{\imath} z 1043$.

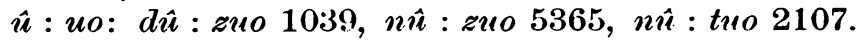

1) $e$ in erne ist jüngerer umlant ('fränk. alem. ärn', Klnge, Et. wh. unter ervte), denn Tatian hat im dat. arni (Nievers, einleitung $\$$ (6i). Ias mhd. subst. diu erve fiir ahd. diu arn, aran ist aus verallgemeinerung des häutign gebranchten dativs in formeln wie ahd. zi armi, mhd. in der erne ahznlejten und nicht aus dem plural. Dieselbe erklärung gilt anch fihr 'crnte': verdrïingung des singulars durch den plural ist gerade bei diesem worto seiner bedeutung nach nicht wahrscheinlich. In dieser bezichung guhiirt also erne, ervete zu den von Paul, Mhd. gramm. \$ 127 anm. 1 z.1ияammengestellten wörtern. - leer ofter vorkommende reim rowe : firme (lirimm.

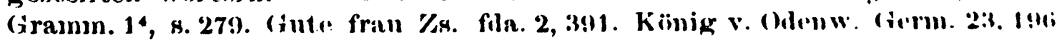
Minneburg v. 35(b7) int ulso reill.

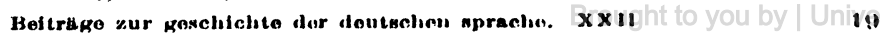


In der heutigen ostfränkischen mundart ist die dehnung älterer küryen in grossem umfang eingetreten, vgl. bes. C. Franke, Bayerns ına. 1, 28 ff. Nach diesem finden sich u.a. gelängt: an, liulu, statt, frech, ich, mich, dich, sich, fluss. Es ist demnach möglich, dass manche ler angeführten reime in der heimatlichen aussprache des dichters schon rein klangen. Andrerseits können in dieser gedâht, bedêhtic u. a. schon gekürzt gewesen sein. - Im Renner wird $a: \hat{a}$ sehr häufig, ca. $180 \mathrm{mal}$, und $o: \hat{o}$ ca. $40 \mathrm{mal}$ gebunden, dagegen nie $i: \hat{\imath}$ und $u: \hat{\imath}$ : hier herscht also dasselbe verhältnis wie bei Wolfram (vgl. Wimmer, I eber den dialekt Wolframs, programm von Kalksburg 1894/95, s. 12), dass wol $a: \hat{a}, o: \hat{o}$, aber nicht $i: \hat{\imath}$ und $\imath: \hat{u}$ reimen.

$\hat{a}$ ist im ostfränkischen zu $\hat{o}$ geworden, 1$)$ daher die häufigen (ca. 20) reime $\hat{a}: \hat{o}$ wie nâch : hôch : zôch, hâr : tôr(e), stît : rôt, ân' : schône, trôst: hâst, underlâz: grôz, lâzen : grôzen u. a. Sie finden sich auch beim König vom Odenwald (Germ. $23,196)$, werden aber von dem der literatursprache strenger folgenden Hugo v. Trimberg nicht gebraucht.

$\hat{a}>\hat{o}$ reimt auf mhd. $o$ in lohen : gevâhen 1959, auf ou in krouch : nâch 4331.

$\hat{e}=a e$ und $\hat{e}$ werden in der Minneburg so wenig gereimt als in den s. 288 genannten ostfränkischen gedichten. Die laute sind als offenes und geschlossenes $\hat{e}$ phonetisch getrennt: in der schrift wird allerdings in übereinstimmung mit der md. orthographie $a$ ebenfalls durch $e$ ausgedrückt. Das gleiche ist der fall im elsässischen: hier wird ebenfalls $e$ geschrieben, aber mhd. $\hat{e}$ nicht auf $c$ gereimt, z. b. bei Altswert (Karl Meyer, Meister Altswert, programm von Göttingen 1889, s. 37), im Parzifal von (laus Wisse und Philipp Colin.:) Desgleichen im Wetterauer dialekt der Heil. Elisabeth und der Erlösung (Rieger s. 30. Bartsch, Germ. 7, 3), in Athis und Prophilias (W. Grimm, Kl. schr. 3, 240), im md. Schachbuch (Sievers, Zs. fda. 17, 385), im böhmischen des Ulrich von Eschenbach ('Toischer, Ueber die sprache Ulrichs v. Eschenbach, programm von Prag-Neustadt

1) Getadelt von Fabian Frangk (Müller, Quellenschriften s. 106), anch von Joh. Nast, Grundsätze der teutschen rechtschreibung (Herrigs Archiv $65,425)$.

2) Die ersten 10000 verse habe ich darauf hin geprift. 
1888, s. 13), im schlesischen in Ludwigs kreuzfahrt (Zs. fdph. 8, 381), vgl. auch v. Bahder, Grundlagen s. 110.

Dem entsprechend ist auch der unterschied zwischen offener und geschlossener aussprache des kurzen $e$ gewahrt (offenes $e$ reimt auf geschlossenes $e$ nur in bestrëbt: entsebt). 1)a das praet. weste im mhd. geschlossenes $e$ hat, so sind reime der Minneburg wie ueste : beste 975 : reste 1797 : veste 3629 : veste(n) 3115 genau. Das abstracte fem. erge reimt auf horbërge (1477. 2543) und plur. ergen auf verbërgen (3527. 3749). daneben schreibt P 3297 irge : grbirge (die stelle fehlt in B). Die aus adjectiven abgeleiteten fem. substantive auf $\hat{\imath}$ schwanken zwischen älterem und jüngerem umlaut. In einzelnen sprechgemeinschaften gilt der erstere in der volks-, der letztere in der gebildeteren sprache. Dem jüngeren umlaut entsprechend bilden erge : herberge : verberge(n) reine reime; $i$ für $e$ in irge auf gebirge lässt sich als älterer umlaut mit geschlossenem $e$ auffassen, wobei allerdings noch eine reimungenauigkeit vorläge. Es sind aber möglicherweise diese beiden reimwörter in der einzigen hs. die sie überliefert $(P)$ verderbt und es ist zu lesen erge: gebërge, welch letzteres bei Lexer aus Megenberg mehrfach neben gebirge belegt ist.

Auch im Renner sind offenes und geschlossenes $e$ beinahe niemals gebunden, beim König vom Odenwald und bei Ruprecht von Würzburg gar nicht. Diese genaue unterscheidung der beiden $e$ beruht nicht etwa auf einer besonderen feinhörigkeit der ostfränkischen verfasser, sondern sie gilt als gesetz für die ganze mhd. poesie, das noch viel strenger eingehalten worden ist als meist nach den grammatiken und sprachlichen einzeluntersuchungen sich schliessen lässt. Denn in diesen werden die $e$ ihrer qualität nach fast nie ganz genau auseinandergehalten. l larauf hat bezüglich Konrads v. Würzburg Edw. Schröder hingewiesen im Anz. fola. 19, 155. Es wäre anch auffallend, dass z. b. die alemannischen, bairischen, isterreichischen, ostfränkischen $u$. a. dichter zwar den verschiedemen klang bei den langen $a$, und $\hat{s}$ wol bemerkten und in ilırer reimkunst berücksichtigten, aber nicht denselben unterschied bei den kurzen $e$.

$u$ fïr o ist, regel im infinitiv liumm (: frumm sh. und vorls.

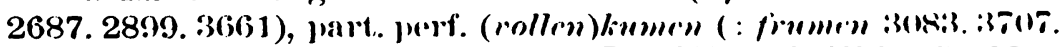


51:39), demnach auch part. (ge-, ver-)numen (: kumen) mehrfach; ebenso in Remner und bein König vom Odenwald, auch die jetrige ostfrinkische mal. hat diese " bewahrt.

" 110 in ruom : linm 2579, vgl. zum König vom Odenwald, (ierm. 23, 198.

$\therefore$ aus eyi in (ye)seit, leite, geleit, treit, treist reimt mit altem $\therefore$ (fïnfzehn mal mit der ableitungssilbe -lecit, -keit, auf cuntrrfrit und zesneit, einmal meist: treist), viermal sind die betr. wörter unter sich gebunden. In gelegt : regt (4241. 4393) und yedagt : gesagt (4631) wie in lilagt : verzagt (4903) ist in übereinstimmung mit der ebenfalls ostfränkischen hs. $\mathbf{P}$ erhaltung des $g$ anzunehmen. Im Renner reimen beluaget, (ge)klaget, maget, unverzaget nur unter sich oder auf saget, welch letzteres nur sehr selten ei aufweist; beim König vom Odenwald vereinzelt unverzeit, Germ. 23, 307, v. 22; bei Wirnt sind die formen mit ei aus egi reichlich vorhanden, vgl. H. Fischer, Zur gesch. des mhd. s. 51.

Noch mehr als die im vorhergehenden behandelten mundartlichen reime weicht von der literatursprache die bindung ron sêlic : heilic (heilig $\mathrm{P}$, helge $\mathrm{cx}$ ) $2641 \mathrm{ab}$. Im heutigen Würzburger und anderen ostfränkischen dialekten ist $a i>c e$ geworden, demnach gäbe sêlic (= scelic) : hêlic (= hoelic) einen vollständigen gleichklang. Es erscheint aber gerade in gegenden des heutigen ostfränkischen jenes weitverbreitete helig, das Kögel, IF. 3, 287 in as. halag, schweiz. hălig, hĕlig (Schweiz. id. 2, 1148) nachgewiesen hat: so henneberg. hêlig adj. und besonders adverbiell gebraucht 'recht, tïchtig, arg, sehr', helltage 'feiertage', Spiess, Beitr. zu einem henneberg. id. s. 99 f.; Die fränk.-henneberg. ma. s. 4; Volkstümliches aus dem fränk.hennebergischen s.14. Frommanns mundarten 5,515: hêlig 'sehr gross, ungeheuer' (und ebenda 7,297); ferner in den nachbarmundarten von Salzungen (Hertel, Wb. der Salzunger ma. s. 19); Ruhla (Regel, Die Ruhlaer ma. s. 201. 207); im fuldischen (Vilmar, Id. s. $163 \mathrm{f}$.): hellig schœen 'ganz besonders, ausgezeichnet schön', hêltag, heltag 'festtag' (wol aus helytag = schweiz. leligtag). ${ }^{1}$ ) Dass helig im älteren ostfränkischen auch die

1) Die grundbedeutung des wortes kann in dem verstärkenden adverbialbegriff 'ungehener, sehr gross, sehr' noch erhalten sein, wonach holuy, 
bedeutung von 'heilig' hatte, beweisen helltage 'feiertage' und die lesart hclig für hcilig in der Würzburger hs. des Renner v. 12000 . - Kögels vermutung, dass in manchen ahd. und mhd. quellen helig mit kurzem $e$ anzusetzen sei, bestätigt sich entschieden, vgl. auch DWb. 4, 2,827. Ich liabe keine erschöpfenden sammlungen angelegt, es ergaben sich mir aber doch folgende gesichtspunkte. Wenn in einer quelle vereinzelt $e$ für $e i$ eintrat, so fand sich unter den betr. wörtern fast regelmässig auch heclig, oder, allerdings in selteneren fällen, es fand sich gar kein $e i>\hat{e}$ und doch helig. Im ahd. erscheint helag, helig nicht häufig (s. Braune, Ahd. gramm. \$ 44 anm. 4. Milstätter blutsegen, Fulder beichte hs. B), auch in den gedichten des 11.12. jh.'s nicht oft, dagegen tritt es mit dem ïberhandnehmen der mundartlichen schreibung in den hss. des 14. 15. jh.'s sehr oft auf und ist in allen md. und obd. dialekten nachweisbar: im mittelfränkischen (hier im cölnischen abgelöst durch hillig), rheinfränkischen, thüringischen, obersächsischen, schlesischen und ostdeutschen, im ostfränkischen und böhmischen, im elsässischen und eigentlich alemannischen, weniger im schwäbischen (doch ist hier noch gebräuchlich holgle 'heiligenbild', aus heligle, neben holge, welches nach Kauffmann $\$ 92 \mathrm{anm} .3$ und H. Fischer, Geogr. s. 45 ci als wurzelvocal hat), und im bairisch-österreichischen. - Auch ein reim seilig : heilig wäre denkbar, $e i$ für $a$ in seilig ist keineswegs nur eine zufällige schreiberlaune, sondern es hat lautliche geltung. Es reimt

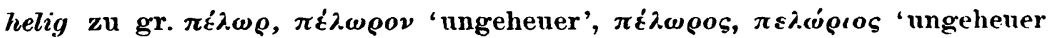
gross, riesenhaft', lat. ex-cello, ex-celsus u.s.w. gestellt werden kann. Tas ungeheure, erhabene erfüllt den menschen mit ehrfurcht und heiliger scheu. - Brenner stellt Beitr. 19,482 ff. einen $i$-umlaut von ai auf, der auch in luailic > hêlic stattgefunden habe. Aber dieser umlaut müsste doch in viel grösserem umfange im ahd., mhd. und nhd. zu belegen sein, auch sind einige der beispiele nicht einwandfrei (so der umlaut flêsk $={ }^{*}$ flaish(i), der umlaut in wênic $={ }^{*}$ wainic, während doch ahd. urspriinglich nur wruur belegt ist, n. a.), und die ganze an sich ansprechende theorie nuks mit unverhältnismässig vielen ausgleichungen rechnen.

1) Auch das verbum bezeirhnen findet sich verhältnismässig oft mit $r$. bezerlunen, geschrieben. Hier ist wol eine einwirknug der vorwanten wuryelform gernn. teih-, trih- (ahd. zerch) anzwnehmen, dir ja urspriuglich anch im

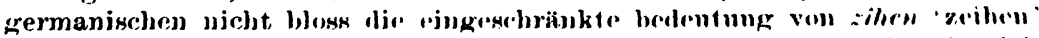

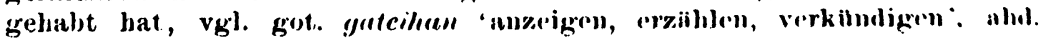
zeigôn 'zeigen'. 
srilir : 11mmeilir in der Martina (i, 5,5) und 81,87 und begegnet all\%u hiiutin in mhol quellen verschiedener landschaften, s. Weinhull, Mhul. gramm.2 $\$ 89$ und 95. Alem. gramm. $\$ 49$ und 58, 5. "Nakernatgel, Al. predigten $1, \mathrm{~V}, 43 \mathrm{ff}$. Bachmam-Singer, Volksbiiclier s. Lxxxır. Non. boica 41, 163 (Lexer, Handwörterbuch IInter seeler). Inocens Misc. 1, 140 ff. Heil. Hieronymus hg. von Benedict s. xıvi. Rückert-Pietsch, kntwurf s. 100. Lacomblet, l'rkundenbuch 3,758 (Weinhold, Mhd. gramm.? \$ 95). Zs. fda. 19.78. \%s. fdph. 27, 205. Beitr. 3,515 u. a. Leitzmann, ebda. 14, 476. 491; ebenso seilikeit und seilde für scelde, s. Weinhold, Bair. gratmm. \$ 66. Alem. gramm. $\$$ 49. Mhd. gramm.? $\$$ 95. Waag, Beitr. 11,95. Zs. fdph. 11, 247. Möglicherweise findet seilic seine erklärung in folgendem psychologischen vorgang: man hatte helic und heilic nebeneinander und bildete danach zu saelic ein scilic, darauf seilileit und scilde; vgl. auch Leitzmann a.a. o. s. 491 . Apokope und synkope des schwachen $e$ ist ganz geläufig. Stärkere tilgungen sind lit(e) (1. sg. conj. praet.) : unfrid(e) 2601, uêr(e)n: yern(e): $\operatorname{crn}(e) 2851.79$, liern : wêr(e)n 401, ich gelernt(c) : ir ger(e)nt 5363, web(be) : viderstreb(c) (subst.) 4277, ıelt : iiberhel(le)t 2905, liuht(et) : $\operatorname{diuht}(e)$ 4789, ruo(we) : fivo: zıo 947. 4607. 4731 u. a.

\section{Consonanten.}

Iie consonanten stehen auf gemeinmhd. lautverschiebungsstufe, das ist eben die oberfränkische. $g$ ist auch im auslaut verschlusslaut $c$, vgl. hac: smac 907, berc: werc 2487. 3803. 3815, getwerc:uerc 683, danc: dranc (praet. zu dringen) 3439.

Abweichend von dem obd. lautstand wirl $d$ mit $t$ gebunden in staden : gewaten 69, beiten : scheiden 2263, brâdem : âtem 1967 (indess ist âdem auch in obd. quellen öfter zu finden, $d$ steht hier in grammatischem wechsel zu $t$, vgl. v. Bahder, Grundlagen s. 244. Braune, Ahd. gramm. $\$ 163$ anm. 6). Im Renner, beim König vom Odenwald und bei Ruprecht von Würzburg kommt dies nicht vor, aber im hentigen ostfränkischen sind $d$ und $t$ nicht unterschieden, vgl. besonders Brenner, Bayerns ma. 2, 269 ff. H. Fischer, Geogr. s. 61 anm. 5.

1) Die hs. hat meilic, es muss aber unmeilic heissen, was von W'einhold, Alem. gramm. $\$ 58,5$ und von Lauchert, Alemaunia 17, 213 ïbersehen worden ist. 
h fällt zwischen vocalen aus (nicht im Remmer, König vom Odenwald, Ruprecht von Würzburg): empfân : sôgctân 1051, an : vâu 2299, stâl : quâl(c) 4567 .

hs wird zu zu ss in liessen 'kniekehlen': cipressen 193, uuos: zuckermus 3285. Dieser übergang findet nach der grenzbestimmung bei Wrede, Anz. fda. 21, 261 auch in einem grossen teile der heutigen ostfränkischen ma. statt und ist besonders im hennebergischen gebränchlich. Hasse, hesse s. bei Frommann, Ma. 2, 49. 496. 7, 292. Spiess, Beitr. zu einem henneberg. id. s.95. Der Renner, König vom Odenwald und Ruprecht von Würzburg haben nichts einschlägiges, aber im Städtekrieg reimt fuchs : sus 1923.

$m$ reimt auslautend auf $n$ : heim : rein(e) 1785 , desgleichen beim König vom Odenwald (Germ. 23, 199. 205), bei Ruprecht man : genôzsam : getân 120, heim: enein 426, in : vernim 643, im Städtekrieg Berchtheim: lilein 1191, hein in den gesetzen Ottos von Wolfskel, Archiv für Unterfranken 11, s. 95; in der heutigen provinz Unterfranken ist heim zu hẽ geworden, Bayerns ma. 1, 27.

$\mathrm{Zu}$ zesem : besem 1879, beide dat. sg., vgl. Lexer unter zëse und Zs. fda. 17, 383; kresen : zesem bei Frauenlob, Ettmüller s. $22,18,1$. Trebnitzer psalmen hg. von Pietsch s. LIx.

Consonantisches $i$ in lateinischen wörtern wird zu $g: g c^{-}$ sperge : materge 461 . 1631, beryen : latwergen 3509 , zibôrge : glôrge 3307 , brisilgen: tilyen 1949, geschedige $(n)$ : remedige 5385 . I Dieser übergang von $i>g$ kennzeichnet die umdeutschung dieser lehnwörter, während daneben die fremdwortform hergieng und meist die oberhand gewann, wie z.b. materie. Andere obd. beispiele ausserhalb der Minneburg sind: $r \cdot j: r g$, in reimen: sorgen : ystorgen in Sachsenheims Spiegel (Keller, M. Altswert s. 151, v. 6), historgen : sorgen in dessen Goldenem temjel v. 82:3; ausserhalb des reims storir 'schar' geschrieben storigr', s. Lexer'

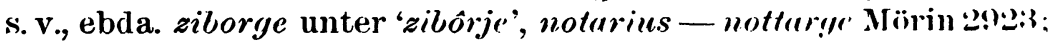
s. Märgen aus s'. Marium, vgl. Behaghel, (i)undriss 1, 581.

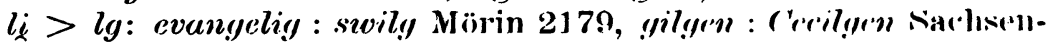
heims Spiegel s. 197, v. :30; gilgr "lilie", (iilg, Adegidius". purter.

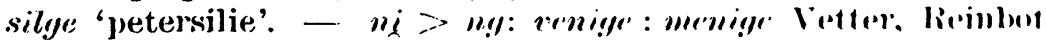

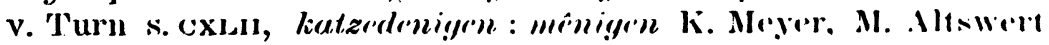

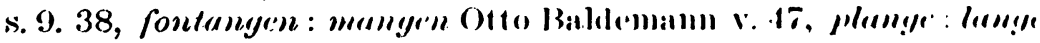




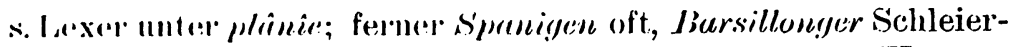
liichlein hee Keller, Altswert s. 2lli, v.!, Jabilonge (Kramm, l'eber Komads v. Heimesfurt splatehe, dissert. von Freiburg i. Br. 18x.', s. 1.); menig(e), minig 'mennig' aus minium, Apollonius. -. I'lïnniges, Antonius > Jünniges (Wackernagel, Kl. schr.

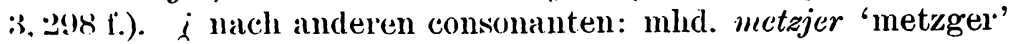
aus *maceurius (Kluge, Et. wb. s. v.), metzje 'metzig'; Venctialinedige. Mal. einschlägige reime s. bei Weinhold, Mhd.gramm. ${ }^{2}$ $\therefore .25$ oben und s.239 f.; viele beispiele, besonders auch von $i>g$ nach vocalen bei Grimm, Gramm. 14,368ff. Kauffmann § 181 und 18. Leitzmann, Beitr. 14,510. I)ieses $y$ folgt der landschaftlichen aussprache des ursprünglichen g, ist also entweder verschlusslaut oder reibelaut - Die lateinischen lehnwörter im ahd. sind unter andern sprachlichen principien aufgenommen worden, vor allem haben sie, im gegensatz zu den erst im mhd. ïberkommenen, ihre betonung der deutschen art angepasst, auch ist das i noch nicht zu g geworden, vgl. pfelli, oli, munistri, -ârius $>$ âri, füra, lector = lectorium und viele andere (s. z. b. Sievers, Beitr. 16, 264), als $j$ erscheint es in kevia, minio (MSL. 2', 190. IWW. 6, 2020), woraus mlid. kevje, lefige 'käfig', minige, minig 'mennig' mit dem obigen übergang von $i$ zu $y$. - Inerklärt sind die nebenformen mit ch: alnd. cpf 'pfi 'eppich, apium', mhd. lullich, lulch(c) neben ahd. lolli (Steinmeyer-Sievers, Ahd. gll. 1, 720, 27), schweiz. lülle (Schweiz. id. 3,1263 ) 'lolch, lolium'. ')

$l w$, rw reimen auf $l b, r b$ : salbet : valwet 2355 , cntverwe : herbe 4935. 5231 .

Inlautendes $m b$ reimt anf $m m$ : schimmert : gezimbert 2405 , nimmer : gezimber 3741, timber : schimmer 4793.

Der wahrscheinlich satzphonetische dental in icmant (vgl. Kauffmann $\S 149$ d, $\vartheta$ und anm. 1. Rich. Schmidt, IF. 1, j7) ist schon angetreten: es reimt auf bckant 2265. In der Würzburger

1) Bei lolch, das crst im mhd. belegt ist, kann allerdings $c h=\prime g$ sein, vorausgesetzt dass das wort in einem der dialekte aufgenommen wurde, der $g$ spirantisch sprach, vgl. Kluge, Et. wh. s. v. Franck, Anz. fda. 11,23. Aber für das ahd. epf th (s. Kluge unter eppich) kann weder der guttural noch die länge rles $\bar{\imath}$ im suffix aus apium erklärt werden. Hier liegt also doch wol eine suffixale umbildung, sei es im lat. oder erst im deutschen, vor. 
hs. des Michael de Leone sind icmant, nicmant viel seltener als icmun, nicman, im Renner, beim König vom Odenwald und Ruprecht von Würzburg begegnen sie nicht.

Consonantisch ungenaue reime sind bist: gesihst 855 , nicrgen : tieren 3985, schonsten : gekrontsten 1897. 2001.

\section{Zur flexion.}

Die 5. pl. praes. ind. endigt auf - $(\cdots$, z. b. sie leben: uf geben. (inf.) 1171 , иz dem vînen : sie schînen 3451 u. a. Das verbum substant. lautet in dieser person sîn: Kin : sîn 25, sîn : schîn 593. 1347.

Im infinitiv fällt $-n$ bez. mit apokope des $e$ die ganze en-

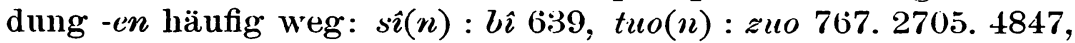

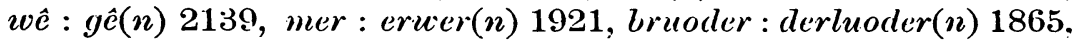
betiute $(n)$ : liute 2043, rême(n) : quêune 1095, verterke(n) : sterke 2085, vein(en) : schinebcin 2571, tac: jag(en) 1, u. a. I)iese infinitive olne $-n$ sind für das ostfränkische und thüringische') charakteristisch und begegnen ausserordentlich häufig auch in den zum vergleiche beigezogenen gedichten von Hugo v. 'Trimberg u. s. w. Ueber ihr vorkommen im ahd. s. Braune, Ahd. gramm. $§ 126$, anm. 2 und die daselbst angegebene literatur; für die gegenwart: Schmeller, Ma. Bayerns $\$ 586.916$. Bavaria 3,1 . 242 f. C. Franke, Bayerns ma. 1, 275 ff. Spiess, Fränk.-henneberg. ma. s. 26-28. Hertel, Salzunger ma. s. 110. Regel, Ruhlaer ma. s. $100 \mathrm{ff}$. Die aufgabe des $n$ beruht auf einem andern vorgang als die sonstige weit verbreitete reducierung der flexionssilbe -en zu $\supset$ (mit oder ohne nasalierung). Jene $n$-losen infinitive treten mit einer gewissen häufigkeit schon zu einer zeit auf. in der die $n$ in den übrigen endungen noch fest sind. Ferner haben einige thüringische und ostfränkische mundarten die ganze infinitivendung -en in bestimmten fällen abgeworfen, also z.b.

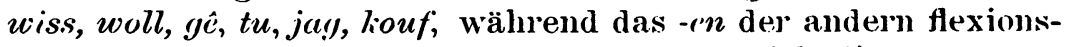
silben nur reduciert ist. Endlich erlauben sich die genannten ostfränkischen gedichte den abwurf eines -n mit ganz wenigen answahmen eben $\mathrm{nur}$ im infinitiv, während derselbe. Wem or in md. und mhd. gedichten anderer ma. vorkommt, nicht auf

1) Steht diese dialekteremoinschaft in zusammenhangr mit der loviode.

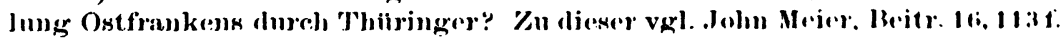
Wrede, Zs. fila. 37, 2!)1. 
den infinitiv beschü̈nkt, ist, iiberhaupt aber nur vereinzelt allfitt. I)er schwund dieses $u$ kamn also, wegen der abweichendell behandlung der ïbrigen auslautenden -en, nicht auf rein phonetischer entwicklung berulen, wie etwa der alle endiugen betreffende abfall des $n$ im altnordischen. Der werhsel \%wischen infinitiven mit und ohne $n$ beruht wol auf nathbildung eines schon vorhandenen und geläufigen typus, mïglicherweise auf den parallelformen der 1. pers. praes. ind.

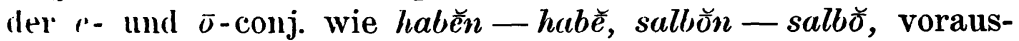
gevetzt dass die zweitgenannten $n$-losen formen schon in die zeit der frühest belegten infinitive ohme $-n$, d.h. an den anfang des 9. jh.'s hinaufdatiert werden dürfen. Es hätte sich also nach dem muster der ersten personen auch in den infinitiven

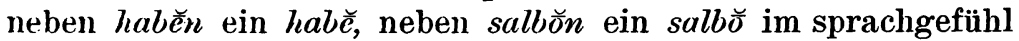
eingebïrgert, und darnach •wäre übertragung auf die andern conjugationen erfolgt, worauf schliesslich die secundären $\boldsymbol{n}$-losen formen auch im infinitiv in einigen gegenden allein üblich wurden wie allgemein in der 1 . person. Bemerkenswert ist, dass gerade in dem altostfränkischen des Williram die doppelheit der 1. personen wie habon - habo reichlich belegt ist.

Der conj. praet. hat in der 1 . schwachen conjugation umlaut: senten : elementen 1831, $\operatorname{liuht}(e t): \operatorname{diuht}(e) 4789$, auch im Renner und im Henneberger urkundenbuch, vgl. Bech, Germ. 15, 149. 154. 24, 140. Rückert-Pietsch, Entwurf s. 29.

gấn, stân haben im ind. praes. und inf. $\hat{a}$, im conj. $\hat{e}$; von gân erscheint das praet. gie (: nie 4321) und gieng (: hieng : gevieng 5467. 1837), mit ie, dem ostfränkischen gemäss.

Das praet. ind. und conj. von hân wird mit offenem kurzen $e$ oder langem $\hat{e}=a$ gebunden; die quantität ist nicht zu entscheiden, da auch kurzes offenes $e$ auf $\hat{e}=\alpha e$ reimt; es lautete also entweder nur hete mit offenem $e$ oder auch hête $=$ hote. Ein unterschied zwischen ind. und conj. ist nicht festzustellen. Im einzelnen zu bemerken ist der reim hëte : an der stete 103. Der gen. dat. und plur. stete reimen im mlid. überhaupt oft auf offenes $\ddot{e}$, z. b. Parzival stete : bëte 621,23. 746,5; Wigalois stete : bëte 1594. 1807 : tëte 6966. 6997, bëte : stete : getëte 305. 2201, vgl. Grimm, Gramm. 14, 885; Gotfrids 'Tristan stete : tëte (Mhd. wb. 3, 134b); Heinrichs Tristan Antret : stet 4627; Ulrich v. Lichtenstein, Frauendienst stet : tët 88,21 , bët stet $482,1.485,9$, stet : 
Lanzilet 484, 9 ; Krone stct : bët 21802, tët : stet 25691; Neleranz stete : bëte 7433, Servatius (Zs.fda.5) tëte : stete 2139; Warnung (Zs. fda. 1) bëte : stete $3575 ; \mathrm{H}$. Ernst $\mathrm{D}$ s. 15 a tët : stet; Mönch v. Heilsbromn tët : stet Merzdorf s. 78, 297; Zingerle, Ueber eine hs. d. Passionals tët : stet s. 70,9. 71, 41. 73, 125. 74, 175, stet : pët 77, 291. 79,355, gepët : stet 78,319. 82, 443. 84,93. Zu Ulrich v. Eschenbach s. Toischer, Ueber die sprache UTrichs v. Eschenbach s. 19. 24, zu Landgraf Ludwigs kreuzfahrt s. Kinzel, Zs. fdph. 8, $390 \mathrm{f}$. Es liegt in dem offenen $e$ in stete wol psychologische umlautung vor: in anlehnung an den nom. stut und an die zwillingsformel von an der stete : an der stat ist nur jïngerer umlaut eingetreten.' )

Zur substantivflexion seien angemerkt die analogisch gebildeten plurale sterner (: gerner 1685), geister (: meister 3357), unumgelautet bander (: galander 2027), bandern (: andern 18:3, vgl. Heinzelein von Konstanz s. 105, 125 und Pfeiffers anmerkung ${ }^{2}$ ) ); zum heutigen dialekt s. Bayerns ma. 2,321. Bloss des reimbedürfnisses wegen steht manyer liander (: Schionatulander) 4539, eine art syntaktischer assimilation.

Eine sonst im ganzen gedichte nicht $\mathrm{zu}$ belegende pronominale dialektform, dat. sg. $d i=d i r$ (gegenüber häufigem dir, mir im reim auf wir, ir, gir) ergeben die reime $2191 \mathrm{f}$ : sol man mich von art einen er nennen oder ein si? der meister sprach, daz sag ich di.

\section{Doppelformen,}

je nach dem bedürfnis des reimes angewendet, sind hab'n hân, lâaen - lân, (ge)legt - (ge)leit, saget - scit, gicng - gir.

1) Aelter als hëte mit offenem $e$ ist hete mit altem $i$-umlant, also mit geschlossenem $e$, jedenfalls alemannisch und bairisch, entsprechend dem altalemann. bez. -bair. hebita (Kögel, Beitr. 9, 520. Weinhold, Alem. gramm. s. 385 f. Bair. gramm. s. 319. Mhd. gramm.2 s. 424 f. Braume, Ahd. gramm. $\$ 368$ ). hëte ist nach Edw. Schröder, Zs. fda. 38,98 (vel. anch (irimm, (iramm. 14, 886), eine nachbildung von täte: zur öfnumg des $c$ in hït kann anch der offene laut in hopte beigetragen halon. Es sind also zwei formen mit kurzem $e$, mit geschlossenem und mit offenem, in die mhl. grammatik antzunehmen.

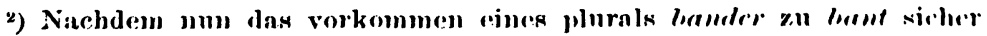

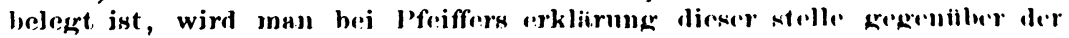

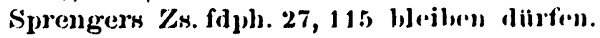


min(e) mí, fermer bride: (:medralj1:3) und beiden (: scheiden 3577), nilht (: !rsilliht 504:3, : grriht 4207, : ruvviht 5121. 5285 1. a.) und nit (: mit 1ti6:3. 2855, : gelit :3361. 4345. 4479 u.a.), hô (: wô

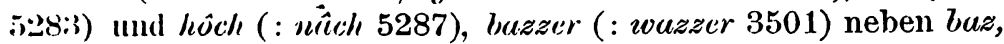
aljectivischer comparativ auch yuoter (: fruoter 1901) neben b'zz'r, cernunft (: liunft 611, : zunft 793) und vernunst (: gunst (i):3. 641, : liunst 5411); statt des adjectivs sïcze erscheint auch das adverbiale sıoz (: gruoz 1683), vgl. König vom Odenwald, Altd. wälder 2, 84 ff. v. 27. Suchenwirt xu, 238.

Fiir die sprache des gedichtes sind aus der

\section{Syntax}

einige verbalumschreibungen erwälnelrswert, die erst im 14. jh. geläufiger werden. So ist das praet. wart mit inf. recht häufig, z. b. ich wart treten, sie wurden werfen u. a. Seltener sind das praes. von werden mit inf. als umschreibung des futurums (daz ich ... uerd ezzen leides zîdelbast 2313, sô wirt mân herze pfimpfen 2341), der conj. praet. wïrde als conditionalis (têt sie daz sô ü̈rdl mir dorren mîn hevze 2333), tuon mit inf. (daz si tuo schuofen 1678, ir minne pfeffer tuot mir murzen 2363).

Zur vervollständigung dieser skizze des ostfränkischen dialekts sei noch verwiesen auf die aus der hs. $P$ beigebrachten, nicht bloss den reimen, sondern meh!̣ noch dem innern des textes entnommenen mundartlichen formen oben s. $258 \mathrm{ff}^{1}{ }^{1}$ )

1) Für die bekannte mitteilung Hugos von Trimberg über die aussprache einiger auslantender cousonanten in Renner $22252 \mathrm{ff}$.

$$
\begin{aligned}
& \text { wan } T \text { und } N \text { und } R \\
& \text { sint von den Franken verre } \\
& \text { an manges wortes ende: } \\
& \text { wer wil dar umb sie pfende? }
\end{aligned}
$$

gilt die erklärung von Sievers, Beitr. 19,549: es soll damit die 'nachlässige aussprache' dieser laute bezeichnet werden. Und in der tat ist dies eine eigenschaft des heutigen ostfränkischen. Eine reihe von fällen für abfallendes $t$ bez. $d$ führt $C$. Franke in Bayerns mundarten 2, $83 \mathrm{ff}$. an; für $n$ ebda. s. $85 \mathrm{ff}$. ('wol am meisten von allen consonanten ist im ostfränkischen $n$ dem schwunde ausgesetzt', wozu wol auch der abfall des $u$ im infinitir, vgl. Müllenhoff, MSD. $2^{3}, 392$ ); auch das auslautende $r$ wird strichweise nur schwach articuliert, ebda. s. 92. Vgl. auch Socin, Schriftsprache u. dialekte s. 119. 


\section{b. Arten des reims.}

Die stumpfen und klingenden reime s. oben s. $283 \mathrm{ff}$.

Rührende reime sind selten: yeborn: durchborn 669, ervarn: willevarn 3139, Fröudenberc : Minnenberc 3163; die compositionsglieder -heit und -lich, z. b. wîsheit : kluccheit 3073 , rerborgenlich : sicherlich 3799, verdrozzenlichste : unnützlichst" 933. 939. Letztere tragen entweder allein den reim, wie in den eben angeführten beispielen, oder sie bilden mit der stammsilbe erweiterte reime, indem dieselbe mitgebunden wird, z. b. wâr-heit : vârhẹit 1311, kluochcit : gefuocheit 857, fruothich : guotlich 1229, kluoclich : gefuoclich 1225, zedellicher : edellicher 1265. Weniger bemerkbare fälle von erweitertem reime. wie solche, wo untrennbare partikeln ge-, ver-, er-, zer-, durchmitreimen, sind häufig, z. b. gesezzen : gemezzen 399, gespracl, : geschach 1119, verdorret : verstorret 2317 u.s. w.; krefticlich: vrnunfticlich 809.

Vier gleiche reime bilden die verse $2337-2340$ sowie die gleich darauf folgenden $2341-2344$.

Von besonderem einfluss auf den gesammteindruck der metrischen form sind die spêhen oder kluogen rîme (s. unten unter IV). Andere reimkünsteleien, klangspiele u. dgl. werden gemieden.

Hauptsächlich durch die überaus zahlreichen, sonderbaren und seltenen reimwörter herscht eine ziemliche mannigfaltigkeit in dem in den reimen niedergelegten wortschatz. Frmüdend sich widerholende bindungen begegnen nicht. Fin lieblingsreim des dichters ist minne : sinne bez. minnen : simmen. der gegen 50 mal vorkommt (vgl. Bock, Wolframs bilder fiir freud und leid s.54), nur viermal, trotz der unendlich ausgedehnten liebesklagen, herze(n) : smcrze(n); häufige reimwïrter sind ferner $u$. a. must (27 mal) und guot (34 mal). Ter dichter handhabt, ohne eigentlich gewant zu sein, die reimbildung mit einiger leichtigkeit.

c. Zeit der entstehung und engere heimat des gedicintes.

Aber es ist doch ain gawaltigar alsstand zwiselen der künst]lerischen form der Mimmeburg nnd derjenigron dex nur

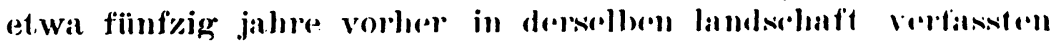


lienner, besonders in der einführung mundartlicher formen, wolurh 114 all\%u of terst genauigkeit der reime erzielt wird. In der anwendung derselben verfährt der dichter der Minnebury sogar noch etwas freier als der König vom Odenwald, jedoch hat dieser einige andere in der Minneburg nicht vorkommende dialektische reime, wie $s: z$, abfall des $n$ im dat. plur. ('normalplural'), plurale auf -lech, grwest, frêgen. Dagegen ist der städtekrieg mit anwendung von dialektismen noch weiter vorgeschritten, $z$. b. in reimen wie $i$ : ic vor andern conss. als $h$ und $r$, oder wie $a: o$, $e i: e u$.

In hinsicht auf die mundartlichen formen wird also das gedicht nicht zu weit gegen den anfang des 14. jh.'s, sondern mehr gegen die mitte desselben zu setzen sein. Viel spätere entstehung anzunehmen verbietet die noch im 14. jh. abgefasste hs. $\delta$. Diese datierung stimmt mit der Schönbachs (erste hälfte des 14. jh.'s, s. Lexers Handwb. 2, Iv) ziemlich überein. Das gedicht noch in das 13. jh. hinaufzurücken, wie Raab tut ('zweite hälfte des 13. jh.'s', s. 36 seiner abhandlung Ueber vier allegorische motive; vgl. auch Georg Richter, Beiträge zur interpretation des mhd. gedichtes 'Kloster der minne', Berliner diss. 1895, s. 9 anm. 1), geht nicht an.

Versucht man den dialekt der Minneburg innerhalb des gesammten ostfränkischen gebietes näher zu begrenzen, so weist der übergang von hs zu ss auf den westlichsten teil und auf das hennebergische. Für letzteres kann noch der einzige dativ $d i=d i r$ sprechen, sonstige speciell hennebergische kennzeichen, wie sal für sol, fehlen. Es wäre darum doch möglich, dass der dichter dem heutigen Unterfranken, dessen mittelpunkt Würzburg ist, angehörte: er konnte die ihm aus der nachbarmundart bekannte form $d i$ eingeführt haben, um einen passenden reim auf si zu bekommen. Man wird also bei der engeren umgrenzung am besten bei der negativen bestimmung stehen bleiben, dass die heimat des verfassers Ostfranken, aber nicht das hochstift Bamberg ist.

\section{Anliang.}

Reim in BI und $\mathbf{B}_{\text {III. }}$

Die ungenauigkeiten und dialektismen sind hier andere als in A. Zwar könnten reime wie verstôzen : ungelâzen 51 , 
ir : schier. 3243, gnâden : misserâten 7, grost : host 3327, wol auch bestuonden : wunden 3193 auch da vorkommen. Aber es fehlen vor allem ganz die infinitive ohne -n, dagegen treten folgende in A keine beispiele habende freiheiten auf: offenes und geschlossenes $e$ reimen in vëter : bleter 3459 , wërt : mêे.t 3305 , sêle : foele 3525 ; ferner verschiet : gelit 55 , son : schôn 53 , torn : zorn 3197, guote (subst.) : luote 3495 , versinkt : missolingt 129, was : fürbaz 155, mezze : metresse 9 , minne : gesinde 3285 , bald : all 3289.

Es ergibt sich daraus, was bislang stillschweigend vorausgesetzt wurde, dass der verfasser von BI und BIII nicht der von $A$ ist, dass also der ursprüngliche dichter und der bearbeiter nicht ein und dieselbe person sind. Die heimat von BI BIII ist nicht Ostfranken, auch alemannische und bairische sowie mittelfränkische und ostdeutsche kennzeichen fehlen: so bleibt als dialektgebiet nur das rheinfränkische, wol genauer das südrheinfränkische. Hierher passen auch die bindungen torn : zorn, son : schôn, sêle : foele, verstôzen : ungelôzen, minne : gesinde $=$ gesinne, bald $=$ ball $:$ all.

Zur genaueren bestimmung der abfassungszeit von B ebenso von der prosa - fehlen anhaltspunkte. Den jüngsten termin bezeichnet die datierung der hs. d v. j. 1468, für die prosa die der Wiener prosahs. v. j. 1463.

\section{III.}

\section{I n h a It}

Das gedicht zerfällt in fünf capitel, die im laufenden text selbst bezeichnet sind; ausserdem ist der hs. $P$ die capiteleinteilung mit kurzer inhaltsangabe in prosa vorangesetzt.1)

Cap. I (v. 1-353). Der dichter kommt an einem heissen sommertag in ein rauhes gebirge, das von einem wildbach durchströmt ist. Fin floss, das er besteigt, bringt iln auf einen schönen, blumenduftigen anger. Bald erblickt er eine prachtvolle, stark befestigte burg, deren brïcke von riesen. löwen und hunden bewacht ist. Fin starkes unwetter schliatert

1) Die inhaltsangabe bej Raal, a. a. o. s. 36 f. beruht auf w , gilt also nur flur die kürzere fassung. A usserdem ist sio libokenhaft, da dir wiolitigen verse $247-343$ in iv fehlen. 
dieso hüler ein und zwingt den dichter zugleich, in der burg schut\% \%u suchen. Innerlialb der burg befindet sich eine runde, mit erker, gesims und fiinf spiegelfenstern versehene, aus gold und edeln steinen überaus kunstreich gearbeitete säule. Während er diese bewundert, erscheint der kämmerer, empfängt ihn höfisch, nemnt ihm auf. sein befragen den namen der burg, Minmeburg, und schliesst ihm die säule auf. Da drinnen steht, hinter den fenstern, aus glas das bildnis eines mannes, oberhalb desselben das stählerne bildnis einer frau. Wenn das frauenbild sich neigt, so blickt es in das gläserne bild des mammes und sieht in demselben, was sich darin von aussen hinein durch die fenster der säule hindurch abspiegelt. Einmal erscheint in diesem glasbildnis das bild eines mannes. Lange bliekt das frauenbildnis dieses abgespiegelte bild an; es wird darauf schwanger und gebiert sofort ein kind; das ist stark, kennt alle sprachen, es hat ein schwaches augenlicht und erblindet bei zunehmendem alter.

In cap. II (v. 354-669) will der dichter daz bisspel reht üzlegen. Er durchzieht alle stätten der wissenschaft, um einen weisen meister $\mathrm{zu}$ finden, der ihm die natur des kindes deute. Fndlich trifft er einen solchen in dem meister Neptanaus zu Alexandrien. Dieser fährt mit ihm zur Minneburg zurück und erklärt: das kind ist die minne, die burg ein reines weib, der löwe (hier nur einer, in cap. I ist von mehreren die rede) ist ihre eigene hut und ehrgefühl, die sie vor schanden bewahren, die riesen sind ihre angehörigen, die hunde sind kläffer und verleumder. Wenn diese wächter schlafen, dann mag der minner ohne schaden in die burg gehen. Weiter deutet er: die säule ist ein reines weib, die fünf fenster sind ihre fünf sinne, der gläserne mann ist ihre vernunft, die stählerne frau ihr freier wille, sie sind vater und mutter der minne.

Cap. III (v. 670-2285) besteht aus fragen des kindes und antworten des meisters über das wesen der minne, ist also durchaus didaktischen inhalts. Dazwischen ist ein underbint gemacht, v. 1421-2034, enthaltend persönliche herzensergiessungen des dichters an seine frouve und darauf eine rede über das thema ich bin eigen der besten, der schoensten und der vesten (v. 1615-2034), wobei diese eigenschaften in streng eingehaltener disposition der reihe nach begrifflich erörtert 
und begründet werden. - Mit v. 2285 schliesst das cap. III, darauf ist wider bis v. 2673 ein underbint eingeschaltet, die anrufung der geliebten, eine minnerede.

Cap. IV (v. 2677-3177). Fortsetzung der allegorischen erzählung. Das kind geht mit seiner jungfrau Cupido, begirle, spazieren. Sie gelangen zu einer. schönen burg, die wie die Minneburg von einem löwen, riesen und hunden bewacht wird. Cupido treibt das kind an, diese zu erobern. Folgt schilderung der bestürmung der burg durch das gesinde des kindes, der unmasse, unsittigkeit, unbesonnenheit und anderer, und ihrer verteidigung durch masse, stärke, weisheit. Nach wechselhaftem, für das kind anfangs unglücklichem kampfe kommt man zu friedlichen unterhandlungen überein. Der rat der weisheit wird gebilligt, nach welchem schliesslich das kind selbst in eigener person in der burg mit der burgherrin verhandelt. Die beiden, die minne und die frau, verständigen sich, aus ihrer vereinigung entsteht ein kind, die 'widerminne'. Es erhebt sich freude ohne zahl, die werte burg wird genamnt daz edel hûs zu Fröudenberc.

v. 3178-3592 ist eine minnerede, underbint, dazwischen eingeflochten eine minneklage an herrn Amor und Tenus, die der dichter in einem felsgebirge antrifft, in das er vor minnekummer gelaufen. Darauf folgt

Cap. V (v. 3193 bis schluss). An einem somntag gehen das kind und seine $a m \hat{\imath} e$, gegen die warnung der huote, vor der burg spazieren. Da wird dieselbe von einem grossen heer, den kläffern und prüfern, beramnt. Auf rat der weisheit verbirgt sich das kind mit seinem gesinde, den belagerern werden die burgtore geöffnet. I)a sie das kind nicht finden. entfernen sie sich wider. Nun bleibt das kind herr in der burg: sus ist ilaz kint noch sicherlich gewalticlich gewaltic .... des hiusess dir zu Fröudenberc. - Nach so hergestelltem frieden will sich das kind seinem gesinde, der treue, weisheit und gerechtigkoit. für die geleistete hilfe gefällig erweisen. Welche der franten einen treuen diener hat, der begrindete klagen über seine greliebte vorbringen kann, dem will es za seinem rechle ver. helfen. J)arauf beginnt, eine gerichtsverhandlumg. Dide drei. weisheit, gesechtigkeit und trene, führen ihre diener: mimende edelknechte und rither, vor den richterstuln der minne. mod 
diese fiillt, ihr urteil iiber die ungetreuen damen. Mit dem dicnes den fran 'I'reue vorfülırt (v. 41:38 ff.), ist der dichter silbst gemeint, und der ergreift nun das wort zu endlosen mimneklagen. Am anfang einer neuen rede bricht die hs. $P$ al. Wie viel noch bis zum urs])rünglichen schluss fehlt, wie weit diese minneklagen noch fortgesetzt wurden, kann aus der ̈̈konomie des ganzen nicht gefolgert werden, da schliesslich jedes mass in der composition des stoffes aufgehört hat. Doch ist das $V$. cap). jedenfalls das letzte gewesen, da es vom dichter selbst als solches bezeichnet wird (v. 3188 und 3597).

Das ist in allgemeinen zügen der inhalt des gedichtes von der Minneburg. Als wichtigste motive treten folgende hervor, die sich zugleich mit der capiteleinteilung decken:

1. Natureingang. Beschreibung der Minneburg und der säule $=$ cap. I.

2. Auslegung der allegorie des I. capitels durch einen weisen meister $=$ cap. II.

3. Minnefragen und antworten = cap. III.

4. Bestürmung und einnahme der Freudenburg = cap. IV.

5. Sturm der kläffer auf die Freudenburg. Gericht der minne $=$ cap. $V$.

Alle diese motive oder wenigstens verwante züge begegnen in den gleichzeitigen minneallegorien und sind beliebte inventarstïcke derselben: keines beruht auf des dichters eigener erfindung. Er suchte die überkommenen zu vereinigen, aber es ist ihm nicht gelungen, sie zu einem organischen ganzen $\mathrm{zu}$ verarbeiten. Sie eingehender zu würdigen könnte nur geschehen auf grund zusammenfassender untersuchung der gesammten mittelalterlichen literatur der minneallegorien, zugleich unter beobachtung der historischen entwicklung der einzelnen vorstellungskreise.') Eine solche fehlt bis jetzt, auch sind viele dieser gedichte noch gar nicht durch den druck allgemein zugänglich gemacht. Das umfassendste einschiägige werk, Trojels Middelalderens elskovshofer, behandelt nur einen teil des stoffes.

1) Die von Erich Bachmann in seiner gehaltvollen dissertation über Everhard von Cersne (1891) angekündigte zusammenfassende darstellung (daselbst s. 55) ist bis jetzt nicht erschienen. 
Es sind nun aber, worauf zuerst Raab hingewiesen hat, mit der zu grunde liegenden rein weltlichen allegorie züge aus der geistlichen literatur verquickt. Die darstellung der geburt der minne aus vernunft und freiem willen ist eine der mystik entnommene idee. Vernunft und wille sind die höheren kräfte der seele, und die oberste der beiden ist die vernunft; die minne aber ist 'eine neigung des willens, die aus der erkenntnis der vernunft entspringt' (Preger, D. mystik 2, 151, vgl. auch s. 420. 422 u. ö.). ') Auch im einzelnen finden sich mystische gleichnisse und bilder: v. $2230 \mathrm{ff}$. wird die minne einem edeln baum gleichgesetzt, was an die mystische palmbaumallegorie (vgl. Strauch, Anz. fda. 9, 121) erinnert. V. 2654 wird der ausspruch der Martha, Joh. 11, 21 beigezogen: die Martha und ihre schwester Maria behandelnden bibelstellen (Luc. 10,38. Joh. 11,21) sind häufig gegenstand der predigten und mystischer symbolik. Aber alle diese der mystik und predigt entlehnten vorstellungen sind hier durchaus in weltlichem sinne aufgefasst, sie beziehen sich immer nur auf die irdische minne. Gerade die verwendung jener stelle Joh. 11, 21: domine, si fuisses hic, frater meus non fuisset mortuus, ist ein deutliches beispiel der verweltlichung des religiösen stoffes. Die verse der Minneburg lauten:

2654 wann ich mac sprechen als Martha sprach:

' frou, frou, wêrst du hie gewesen, mîn fröude diu wêr wol genesen und wêr von tôd erlceset'.

Es klingt fast wie eine profanierung der heiligen worte.

In dem grundmotiv selbst, von dem das gedicht den namen hat, in dem von einer burg der minne sind ursprünglich zwei ganz getrennte vorstellungskreise vereinigt. Den ausgang für die weltliche allegorie bilden einige stellen in Ovids Amores. vgl. Raab s. 35, wie habet sua castra Cupido, castra Amovis. Hingegen quelle für geistliche auslegung sind alttestamentlicho' stellen, Psalm 60, 4 und Hohes lied 4, 4 turris Darid, und hesomders die oben erwähnte neutestamentliche luc. 10. is of ipss intravit in guoddam custcllum (vgl. hiezu besonders salzer. Ilie

3) Die quellen des stofies. woriber oben nur andentumgen gregreben sind, hoffe ich hei anderer gelegenheit in cinem gröseren gusanmmenhung." behandeln zu konnen. 
simnbilder und beiworte Mariens s. 12. 284-292), die auf die jungrian Maria credeutet wurlen. I)em entsprechend ist in dier weltlichen allegorischen dichtung das im bild der burg dirgestellte weibliche wesen die irdische geliebte, die amîe, in der geistlichen die heilige jungfiau. Es lag also schon im stoffe des mhd. gedichtes eine beiziehung religiöser elemente malıe. -- Ebenfalls ein anknüpfungspunkt an die geistliche literatur liegt in der episode von der erstürmung der Freudenbur. In. Iieselbe entspricht dem alten geistlichen thema vom kampf der tugenden und laster, welches Raab s. 25 ff. schön entwickelt hat. Und widerum steht dieses motiv der psychomachie in ideenverbindung mit dem von der heiligen jungtrau als custellum, turris dadurch dass diese burg verwahrt ist durch verteidigungswerke, das sind die tugenden (Salzer s. 284 ff.).

Das zu grunde gelegte schema der fünf capitel, in welches sich der stoff gliedert, ist klar und durchsichtig, und diese anordnung ist im gedichte auch eingehalten. Aber die einzelnen elemente des stoffes sind nicht durchweg in glatten innern zusammenhang gebracht und sind ganz ungleichmässig behandelt. Von einer richtigen verteilung, einer ebenmässigen gliederung ist keine rede. Es mangelt dem dichter überhaupt der begriff für verhältnisse des masses und die fähigkeit der abwägung verschiedener werte. So ist wichtiges und unwichtiges unterschiedslos und gleichwertig behandelt. Diese formlosigkeit nimmt im verlauf des gedichtes immer mehr zu. So ist in den beiden ersten capiteln die erzählung und allegorische deutung verhältnismässig einheitlich durchgeführt und nicht $\mathbf{z u}$ weitläufig, wie sich schon an dem geringeren umfang dieser capitel bemerken lässt. In den beiden letzten dagegen steht die ausführung in gar keinem verhältnis zu dem dürftigen inhalt. Die übermässige anschwellung bei der armut des stoffes wird besonders veranlasst durch die reden, lyrische zwischenschiebsel, welche der dichter underbint nennt, zum unterschied von dem eigentlichen thema, der materge (s. oben s.285). Diese minnereden unterscheiden sich in metrik (s. s.285) und stil (s. s. 313) von der allegorischen erzählung und den lehrhaften stellen. Sie wirken mit ihren geschraubten phrasen besonders ermüdend und die eintönigkeit, die das lesen des 
gedichtes unerquicklich macht, wird in ihnen am meisten verspürt.

Es scheint, nach diesem fortschreitenden anwachsen des umfangs, dass der dichter seine arbeit ursprünglich kleiner beabsichtigt hatte, im laufe des hervorbringens aber, vom stoffe beherscht statt über ihm stehend, seiner redseligkeit keine schranken mehr zu setzen wusste.

Mit dieser planlosigkeit hängen auch andere mängel in der behandlung des stoffes zusammen. Mehrfach werden motive widerholt, so die geburt der minne in cap. I, der widerminne in cap. V; die schilderung der Minneburg in cap. I und der burg zu Freudenberg in cap. V; der sturm auf die Minneburg in cap. IV, auf Freudenberg in cap. V; spaziergang des kindes in cap. IV und V. Auch in diesen widerholungen zeigt sich die mangelhafte erfindungsgabe des verfassers. - Anderes. das stark betont war, wird in der folge vergessen. So wird die mit dem alter zunehmende erblindung; die in cap. I und bei der auslegung in cap. III als wesentliche eigenschaft des kindes hervorgehoben ist, im verlauf der erzählung ganz ausser acht gelassen. Ueberhaupt lässt sich die vorstellung von der allegorischen figur der minne, wie man sie aus cap. I-III gewinnt, mit den ausführungen von cap. IV und $V$ nur schwer vereinigen. - Auch offenbare widersprüche finden sich. So kurz nach einander in cap. II bei der deutung der Minneburg und der säule: beide, sowol die burg, worin die säule steht. als diese säule bezeichnen ein reines weib.

Der dichter hat sich von vornherein keinen festen plan gebildet, hat sich selbst die verschiedenen motive nicht deutlich vorgestellt. Darauf und auf der künstelei des stiles heruht die unklarheit, die man ihm mit recht zum vorwurf gemacht hat (Raab a. a. o.); doch liegt die unverständlichkeit. die Raab rügt, zum teil in der beschaffenheit der von ihm benutzten Wiener hs. (w), in welcher die unentbelurlichen verse 247-343 ausgelassen sind (s. oben s. 30:3).

Es jst indes immerhin möglich, dass der dichter mrspiunglich zwei ausgaben veranstaltet hatte, eine kïrepe. die. wie 13. mit der endgiltigen behauptung der Frendenlourg dur.h dic minne abschloss, und rince un das minnegericht und die dort eingestreuten reden nacht,rïglich vorlängarte. Wio sis in $A$ 
( P) rorliegt. I)afür lass in der ersten anlage in der tat das mimmegrericht nicht einbegriffen gewesen wäre, könnte der umstand sprechen, dass in der inhaltsangabe, die im text selbst das V. capitel einleitet (v. 3596-3604) und in prosa in dem allgemeinen register dem gedichte vorgesetzt ist (s. s. 257), nur ingefiihrt wird, dass die minne die burg gewann und wie die burc behalten wart, von dem gerichte aber, das mit den eingestreuten reden doch über 1500 verse beansprucht, gar nicht die rede ist. Die oben getadelten auswüchse in der composition wären dann vom dichter zum teil erst bei der erweiterung hineingebracht worden. Das unerweiterte gedicht würde dann bis v. 3806 der jetzigen fassung A gereicht haben, womit auch ein passender schluss gegeben wäre:

$$
\begin{aligned}
& \text { v. } 3800 \text { sus ist daz kint noch sicherlich } \\
& \text { gewalticlich gewaltic } \\
& \text { mit êren manicfaltic } \\
& \text { des hûses dâ zu Fröudenberc; } \\
& \text { ez hât ouch daz zubrochen werc, } \\
& \text { daz dâ gevallen was dernider, } \\
& \text { allez schôn gebn̂wet wider. }
\end{aligned}
$$

Aber mit sicherheit ist in dieser frage, zumal ohne kenntnis des schlusses von $\mathbf{A}$, der ja in $\mathrm{P}$ fehlt, kein urteil abzugeben.

\section{Inhalt von $\mathrm{B}$.}

I)er grössere teil von B, v. 81-3118 (A) hat den gleichen text wie $A$, verschieden sind der eingang und der schluss (s. s. 276): statt v. 1-80 in A hat B 180 verse, davon steht den versen 1-134 B in A gar nichts entsprechendes gegenüber. Auf eine anrufung der geliebten (v. 1-17) lässt der bearbeiter in v. 17-28 eine anspielung auf seine änderung des textes folgen, wenn anders die hier gegebene erklärung dieser schwierig $\mathrm{zu}$ verstehenden verse richtig ist:

$$
\begin{aligned}
& \text { v. } 17 \mathrm{ff} . \mathrm{B} \\
& \text { mîn underwinde, }
\end{aligned}
$$

ob ich bin des der blinde

der sich in fremdung wirret, so blîbt doch ungeirret daz bezzer nie vor gemacht. wes sich hie mîn sin vervâcht in dem anfang und dem end, sô bin ich doch der hekennt, ich sprich: 'daz mittel prisen gedichtes kunst die wîsen'. merket nu des underscheid! merket nu des unt

'Mein unterfangen (underwinde, ein zu sich underwinden aufs geratewol gebildetes substantiv), wenn ich auch damit ein blinder 
bin, der sich ins fremde verirrt (anakoluth) - so bleibt doch ungestört (unangetastet) das niemals vorher besser gemachte (nämlich der unübertroffene mittelteil des gedichtes). Wessen ich mich auch unterfange am anfang und am ende, so bekemne ich doch und spreche: die mitte preisen die kunstverständigen. Merkt nun den unterschied darin! Nun wolan, vernehmet uns beide (d.h. den ursprünglichen dichter und mich)!'

V. 29-134 B enthalten einen preis der dreieinigkeit und göttlichen minne. v. 135-180 B schildern dann ebenfalls den sommerspaziergang des dichters, aber in anderer auffassungsart und darstellung als A: er kommt in einen schattigen, quelldurchrauschten tannwald, dann, am ufer eines baches entlang, auf das blumige gefilde. Der spaziergang wird in eine freundlichere gegend verlegt als in $\mathrm{A}$, wo die schrecknisse des gebirgs und des wildbachs zu überwinden sind. Darauf folgt das in $A$ und B gleiche mittel. Mit v.3119 beginnt B wider ron A abzuweichen. V.3119-3177 in $A$ sind in B (v. 3219-3272) nur im wortlaut verändert, nicht auch im inlalt. Der in A folgende underbint v. 3178-3592 ist in B weggelassen, dieses setzt wider ein mit cap. $V$ und erzählt, inhaltlich wie $A$ aber in verschiedener sprachlicher widergabe, den spaziergang des kindes, den sturm der kläffer auf Freudenberg und die widerherstellung der ungestörten herschaft der minne (v.3273-34:613 $=3605-3825 \mathrm{~A})$. Ier ganze weitere inhalt des cap. V bei A. das gericht der minne mit den eingeflochtenen minnereden, ist von B weggelassen und dafür ein ganz selbständiger schluss gebildet (v. 3427-3627 B). Dieser ist, wie der eingang v. 29$134 \mathrm{~B}$ bezeichmend für den bearbeiter: es wird hier wie dort ein religiöses moment in den interessenkreis gezogen, von dem die längere fassung frei ist. V.3427-3564 preist er die minne. aber nicht lediglich die irdische, sondern er fasst unter diesem begriff die himmlische mit ein und macht in ihrer bojder wesenheit keinen unterschied. Ganz der religiösen betrachtung ist das ende geweiht (v. 3565-3628). Fs sind wider fragen des kindes und antworten des meisters: "ws ist betriibend, dass der tod die liebe scheidet': -.. 'deshall sollst du gan\% die liebe gottes in dich anfmehmen': dann dic frage: 'wer ist gott?' und zuletzt: 'wie wirkt gottes gmade im mensilhen?" B ist um etwa 1500 verse, d. h. mehr als ain violtel. hleine. 
als 1 ; geralle die so bresit ausgesponnene, mit dem vorherfrehenden in gar keinem notwendigen zusammenhang stehende s.hlusspartie von dem gericht der minne fehlt, und dies zum vorteil fïr die abrundung und einheitlichkeit.

Die griinde für seine änderungen hat der bearbeiter in den obigen versen (s.310) nicht angegeben. Es sind zwei wesentliche punkte, in denen seine fassung von $\mathbf{A}$, so wie es in $\mathbf{P}$ ïberliefert ist, abweicht, einmal eben die kürze des schlussteils - doch ist nicht zu entscheiden, ob er hier wirklich selbständig eine dem umfang von $\mathrm{P}$ entsprechende redaction des gedichtes gekürzt hat, oder ob ihm nicht überhaupt jene oben s. $309 \mathrm{f}$. in frage gebrachte erste kürzere ausgabe vorlag. Ind dann sein religiöse tendenz. Damit ist, wenigstens stellenweise, eine verschiebung des ethischen hintergrundes eingetreten. Während in A auch die dem religiösen gedankenkreise entnommenen teile des stoffes ganz nur der verherrlichung der irdischen minne dienen, strebt seine sehnsucht über das vergängliche hinaus zum ewigen, zu der liebe gottes und seiner barmherzigkeit. Aber seine kräfte sind zu schwach um der grösse dieser idee ausdruck verleihen zu können, und in äusserlicher weise, unvermittelt mit dem das ganze beherschenden geiste, sind am anfang und am schluss seine frommen gedanken in ungelenken versen ausgesprochen.

\section{Die prosa.}

I)ie prosa benutzte die bearbeitung $B$ als grundlage, nur in nebendingen des wortlautes ist auch auf $\mathrm{A}$ eingegangen (s. s. 279). Umgeändert ist die kurze abhandlung über die dreieinigkeit, die B im eingang enthält, indem andere eigenschaften derselben hervorgehoben werden. Grössere abweichungen finden sich sonst nur in den fragen und antworten des cap. III, von denen einige ganz weggelassen, andere nicht in der ursprünglichen reihenfolge aufgenommen rind. Dreimal finden sich einschaltungen lehrhafter art: 1. aufzählung, der kenntnisse des weisen meisters, 2. die vier stufen im wachstum der minne, 3. verhältnis der minne zu seele und leib mit berufung auf Aristotiles und sein Buoch von der natur. Am meisten aber ist der ursprüngliche charakter geändert durch weglassung der minnereden. Das lyrische elementivist demnach 
zurïckgedrängt, das allegorisch-didaktische herscht durchaus. Belehrung ist der hauptzweck. Darum auch die form der prosa. Besonders die zergliederung des wesens der minne in dem schema von fragen und antworten macht den eindruck eines mittelalterlichen lehrbuchs in art des Lucidarius oder eines wissenschaftlichen tractates (vgl. unten gegen schluss von IV).

An umfang ist die prosa noch kürzer als $B$, besonders durch die abstossung der minnereden. Dadurch ist aber auch das verhältnis von inhalt und ausdehnung ein ebenmässigeres geworden als in B und noch mehr als in A. Auch die gliederung des stoffes ist in annehmbaren massen gehalten. Er verteilt sich in folgender weise:

3 seiten der hs. religiöse einleitung,

$\begin{array}{rrrr}\operatorname{ca.} 11 & " & " & , \\ \operatorname{ca.} 22 & " & " & " \\ 11 & " & " & " \\ 6 & " & " & \end{array}$

allegorische erzählung,

lehren in fragen und antworten,

wider allegorische erzählung,

schluss, betrachtungen über die minne, über gott ihren urheber.

\section{IV. \\ Stil. Die geblümte rede. Meister Egen.}

Der dichter hat, wie schon bemerkt, immerhalb des eigentlichen themas, der matergc, grössere abschnitte lyrischen und reflectierenden inhalts eingeschaltet (underbint oder undrrumt). die er selbst mit rede bezeichnet. Fr hält die scheidung strenge ein und unterlässt nie es ausdrücklich zu bemerken. wenn eine rede anfängt. Wie im inhalt, so sind auch in der metrischen form (s. s. 285) und im stil materge und rede ron einander unterschieden. In den erzählenden und lehrhaften teilen, in der matergc, entfernt er sich nicht von der normalen ausdrucksweise. ('harakteristisch aber fiur ihn und fiis rim gewisse richtung des 14. 15. jh.s ist der stil der redrn. Hiw ist die darstellung zur geschmacklosesten manier ansqeartet. als oberster asthetischer grundsat\% gilt: um jeden prois originoll

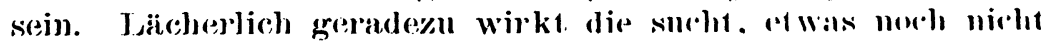
dagewesenes \%u bieten, den hombast dor vorginger moch z.ll iibertrumpfen. Der mangel an immerer walulecit soll verdeckt 
Werclen durch unemblichen phrasenschwall, und in diesem haschen nach effecten zeigt sich am grellsten die ganz mittelmässige begabung des verfasser's. Vom ästhetischen standpunkt atus ist das abfällige urteil von Gervinus (Gesch.d.d.dichtung $.25,44: 3)$ gerechtfertigt, von diesem aus verdient das gedicht keine weitere beachtung. Entwicklungsgeschichtlich betrachtet ist jedoch diese manier nicht ohne interesse, denn sie beruht nicht auf den verrückten einfällen eines einzelnen, sondern sie ist typisch für eine absonderliche geschmacksrichtung in der späteren mhd. dichtkunst und findet sich nirgends so ausgeprägt, so deutlich von dem gewöhnlichen stile abgehoben als eben in der Minneburg. Es ist die sogenannte gebliiemte rede. Der dichter selbst wendet diesen technischen ausdruck an v. $468 \mathrm{f}$.:

er kunde kriechisch, er kunde kaldeisch

mit geblüemter rede gemacht guoter;

ferner mit worten wol gebliiemet v. 1651. 1811. 1939, diu kluoge rede v. 2395. 2719, ein rede fin v. 5346 , es sind wahe sprüche v. 689, wildiu wort v. 696. 4641, die nicht jedermann versteht, deren abfassung sowol als auslegung einen gewissen grad gelehrter bildung voraussetzt. Durch diese bezeichnungen ist die manier passend gekennzeichnet. Geblüemt sind die minnereden durch eine ïberfüllung mit gesuchten und geschraubten bildern, vergleichen und hyperbeln, und durch 'wilde', d. h. seltsame und fremdartige worte und wortbildungen.

Doch nicht nur durch die stilistische, sondern auch durch die metrische form zeichnen sich die reden von der matcrge aus. Als besonderheit des versmasses in den lyrischen stücken ist schon oben s. 285 die beliebtheit der klingend endigenden verse angegeben. Die formale künstelei besteht aber vor allen dingen in der wahl der reimwörter, der effect soll erzielt werden durch auffallende, bislang unerhörte bindungen. Deshalb finden sich die wilden wort in grosser anzahl in diesen reimen der minnereden. Der dichter nennt sie spêhe'rîme v. 2303, als gegensatz zu den slehten rîmen v. 4285, und spielt auf sie wol auch an mit dem ausdruck mit hluoger süezer rîue tritel (tritt) v. 351. Indem so der schwerpunkt in den reim verlegt wird und der ausgang des verses überwiegend das interesse auf sich zieht, ist auch das 'ethos' der verse in den 
reden ein merklich verschiedenes von dem der in ebener stimmung verlaufenden zeilen der erzählung und lehre.

Am besten wird ein beispiel die verschrobenheit und den schwulst der geblümten rede zeigen:

\section{v. 2305 ff.:}

5 ach got wie ist verselket, vermûret und verkelket in mich der Minne kunder! die Minne hât niuwe wunder mir in daz herz gestiftet.

10 ich forht, mir sî vergiftet mîn fröudenrîcher wandel, daz ich für fröuden mandel werd ezzen leides zîdelbast! ir minneclicher süezer glast

15 mich in dem herzen kützelt, daz mir mîn fröude verhützelt ist und ouch gar verdorret, alsô bin ich verstorret! si hât mir ab geblundert

20 mîn fröude, daz mich halt wundert wie ich sî sô veraffet. ich hân sie angeglaffet lang mit miner ougen zwirbel, daz mînes lîbes sinnes wirbel

25 ist iff sie getorkelt.

nu hoert wie sie nich morkelt, zudresch und ouch zumiurschet, zusluoc und ouch zupfnürschet! ob sie vor fröuden kittert

30 wenn mir mîn herze zittert, und ob sie darumb snöuwet ob ich mich durch sie fröuwet? têt sie daz, sô würd mir dorren mîn herze glîch dem dürren stor-

35 alsô würd ich gederret! [ren, ist daz sie mir derkerret mîn herz, daz ez derkirret und sam ein doner zirret, sô bin ich fröud verirret.

40 swie sie sich ron mir virret. sô wirt mîn herze pfimpfen und sam ein kole dimpfen daz ich vor ungelimpfen niht fürbaz mac geschimpfen.

45 darzu wird ich zuhadert, zuzerret und zufladert. zurizzen und zulumpert. daz trúren umb mich slumpert ob sie sich gein mir wildert 5) und nicht gein mir gemildert.

T)iese probe zeigt schon, wie der dichter sich abhetzt mit ästhetischen figuren, metaphorischen ausdriicken und hỵerbeln. aus deren wirrsal sich kaum eine deutliche vorstellung losringen kann. Fine auslese der gesuchtesten und alogeschmarktesten bilder und vergleichungen möge noch zur verdeutlichumg der geblümten rede angefiulurt sein'):

v. 458 wie der künste ein blüendez zwi

durchsaffet hal, in (dem meister Neptaunus) siniu lider.

1) Der diesello cloenfalls charukterimieremde wortsehatz soll an anderer stelle behandelt werden. Vicle gar nicht obler seltal lellegte wirter siml

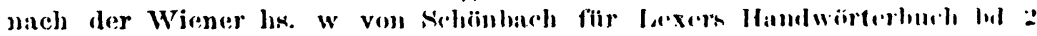
und 3 geliefert worden. 


\section{v. $670 \mathrm{ff} .:$}

ri kunst, tho mich mit wiz durchborn, wonn inh oh kiinsten tischelin sit\% und hân niht sinnes wîn diuruf noch kiinsten wilprett! ich hiun von wiz ouch kein gerêt diaz mir mîn grobez herze erquick und kïnsten sterke in mich schick. daz ich der hôhen künșten kluoc liz her nie hân gehabt genuoc zul ezzen noch zu smecken und sie niht moht gestecken under mînes sinnes riben, des ist mîn sin gar klein bekliben reht alsam ein klein getwerc.

\section{Oder 1562 ff.:}

mîns armen herzen fiurstein riiert hart ân alle zerte din (d. $i$. der minne) stahelfiurisen herte, dâ zwischen hât gestôzen zunder ein zartez wîp, des lobes ein wunder, bewart von meiles smerzen, daran mîns leides swefelkerzen fïr wâr sîn entzündet, die hân fürbaz angekündet mîns herzen hûs, daz ez ân stiure stêt in hôhen lohens fiure und brennet stête tac und naht. der rouch mir tempfet lîbes maht. ei kum, vil süeze trœsterinne, lesch mich mit trôstes wazzers minne! ${ }^{\text {) }}$ hilf mir ûz nœten, die ich dol, wann unîner fröuden swarzer kol glimmet sêr in leides hitze. u. s. w.

\section{v. 1708 ff.:}

künd ich mit lobes gezierde die sinne hier umbzismen, durchbalsmen und durchbismen, daz sie mit vîolischen sprüchen den liuten in ir ôren rüchen!

$$
\text { v. } 2550 \mathrm{f} \text { : }
$$

ez sint mîns herzen hend und bein zusamen ouch gelidet ...

$$
\text { v. } \$ 3730 \mathrm{ff} .:
$$

reht als der dahs daz fliuhet dâ der fuhs geharnet hât, sin art in niht belíben lât swâ in der selbe smac wirt kunt: alsó, Minne, swâ ir ein stunt sît reht gewesen genzlich von iuwerm smac kreften rîch haz und nit der keinez noch ihr gesleht unreinez ... miigen gewonen nimmer genzlich in dem gezimmer.

Ftwa ein dritteil der Ninneburg ist in dieser schwïlstigen manier abgefasst. Sie wird, als in den reden, vornehmlich da angewendet, wo gesteigerte gefühle zum ausdruck gebracht werden sollen, hier natürlich meist solche der minne. Da wirkt der hohle bombast oft geradezu lächerlich, in dem phrasentum tritt des verfassers mangel an künstlerischer begabung nur

1) Statt 'mit dem trostwasser der minne'. 
allzu deutlich zu tage. Nicht unwillkürlich kleiden sich die gedanken in bilder, sondern mit spitzfindigkeit sind diese ausgeklügelt. Abgesehen von der überfüllung und der nicht seltenen geschmacklosigkeit decken sich die tropen oft gar nicht mit den zu grunde liegenden gedanken oder sind in sich nicht einheitlich und logisch durchgeführt. In folge der mehrfachen bezugnehmungen auf die malerei könnte man ein geschärftes beobachtungsvermögen bei dem dichter voraussetzen. Aber es mangelt ihm die anschauungskraft, die gegenständliches in scharfen umrissen $z u$ fassen versteht, und ein sicheres und geordnetes vorstellungsvermögen.

Ein in der geblümten manier übertrieben angewendeter stilistischer kunstgriff besteht darin, statt eines einfachen substantivs eine uneigentliche substantivische composition, substantiv, mit vorangehendem substantivischem genitiv, zu setzen, wobei der ursprüngliche begriff in den genitiv tritt. Je nach dem logischen verhältnis beider begriffe ist die so entstehende umschreibung mehr oder weniger passend, jedenfalls ist sie oft schwerfällig und gekünstelt, in den meisten fällen überhaupt überflüssig, indem von dem durch ein substantiv (dem im genitiv stehenden) ausgedrückten grundgedanken durch die erweiterung vermittelst eines zweiten substantivs doch nichts wesentlich neues ausgesagt wird, z. b. âne zwîfels rête ist so viel wie âne zwîfel, der rede krî $=$ diu rede, zornes pfliht =zorn, von gewaltes sinnen $=$ ron geualte, $\hat{a}$ spotons hôn :-:= âne spot, der steine rotschen $==$ 'felsen', der vernunft list -..'vernunft' u. s. w., vgl. auch Weinhold, Lamprecht von Regensburg s.16. In weiter ausgeführten bildern häufig angewendet tragen sie hauptsächlich zur verschnörkelung des stiles bei. z. b. v. 1750 ff.: seine dame ist dem dichter feindselig. diesse tatsache ruft in ihm die vorstellung eines bildes von einem kampf hervor: die frau nimmt ihrer minne lanz'n (vol. Parz. 76, 14) und wirft sie auf seines sinnes blatten (blattenharnisch); sie gibt ihm manchen stoss auf seines muotrs liclm. dass er auf der sorgen molm vor sie "hurzelt"; dam zielht sie ihn mit leides seil anf des sorgh'n arlier. lässt ihn in trauerns kerker fallen und sohlägt ihn in "mmuts leloch" us. w. Haufig sind die beiden substantive fast bedeutumggleich, umgekehrt besteht oft ein innerey zusammmenhinng 
\%Wischr"l ihnen iiberlatupt, nicht, sondern willkürlich sind in drin rahmen eines eimmal begonnenen bildes einzelne bestandteile dieses bildes auf einzelne begriffe der zu grunde liegenden illee angewendet. So sind an eben angeführter stelle aus dem bilde: herats die vorstellungen von lanze, blatte, helm u.s. w. ohne weiteres den der zu grunde liegenden gedankenreihe angehörenden abstracten begriffen minne, sinn, muot II. s. w. beigelegt. Anf diese rein äusserliche weise sind viele der bildlichen ausführungen des gedichtes entstanden. Die beiden gedankemreihen, die der nackten tatsache und die in tropen gekleidete, kreuzen sich dabei fortwährend, ein losgelöstes, in sich abgeschlossenes und durch sich selbst interessierendes bild entsteht nicht. Fines der stärksten beispiele tïr diese manier bilden die von W. Grimm, Heldensage ${ }^{2}$ s. 283 angeführten verse. - Einige male ist das logische verhältnis der beiden substantive im sprachlichen ausdruck geradezu umgedreht, so z. b. v. 565 f. ez sî denn daz enbrinne der starken ueter minne statt diu starken weter der minne; $1575 \mathrm{f}$. ei kum, vil süeze trosterinne, lesch mich mit trôstes wazzers minne statt 'mit dem trostwasser der minne' (s. s. 316).

W'eniger häufig kommen zweigliedrige ausdrücke, aus synonyma bestehend, vor, mit und ohne bindewort, z. b. ergalmt und erdôz 31, mit gir und ouch mit grôzem gît 292, zutrennet und zutrant 300, mit hâr mit hiute 1726, umb stiur umb helf 1675, wenden kêren 22; asyndetische aneinanderreihungen begegnen überhaupt öfter, so noch: daz kint die kamerer dic nâmen 522, uaz sî diu burc diu siule umgrabt 668, wêr dîn leben in herz in lîb 785 u. a. Auch dreigliedrige synonymische formeln finden sich, wie durchfînet, durchylenzet und durchschînet 147.

Bei all seiner virtuosität beherscht der verfasser die sprache doch nicht recht, das zeigt sich in groben verletzungen gewöhnlicher sprachregeln, z. b. vernachlässigung der flexion v. $240 \mathrm{f}$ : daz gap dar inne vil liehtern schîn dann îzen dran und glenzer (statt glenzern) im reim auf genzer. Fehler in modus und tempus des verbs v. $2326 \mathrm{ff}$. (vgl. s. 315) nu hort wie sie mich morkelt (ind. praes.), zudresch (conj. praes.) und ouch zumiirschet (ind. praes.), zusluoc (ind. praet.) und ouch zupfnürschet (ind. praes.) u. a.

Den stil ins einzelne zu verfolgen dürfte sich bei der 
mässigen literarischen bedeutung des gedichtes nicht lohnen, und allgemein giltige ergebnisse können nur aus der betrachtung der verwanten dichtungen insgesammt erzielt werden. In erster linie kommen hierbei die typischen formeln, ${ }^{1}$ ) die immer widerkehrenden metaphern, auch formelhafte reime in betracht. Eine sammlung derselben mit statistischer beobachtung würde am besten die unselbständigkeit jener epigonen zeigen und zugleich ihre abhängigkeit von den meistern der mhd. dichtung. Denn der einfluss Wolframs und Gotfrids lässt sich in solchen einzelheiten durch die ganze periode hindurch verfolgen (s. unten). So geht die umschreibung eines begriffes durch substantiv und genitiv besonders auf eine bekannte eigenheit Wolframs zurück, der in der Minneburg speciell nicht hervortretende parallelismus zweier substantive auf Gotfrid. Ein kunstmittel jedoch, das sonst in zeiten gesunkenen geschmacks, wie z. b. bei der zweiten schlesischen schule, zur verschnörkelung und auszierung wirksam verwendet wird, tritt in der 'geblümten rede' zurück, das ist das malende beiwort.

Ebenso gibt es einen ständigen vorrat einzelner motive, gemeingut der literarisch gebildeten, aus dem die dichter nach belieben schöpften. Auch in der Minneburg finden sich solche vielfach verwertet, die daneben in andern dichtungen der nachblütezeit widerkehren, so die weit ausgesponnenen symbolischen wappendeutungen, das prunken mit edeln steinen und fremdartigen pflanzennamen, farbensymbolik, turnier, jagd, der baumzucht entlehnt der beliebte tropus von dem auf einen baum neu gepfropften reis, beschreibung des epitaphs der minne (diese stelle, 2638 ff., führt R. M. Werner im Anz. fda. 7, 146 an zum vergleich mit MSF. 129, 36 ff., wozu nachzutragen Veldekes Eneide 8333. Parzival 107,30. Willehalm 73,27. Wigalois 211.32. Mai u. Beaflor 174, 32. Massmann. Alexius 66, 85. ITrichs Alexander 11105-11820, lat. in Frommanns Herbort s. 301.9. Zs. fia. 33,252 u.a.). Individuelle züge sind nur wenige zu verzeichnen. Indessen sind doch manche dem verfasser allein eigen, so die geschmacklosigkeit in der sprecialisierung der

1) Solche sind auch die aus der geistlichen literatur, dor Mariemdicls. tung, vor allew Konrads Goldener schmicde chtnommenen hilder zom previse

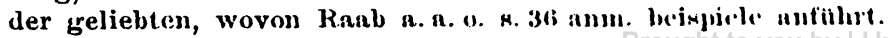


rerepto gregen dic minnesehnsucht, deren bestandteile genau in pfunden und quintinen vorgeschrieben werden (v. 3828. $5442 \mathrm{ff}$.), die beizichumg der malerei (s. unten), eine beschreibung mehrerer folterproceduren (2562 ff., Hätzlerin 2, 25, 160 ff., s. 181).

I)em entsprechend steht der dichter auch in seinen sonstigen litelarischen und gelehrten anspielungen auf dem niveau seiner zeit. Es werden beigezogen die heldensage (das von II. (irimm alogedruckte stück, Heldensage ${ }^{2}$ s. 283), der Parzival bez. der jüngere 'Titurel (Gral, Nuntsalvas, Artus, Anfortas, (xamuret, der baruch, Schastelmarveil, Sigune und Schionatulander; die beschreibung des gralstempels und des palastes des priesters Johannes mit der säule im j. Titurel hat offenbar bei der schilderung der Minmeburg im cap. I vorgeschwebt; daz fiur ron Agrimontîn s. unten. Aus Wolframs Willehalm entnommen sind die hinweisung auf sant Wilhelmen lilug um rivianz v. $4532 \mathrm{ff}$. und $1921 \mathrm{ff}$. daz wilde mer molıt sich mit nihte des erwer, ob sie (die geliebte) einen finger dar in stiez, ez gevünn an süeze den geniez sam ez $\hat{\imath} z$ honiges brumnen flïzze daz sîn liut und vihe genüzze swaz dâ wêr gesezzen: die entsprechende stelle des Willehalm $(62,11 \mathrm{ff}$.) ist, unter nachweisung anderer nachahmungen, eingehend ron Stosch, Zs. fda. 33, 127 f. und 38, 138 ff. besprochen worden. Bemerkenswert ist, dass hier in der tat Wolframs zêhe durch das, wie Stosch richtig bemerkt, unserem geschmack mehr zusagende finger ersetzt ist. Ferner werden genannt Kamille, ron der in Eneas man sayct (4174ff.), und als beispiele berühmter liebespaare Helena und Paris, Wigalois und Larîe, I a nzelet und Iblis (3169 ff.) Verhältnismässig häufig treten namen aus der bibel, besonders aus dem alten testamente auf; aus der legende der weithin verehrte S. Martin als muster der barmherzigkeit (der sînen muntel halb zusneit und in $\hat{u} f$ einen blôzen leit $2529 \mathrm{f}$.) und S. Lienhart, bekannt als erlöser aus banden (dîn trôst mich alsô süezlich labt in diser gefenknis hart, reht als mich Sant Lienhart hab dannen brâht genuhtic 2624 ff.). Als männer der weisheit und wissenschaft werden genannt Salomo, Aristotiles, Alanus, Ypocras (3356 ff.), als berühmte ärzte Avicenna, Pitagoras, Galien und widerum Ypocrates (5415 f.), als stätten der gelehrsamkeit Lunders, Brügge, Paris, Dolet 186 f. Paris, Salern, 
Padaw, Montpelier, Dolet $388 \mathrm{ff}$, und, als heimat des Neptanaus, Alexandrîe 398. - In dem weisen meister der um auskunft über das wesen der minne angegangen wird und der die fragen des kindes beantwortet, stellt der dichter sein ideal eines meisters der wissenschaft, der sieben freien künste dar. Er gibt ihm den namen des zauberers der nach der sage von Alexander im grössten teil der überlieferung dessen vater war und für ein gefäss der weisheit galt. A $(\mathrm{P})$ hat Neptanaus (464 Naptanaus), die verschiedenen lesarten von B gehen auf eine grundform Nectanabus oder Nectanelus zurück. Die erstere form mit $p t$ stimmt $\mathrm{zu}$ derjenigen in der pseudoRudolfschen Weltchronik (Neptanabus, vgl. R. M. Werner, Die Basler bearbeitung von Lamprechts Alexander s. 7), in Ulicichs von Eschenbach Alexander (ebenfalls Neptanabus) und im 'grossen' Alexander (Beitr. 10,346. 348). Ulrich schildert die minne des zauberers zur königin Olimpiadis als eine tat $d e r$. frou Amor (v. 301), der frou Minne (v. 315) und es ist nicht unmöglich, dass diese scene mit der personification der minne (v. 300-350) die veranlassung dazu abgab, dass der dichter der Minneburg gerade den Neptana[b]us als sachverständigen im minnewesen wählte. ${ }^{1}$ ) Die formen von B (Nectanabus u.s.w.) und der prosa (Nectanabris) mit ct scheinen dann wider dem sonst in der Alexandersage gewöhnlichen Nectanelus nachgebildet.

Einen tiefern ethischen gehalt wird man in dem gedicht nicht suchen. Von gemeinheiten oder lüsternen anspielungen hält sich der verfasser zwar frei, aber seine begriffe von liebe erheben sich nicht über den äusserlichsten minnedienst. I)is übertreibungen im preis seiner dame, die endlosen liebesklagen lassen den mangel wahrer empfindung nur um so stärker hervortreten. Das dichten ist für ihn in der tat eine kunst in der mhd. bedeutung des wortes, eine technische fertigkeit. ${ }^{2}$ ) Bej allen auf gefühlserregung berechneten effecten kein gromiit.

1) Vielleicht hat die in vielen bearbeitungen der Alexandirsange vorkommende schilderung des tempels des .Jupiter mol der .Inno in Ackgyten mit den statuen dieser beiden gottheiten das vorbild gerliofert tiir dir dar.

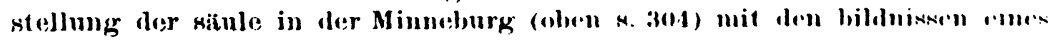
mamues und einer frau.

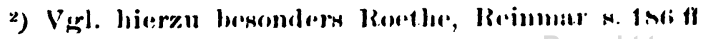


in den gesuchten ideenverbindungen keine klare anschaulichkeit, plattheit neben unwalıer sentimentalität. So ist die Mimmeburg ein ausgeprägtes beispiel fiì eine kunstverirrung der abblühenden mhd. dichtung, welcher das wesen der poesie in der übertreibung und masslosigkeit stilistischer formen liegt.

Fiir die stilistik der nachblütezeit der mhd. literatur ist die beobachtung der mit dem terminus technicus 'geblümte rede' bezeichneten stilgattung von einschneidender bedeutung. Ein nicht unbeträchtlicher teil der denkmäler ist darin abgefasst. Es ist eine mit bestimmten hier aus der Minneburg erwiesenen kunstmitteln und meist unter bestimmten bedingungen von den dichtern angewante technik. Wol zu bemerken ist: die schwülstige darstellung ist, mit wenigen ausnahmen, nicht die durchgehende, einem autor unter allen umständen eigene, individuelle ästhetische ausdrucksform, sie ist nicht 'der stil des dichters', sonder'n ist ihm nur ein stilistisches mittel, um gewisse stellen seines werkes sinnfällig auszuschmücken, besonders den eingang, seltener auch den schluss, oder um, ganz durchgeführt, gedichten meist kleineren umfangs, besonders lobpreisungen, einen - vermeintlich - höheren schwung zu verleihen. Beide stilarten, die ungeschminkte darstellung und das phrasentum der geblümten rede, gehen oft in ein und demselben gedichte nebeneinander her, wie gerade in der Minneburg. Darum ist Gervinus' urteil über den stil der Minneburg insofern nicht erschöpfend, als der vorwurf des bombastes vorzüglich nur die lyrischen einschaltungen, nicht das ganze gedicht trifft. Häufig sprechen es die dichter, wie der der Minneburg, selbst aus, dass sie in 'geblümten worten' reden wollen oder bedauern ihre unfähigkeit, dieses nicht genügend tun zu können.

So besonders Suchenwirt, und dessen erläuterungen sind für den gegensatz der beiden stilarten belehrend. Z.b. gibt er zum ged. IV in v. 557-559 die stilistische bemerkung: die red han ich gedichtet, mit worten slecht berichtet, als sich die ruis ergangen hat, und in der tat ist das gedicht ohne übertriebene redensarten im tone eines historischen berichtes abgefasst. Ebenso XI, 5 f.: daz ich mit sprüchen slechtev uort weltleicher lauff beticht ein ort: das gedicht ist in schlichter 
form gehalten. Desgleichen ist das gedicht XIV 'ungeblümt' gelassen in übereinstimmung mit v. $5 \mathrm{f}$.

pluemt ich nu end und anevank, so würd di red ein tail ze lank.

Von diesen sprüchen unterscheiden sich die, in denen der dichter auf seine anwendung der geblümten rede bezug nimmt, durch mehr oder weniger stark aufgetragenen schwulst. Es sind dies no. I, III, VIII, XIII, XVI, XVII, XVIII, XXI, XII, XLVI. Sein gewöhnliches verfahren ist, dass er am eingang in einigen phrasen seinen mangel an fähigkeit zur ausübung der 'geblümten kunst' beklagt' (einmal am schluss XXV, 371). Gerade in diesen einleitenden versen sind die redeblumen am verschwenderischesten ausgestreut, während dann der hauptteil, die schilderung der ruhmestaten des gepriesenen herrn, fast immer (nicht durchweg) in einfacher darstellungsform gehalten ist. Der schluss ist öfter gehoben, doch weniger pompös als der eingang. Dieses schema hat er nun natürlich nicht überall streng durchgeführt, aber es besteht doch eine iiberwiegende neigung es einzuhalten. In den oben angeführten versen XIV, $5 \mathrm{f}$. spricht er dies letztere selbst aus. Die technischen ausdrücke für die geblümte rede bei Suchenwirt sind spache fünde, warhafte uort geplimet I, 5 und 19; witz und nol grwegne wort, wol brdachte sinne mit weisheit auz und inne geplumt u.s. w. III, 2 ff.; geplimte chunst VIII, 5 ; dy reynen wort XIII, 4; gepluemten wort XVI, 9; grpluemte red XVII, 7; di spcehen fïnd, reim unde wort XVIII, 16; speher fünde chram, di spchen spruch durchiflovirt XLI, 18 ff.; clugge sprich, die fremden wort XLVI, 1 ff.

Derartige bezeichnungen des manirierten stils finden sich häufig in der literatur des ausgehenden 13., des 14. und 15. jh. $\therefore$. so bei suchenwirts verehrer Hugo von Montfort: or (Nuchenwirt) vacht' $z$ mit geblürmten worten an II, 143 (Wackernell): geblüemer wehe wort, mit gfloriorten uorton, gar spelvi wont XXXI, 5. 13. 26; cluoge wovt XXVIII, 245. XXXVI, 1. XXXVII. !8; sïessi wort XXIV, 5. 98; mit. bezug anf versmass und reimkunst: kluoge silmen III, 6; kluogr rime XVIII, 111. XXIV. 161;: silmen vime cluo! XXXI, 25; suessi noort mit viumen sslion !"rmessen XXIV, $5 \mathrm{f}$. Inagegen ist wider die einfache ausdrucks-

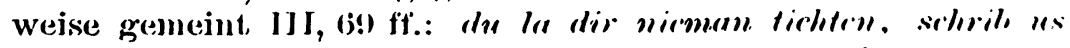

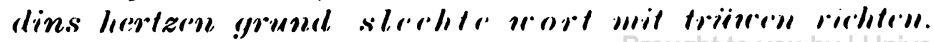


Weitere beispiele: Frauenlob (Wttmüller) sprüche no.370, s. 210 ff.: irh wil des sinnes lir flôriren, mit rôselohten worten schôn probirren, mit redebluomen sunder vrist hie rềlvar rolzierre rin lop u.s.w. swer az sol spehe blüemen. Selbst bei diesem dichter sind verschiedene grade stilistischer formgebung zu bemerken: der höchste bombast in Marienleich und in den lobsprüchen, dagegen beschränkung in den lehrhaften gedichten.

Der minne falkner (ed. Schmeller, Hadamar v. Laber) s. 207, v. 183 ff.: ist mit spcehe das gedichte noch cligg an allen orten, so sey doch sein die slichte mit groben reimen und unbesniten worten. Kluoge fünde und spahe sprüche sind mir tewre.

Quilichinus-Alexandreis: mit versen geflorieret Beitr. 10,335 .

Lassbergs LS. 1, 105, v. 1 ff.: kind ich mit rosenlechten spruchen wol geflechten vnd mit geblumpten worten u.s.w.; 2, 698 v. 127 spahe rede.

Hätzlerin 2, 73, v. 137: vnd plümt es mit hübschen worten.

Keller, Fastnachtspiele s. 260, 5 f.: und habs mit worten nit verplümt und unversunnen herausz lan farn; s. 262, 17: wann ich kan meine wort wol plïmen.

Hermann von Sachsenheim, Goldener tempel (Martin) s. 232, v. 1: spche wort, v. $100 \mathrm{f.:}$ mitt kligen worten min stifftung spech subtyln, v. 500 und 555: floriern (='mit worten schmückend preisen'); Grasmetze, Hätzlerin 2, 72, v.162: kluoge sprüche gespengelt.

Besonders lehrreich für die theorie der geblümten manier ist Der meide kranz von Heinrich von Mügeln. Der eingang ist hier ganz geschraubt, die reden der einzelnen vor dem kaiser auftretenden künste sind es weniger, sehr stark dagegen, und dies ist bezeichnend, die der Rhetorica. Sie gibt zugleich ein musterbeispiel für geblümten stil. Die ganze stelle lautet nach Cod. pal. germ. 14, mit beiziehung der Göttinger hs. (g):

bl. 9 a.

dy virde kvnst rehto'ica ging fur den w'den keys[er] da. pla sam lasúr was ir wat, dar ein gar meisterlich gesat vil manig plum von golde rich: ni ich gesach des cleides geleich. 
bl. 9 b.

nym czaich̄̄ diser krancken schrift: 'des zornes flam wekt mordes gift. wa czornes sw't dez keysers reist, da ist der veinde guft verweist. in leides norden auch zehant ir freuden sumer wirt gewant. ob schuld erwecket sinen czorn, uz sent er simner rache dorn, damit er bruches stůrm verhert und rechter czorn sein fride wert. wa aber schuld genaden gert, czu wachse wirt sins czornes swert; das v'sneit (= vor sneit?) grim̄er dē̄ ein fewr, daz gibet solt der genaden $(g$, schult genaden $P$ ) steur.'

wer tihten kan, der merket io, wy daz hi lauft transsumptio der farben; sechs und dreyszig sein der worter nach der lere mein, der sinne vir vnd czwanczig han. manch tichter ir nicht czwelfe kan, da mit er felschet meine kunst

u. s. w.

Vgl. auch bl. 24 b:

dy virde (die rhetorik) sechczig varben seczt, da mit si plủmet vnd vereczt waz rostes in dem tichte lag.

Sehr deutlich zeigt sich der unterschied der beiden stilarten in seinen von W. Müller herausgegebenen fabeln und minneliedern; die ersteren sind rein erzählend, also in natürlicher sprache abgefasst, die lyrischen gedichte dagegen sehr geblümt.

Die rhetorik ist diejenige der sieben freien künste, die die feine und zierliche, besonders aber auch die blumige sprache lehrt (vgl. Diefenbach, Glossar $496 \mathrm{~b}$ : Rhetor u. a. schoner redner, lerer der schonen und hubischen red, zierer der red u. a. [auch die minnesinger bez. meistersinger heissen rhetores], Rhetorica ein kunst von der zierheit der rede, von schon reden, s. auch Nov. gloss. s. 318). Deswegen preisen sie die dichter des 14.15. jh.'s häufig, z. b. Regen bogen MSH. 3, 468l no. 5: wer singen wil unt vrîe leunst hie wegen, der nem retorica die schon, ir bluomen wol bchak: si blüemt vür alle bluomen in dem hak, si blüemt vür all' varwe glanz, ir bluomen gênt vür golt, edclz gestcin, dic silben. rîm mit worten glanz (oder ganz nach .T. Meier, Tolande s. 75) mit blüender red gesliffen uf cin stein; si blücmet uol gesanges kranz u.s. W.; ebenda no. 6: yrammatica, si heldet warheit unt daz reht lilft ir blücmen schôn retorica. - Muscatblüt (Groote) s. 250, Iv: ich wil die drifte spissm, die lolben onch die wisen, si hoizt rethorica, der wil ich mich geriü'me'n. alle. wort kan si wol blüenen und heiat der livinste lirun, si lun 


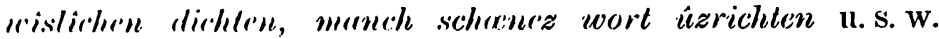
lolmarer liederhandschrift (Bartsch) s. 93: rethorica. "III spechen spruch wort mund red florieren; s. $320,25 \mathrm{ff}$ : rithorich ich loben wil: gesanges spil durchblïemet sie; s. 124, 27: rethoricâ mit worten wîs. - Vintler v. 10128 f.: so) chan ich nicht rethorica, die hïbsche red pricht enzwai. - Keller, Fastnachtspiele s. 740, 18 ff.: Tullius lert retorica, hïbschlich reden nein und ja und mit geblumten worlen dictiren und sach von sach specificiren. - Ritterspiegel von J. Rothe (Bartsch, Md. gedichte) v. 2645 ff.: di derte daz her gesm uckte rede hobischlichin lan uz gerichte und manchirlei gevime darmede und schone materien getichte. - Pfaff von Kalenberg (Bobertag, Narrenbuch) s. 7, v. 7 ff.: das ich nit hab auff disse furt suptile und goplumpte wart, alsz die rethorica hat in ir.

Die lehre vom stil gehörte im unterrichtswesen des mittelalters in das gebiet der rhetorik und war somit ein gegenstand der schulen und universitäten. Die maniriertheit des stils war für das ästhetische gefühl der epigonen der ideale ausdruck der poesie. Diese konnte gelernt werden, und somit die kunst selbst. So trifft die dichtkunst zusammen mit dem kanzleistil, in den schon seit anfang des 15. jh.'s die florierte rede eingeführt war, vgl. Zs. fda. 37, 111; Muscatblüt s. 251, Iv 55 von cler rhetorica: in mancher kantzeleyen wont si den fursten by, und mit dem briefstil. Diese hatten ihre lehrbücher in den zuerst lateinischen, dann seit ende des 15. jh.'s auch deutsch abgefassten formelbüchern und rhetoriken, die als technische ausdrücke für die ausschmückung ebenfalls die wolgezirt geplümte red, gezierte geblümbte synonima, auch kostlich colores der rethorica gebrauchen, vgl. besonders Edw. Schröder, Jacob Schöpper von Dortmund s. 28. Szamatólski, QF. 67, 19 ff. Joachimsohn, Aus der vorgeschichte des 'Formulare und deutsch rhetorica' Zs. fda. 37, 24 ff. Weinkauff und Crecelius, Alemannia 6,68. 200. Daran schliessen sich die complimentierbücher, deren Hoffmann v. Fallersleben ein beispiel im Weimar. jahrb. 1, 322 -327 herausgegeben hat, voin jahr 1654, wo am schluss ein 'Extract der verblühmten Reden und sprïich-Wörter ..... zusammen getragen' ist, vgl. auch Denecke, Beiträge zur entwicklungsgeschichte des gesellschaftlichen anstandsgefühls 
(progr. v. heil. Kreuz in Dresden 1891) s. xxv ff. Die redeblumen waren für die letzgenannten zwecke natürlich wider anderer art als in der dichtung, zumeist synonyma. - Weitere beispiele für blüemen, verblüiemen in dem speciellen hier behandelten sinne, besonders aus dem 16.17. jh., s. DWb. 2,160 und 12, 146. Heyne, DWb. 1, 459 f. und 941 (floskel). Im DWb. 12,146 wird der ausdruck redeblumen direct an Cicero und Quinctilian (flores verborum u. dgl.) angeknüpft, es ist aber für das mhd. blüemen u.s.w. vermittlung des mlat. und roman. wahrscheinlicher, vgl. Du Cange unter florere, flos, flosculus $\mathbf{u}$. a. Im mhd. kommt blïemen in übertragener bedeutung besonders in der phrase mit lobe-blüemen oder (ein) lop blüemen ausserordentlich häufig vor, zuerst in Gotfrids Tristan v. 23.

Schliesslich sei noch auf die berührung mit der schwesterkunst musik hingewiesen. Auch diese hat unter ihren technischen ausdrücken die flores, auch colores, coloratur, blumen, colorieren, blümen, vgl. Jacobsthal, Zs. fda. 20, 75 f. Plate, Ilie kunstausdrücke der meistersinger, Strassburger studien 3, 198. Adam Puschmann, Gründlicher bericht hg. von Jonas s. 11.16.26. Wagenseil, Von der Meister-Singer Holdseligen Kunst s. $531 \mathrm{f}$. Gräters Bragur 3,82, und die vereinigung von dichtkunst und tonkunst ist ausgesprochen in stellen wie der Kolmarer liederhandschrift 320, 25 ff.: vîthoricâ ... gesanges spil durchblïemet sie; 407, 21 f.: rethoricâ .. . diu ziert gesanc mit hôhem lobe; 597, $39 \mathrm{f}$ : : rethoricâ, dâa mite er blüemet sîn gesanc.

Um die historische entwicklung des geblümten stils in der deutschen dichtkunst bis zur quelle zu verfolgen, sind noch einige frühere belege für das vorkommen der betr. technischen ausdrücke anzuführen. So leitet Heinrich von Freiberg seinen Tristan ein: wâ nu rîcher kü̈nste hort, wâ schonc rede, wâblüende wort u.s.w., v. 34 f. uol geblücmet und wol geberlt ist siner (Gotfrids) blüenden vünds krans. v. $1302 \mathrm{f}$. geblïemet schône und hülbeschlüch was alle sîne réde' gar. - Erlösung v. $85 \mathrm{ff}$. ich kian nilht vil gesmicren moch die wort gezieren. Ich wil die rede furrierene an allez flồior'n. Geblêmet rede seit der grâl, n.s.w. ... dess rede irhermestlîche dar mit blózen worlen umle bar; ähnlieh derselloe diehter in dej Heil. Elisabeth v. 4:3 45 und 5.4 ff.

(in) geb) geimt jst der schluss des bohengrin, darin n. a. die kunstausdrücke 
mit !rflirlen morten. 75,67, dis brief mit grammaticâ het meistors linust geblïcmet 7577,1) vremde sprïche 7626, als der eon Lsischenbach sic (diu wort) schôn flôriert mit rîcher uitze gesmuläe 76:35 f. u.s.w. Wndlich beispiele aus dem jüngern 'Titulel: ob ich da sunderlichen gepriéfen kunde mit geblìmeten worten 862, 1; mit sèzzer rede geblìmet sin pris da wart bezellet 5097, 1 (vgl. Bech, Germ. 10, 404). Und aus Konrad voll Wrïzburg, 'Trojanerklieg v. $8 \mathrm{ff}$. (1a): da von mich "'unde'r nenen sol, daz beide rîche und urme sint an êren worden alsô blint, daz si die wîsen ringe wegent, die wol gebluomter rede pflegent; Goldene sclimiede v. 60 ff.: er muoz der kïnste meijen rîs tragen in der brüste sîn, sweir dîner virde schapelîn sol blii emen unde vlehten, daz er mit raselehten sprïchen ez flôricre und allenthalben ziere mit vî̀lînen worten, sô daz er an den orten vor allem valsche ez liuter und wilder rîme kriuter dar under und dar zwischen vil schône künne mischen in der süezen rede bluot $\mathrm{u} . \mathrm{s}$.w. Und hiermit sind wir bei den unmittelbaren quellen angelangt. Diese sind der $\mathbf{j}$. Titurel und Konrad von Würzburg, besonders dessen Goldene schmiede. Den letzteren preisen als ihren unerreichten meister Heinrich von Mügeln (Zingerle, Wiener SB. 37, 340. Schröer, ebda. 55, 457): von Wirzburg Kônrad baz polîret hât dîn lôses glas, der blînder spruch ein bilder was, ein former und ein houbetsmid: wann ich getichtes twerc von Mogelîn Heinrich solchez werc nicht mac floriern, der kunste berc ist mir zu

1) An der stelle der die beiden letzten citate entnommen sind, rühmt der dichter des Lohengrin die stilistische kunst des von papst Benedict (VIII.) an Heinrich II. gesanten einladungsbriefes zur kaiserkrönung. Auf die stilistische ahfassung solcher, wie überhaupt der verschiedensten arten briefe wurde unter umständen eine besondere sorgfalt in der wahl des ausdrucks verwendet, und es gab dafür bestimmte muster, die in den briefstellern und formelbüchern gesammelt waren. So enthält z. b. der zu ähnlicher zeit wie der Lohengrin abgefasste Baumgartenberger formularius einige beispiele für päpstliche, auf die kaiserkrönung bezug nehmende briefe, vgl. Rockinger in den Quellen und erörterungen zur bayr. und deutschen geschichte 9, 806. Dieser gebrauch mag der grund sein, weshalb der verfasser des Lohengrin das betr. schreiben des papstes in solcher redekunst abgefasst sein lässt. Es ist darum zweifelhaft, ob gerade für diese stelle, wie J. Neier, Beitr. 18, 404 annimmt, eine besondere uns unbekannte quelle vorliegt, wenn auch diese möglichkeit nicht zu bestreiten ist. 
hôch, ich stúre bit; Suchenwirt XLI, 8 ff.: als vor mit maisterscheffte von Wirtzpirch maister Chimrat dich virdikleich gepreisct hat, Maria miter unde mait ... er saz in speher. fïnde chram, bestrent mit plimen unde lile ... und tycht aus scines hertzen grunt di spehen sprüch, aurchflorirt; Hermann von Sachsenheim im Goldnen tempel (Martin) v. 554 f.: von Würtzburg meister Conraut lund es florieren bas; vgl. auch W. Grimm, Goldene schmiede s. xIx ff.

Die geblümte manier ist eine seit den letzten jahrzehnten des 133. jh.'s allgemein beliebte stilgattung, nicht nur die nachahmer Wolframs wie die dichter des j. Thiturel und des Lohengrin sind ihr verfallen oder rühmen sie wenigstens, sondern auch die verehrer Gotfrieds wie Konrad von Wiirzburg. Schon Rudolf von Ems beklagt um die mitte des jh.'s in der literarischen stelle seines Alexander das überhandnehmen der effecthascherei bei der wortwahl: alliu unser arbeit ist nu an wildiu wort yedigen, diu vor uns wâren ie verswigen und selten is mê vernomen, an diu wollen wir nu komen. Die poetische begabung schwindet eben in dieser zeit, und das ideal der kunst wird in trivialen äusserlichkeiten der form gesucht. Bei weitem nicht alle dichter haben diese mode mitgemacht. So unterscheiden sich, um nur éin beispiel zu nemmen, des Teichners gedichte von denen seines landsmanns suchenwirt formal nicht nur durch den metrischen bau der verse, sondern wesentlich auch durch den klaren, einfachen stil. In der volkstümlichen dichtung ist sie iiberhaupt nie heimisch geworden.

\section{Egen von Bamberg.}

Als sein unerreichtes vorbild in der erfindung der lilnogen vede, der wéhen sprüche nennt der dichter der Minneburg an vier stellen den meister Egen von Bamberg:

v. 451 ff. Ich könnte nicht halb das erzählen, was mir der weise meister Neptanaus sagte:

(:\% miiest iuch sagen Meistor ligen vou Babeubare der wise man,

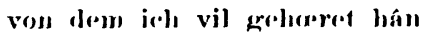
wive er lor kunst. rin moristar sî und wies ler kiusta r.in blibrolley \%wi durchsaffet hal, iun miniu lickr. v. bixk.

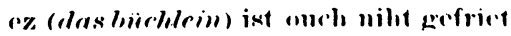
mit weher spribular slegren.

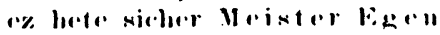

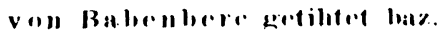




$$
\text { v. } 27111 .
$$

erfiimr a\% danne Meister Egen, laz ioh da\% hiiechlin tihte, ich weiz in in der pflihte und in den triuwen die er hât, daz er mir gêbe dar zuo rât... mich wuudert zwâr etwenne, wanu er dic klıogen rede neme die er mit worten kan beschreme.

$$
\text { v. } 5426 \text {. }
$$

ich weiz für wâr, daz Meister Egen ist an witzen sô durchvirnt $(=a l t$ geworden, ergraut), daz er die kunst hât gar durchkirnt ler vor guoten meister hie.

Von meister Egen sind zwei gedichte im Cgm. 714 fol. 161 b -170 (vgl. Keller, Fastnachtspiele $1377 \mathrm{f}$.) in schlechter überlieferung erhalten, in der hs. überschrieben $D y$ klag der mynn, il 108 reimpaaren, und las hev $z$, in 69 reimpaaren, beides mimnereden; in beiden nennt sich der verfasser, am schluss der ersten also redet meister Egen de amore, an dem der zweiten die red hat meister Egen gemacht. Sie sind durchaus in dem schwülstigen stil der geblümten rede abgefasst. Die künstelei in den metaphern und seltsamen wörtern ist hier noch stärker als in der Minneburg, und der dichter derselben hat recht, wenn er dem meister Egen in dieser beziehung seine bewunderung zollt. Es ist ihm in der tat nicht gelungen, ihn zu erreichen. Es ist kaum möglich, aus diesem wust von phrasen einen vernünftigen simn herauszulesen.

Der stoff des ersten der beiden gedichte, De amore, gleicht ganz den lobpreisungen der geliebten in den reden der Minneburg. Das andere gedicht, Das herz, eine zwiesprache des verfassers mit seinem herzen über dessen liebespein, ist nachgeahmt in v. $5013 \mathrm{ff}$. der Minneburg. - Auch in einzelheiten ist der einfluss des meister Egen auf die Minneburg zu erkennen in entlehnungen von reimen und einigen floskeln. So sind dem erstgenannten gedicht Egens entnommen die reime ïscln : beknïseln Mbg. 2371, liützelt : verhïtzelt 2315, krisem : bisem 1337 und 3589, livabelt : zabelt 2367; nachgebildet sind Mbg. 2387 honig : diptonig, vgl. Egen I, 3 honig : personiy, Mbg. 687 gezuviet : gefî̀et, vgl. Egen I, 5 gedrîet : gefrîet; ferner die ausdrücke Mbg. 1628 torlich atzeln, vgl. Egen I, 47 toerlich achzeln, IIbg. 4005 der zungen hamer = Egen I, 140, Mbg. 3526 clarificieren = Egen I, 13 u. a. Im zweiten gedicht Egens stimmen zu der Minneburg der reim Mbg. 3291 prasteln : Krasteln = Egen II, 17, die umschreibungen Mbg. 1495 triacliers trôst $=$ Egen II, 49, Mbg. 122 der sterne trôu = Egen II, 118, 
Mbg. 2431 fuur von Agrimontîn = Egen II, 124 (aus dem j. 'Titurel str. 6064); die ganze stelle Mbg. 2411-2472 ist eine erweiterte nachahmung von Egen II, 123-133. Auch stilistische kumstmittel sind in derselben weise gebraucht wie von Egen.

Ueber die person Egens ist nichts bekannt. Wilken, Gesch. der Heidelberger biichersammlungen s. 459.481 hielt ihn, in falscher auffassung der oben angegebenen citate, für den verfasser der Minneburg, welcher fehler auch in Goedekes Grundriss übergegangen ist $\left(1^{2}, 267\right.$, zurückgewiesen von Strauch, Anz. fda. 11, 252) und auch sonst widerholt wurde (z. b. von Stejskal. Zs. fda. 22, 282. Richter, Kloster der minne [s. oben s. 302] s. 8. .Jos. Haupt im Gesammtkatalog der hss. der Wiener hofbibl. 2, 168 [s. oben s. 275]. H. Holland, Gesch. der altd. dichtkunst in Bayern s.304). Im übrigen hat die behauptung Wilkens keinen anklang gefunden. Ausser letzterem und Goedeke haben über Fgen noch besonders gehandelt Docen, Altd. mus. 1, 153. v. d. Hagen, Grundriss s. 412. 442. Gervinus $2^{5}, 443$. Wackernagel, Lit.-gesch. 12, 373. 466. Bartsch, ADB. 2, 36 und Heidelberger hss. no. 208.

Zum versmass der gedichte Egens s. oben s. 285 . In den reimen finden sich noch mehr mundartliche und andere freiheiten als in der Minneburg, ausser $\ddot{e}: \omega$, $\alpha: \hat{o}$ und inf. olne $-n$ (gern[e]: lern[en], harm : erbarm[en]), auch ïu: ei (fröudle : heide' :

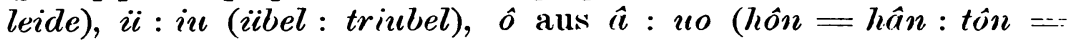
tuon) u. a. Die willkür in den reimen erlaubt kaum einen sichern schluss auf die heimat des verfassers. doch kann er wol in Ostfranken bez. Bamberg zu hause gewesen sein, vgl. besonders die infinitive ohne $-n$. I er dialekt der $h \mathrm{~s}$. ist bairisch.

Nur von den gedichten des meisters Egen konnte ummittelbare einwirkung auf die Minneburg festgestellt werden. 1)a die hauptmasse der formeln und bilder gemeingut der verwanten literatur war, so ist gegenseitige entlehmung im einzelnen schwer mit bestimmtheit zu constatieren. Eine sichere nachahmung wichtiger bestandteile der Ninneburg ist nachzuweisen. W sind dies die verse 480-5:37 bei dem nachahmer Hormanns von Sachsenheim. I)je entstehung und das wesien der mimme sind hier nach der Minneburg gess.hildert. Dass diese vorbild

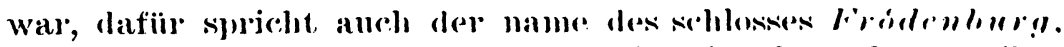

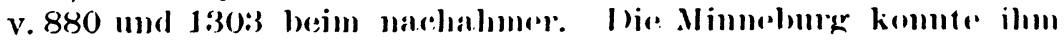
Jeicht bekannt sein, da sir ja gerade in schwalken verheritung 
grefunden hatte (schwäbische gruppe $x$ ). In seinem stil zeigt sich keine beeinflussung durch unser gedicht.

Wine gewisse, freilich nur oberflächliche ähnlichkeit mit der naturschilderung im eingang der Minneburg zeigen die verse $35-77$ von Otto Baldemanns Rede von dem laufe des römischen reichs (hg. von .J. M. Peter, Allegorisches gedicht auf den verfall des hl. römischen reichs, programm von Mïnnerstadt 1841/42, vgl. auch Zs. fda. 3, $441 \mathrm{f}$. Archiv f. ('nterfianken 11,32. MSH. 4, 882). Der verfasser war aus Karlstadt am Main und plebanus zu Ostheim bei Aschaffenburg (s. Archiv f. ('nterfranken a. a. o.), also ein landsmann des Minneburgdichters. $\mathrm{Er}$ vertritt in seinem gedichte, einer 1341 gefertigten übersetzung des Dictamen de modernis cursibus von Leopold von Bebenburg, dieselbe kunstrichtung wie jener in seinen Reden, denn sein stil ist in hohem grade geblümt. W liegt darum nahe, zwischen beiden gedichten eine gewisse beziehung anzunehmen. I)ie einwirkung müsste wol von der Minneburg als dem monumentaleren werk ausgegangen sein und nicht von dem kürzeren und wenig beachteten spruche des pfarrers. Wenn diese blosse, auf keine sicheren gründe gestützte vermutung das richtige treffen sollte, dann wäre als späteste grenze für die abfassung der Minneburg etwa das jahr 1340 anzusetzen. Jedenfalls sind die verse Baldemanns ein weiteres beispiel für die beliebtheit der geblümten rede in Ostfranken.

Zum schluss ist noch der stil der bearbeitung $B$ und der prosa zu berühren. Der verfasser von B kommt dem dichter des originals gleich an phrasenschwulst, steht aber in der beherschung der sprache noch hinter ihm zurück. Er ist entschieden ungebildeter. $\mathrm{Er}$ hat überhaupt keinen rechten begriff von satzbau, weshalb oft schwer zu erraten ist, was er eigentlich sagen will. Die bearbeitung ist also wie in der reimkunst, so auch in der behandlung der stilistischen form roher als das ursprüngliche gedicht. - Die prosa schliesst sich sprachlich eng an ihre vorlagen an und nimmt viele einzelheiten unmittelbar aus ihnen herüber, doch sind die reime kaum mehr bemerkbar. Da sie die lyrischen stellen, die 'underbinde' und minnereden, auch die bezugnehmungen auf 
meister Egen, weglässt, überhaupt die gedrechselten phrasen und auffallenden wörter möglichst meidet, so ist damit die geblümte rede ganz geschwunden. Auch der satzbau ist einfach. Somit ist die form, wenn auch unbeholfen und $\mathrm{zu}$ wenig frei aus dem originale herausgearbeitet, doch eine ungeschminkte, einer prosaabhandlung angemessene. Der stil erinnert mehrfach an nicht allzu überschwängliche mystische tractate oder an die schulprosa des Lucidarius, vorübergehend auch an die predigt (vgl. oben s. 313).

\section{V. \\ Der dichter.}

Aus der beobachtung der reime hat sich als heimat des dichters Ostfranken, als zeit der abfassung seines werkes die erste hälfte, genauer vielleicht das zweite viertel des 14. jh.'s ergeben. Nach Ostfranken gehören auch die beiden einzigen ihm gleichzeitigen persönlichkeiten, die er in seinem gedichte nennt, nämlich meister Fgen von Bamberg und der maler Arnold von Würzburg. Letzterem sind folgende verse gewidmet:

v. 4466.
ich wolt ûzer mâzen gern

daz meister Arnolt der mâlêr

von W'irzburc in ir (d. i. der geliebten)

kuntschaft wêr!

an guot müest ez in helfen sêr, wen er bedörft niemer mêr

brisilgen varb koufen kein, er nêm nur sîn pensel rein und habt in an ir rôten munt: zehant und an derselben stunt sô vil der roete dar în schïzze daz ein ganzez jâr dann flìzze Paris varb genuoc dar n̂z.

Diese stelle ist interessant für die geschichte der malerei als eines der frühesten zeugnisse für die Würzburger malerschule. Man hat angenommen (s. Janitschek, (xesch. d. d. malerei s. 218), dieser maler Arnold sei der gleiche wie der 'maler von Würzburg' in Rosenplüts gleichnamigem spruch (kellel. Fastnachtspiele s. $1180 \mathrm{ff}$.). Aber dieser schwank herulit aut einem internationalen thema, in einer frïheren fassung (koller. Esyällungen s. 173 ff. Bartsch, (xerm. 18, 41 ff.) ist der soliumjlaty gar nicht, W'üzburg, sondern eine stadt am Rluein. Ausserdem gibt es noch eine im stoff ganz abweichende croiblump.

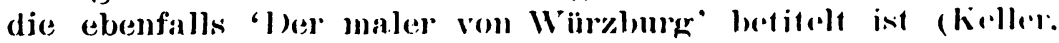

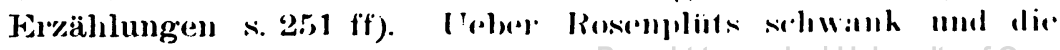


hierher gehörige literatur vgl. Michels, Studien über die ältesten deutschen fastnachtspiele s. $163-169$.

l)ie einzige anspielung auf eine bestimmte örtlichkeit ist enthalten in den versen

I956; sie (d.i. dic getiebte) kan ouch also helle lochzen als eins nalits enbrunnen wêr der grôze walt der Scherenzêr und vor tiur gể hôhen lohen.

I)amit ist die Scharnitz in den oberbairischen Alpen gemeint, im mittelalter häufig genannt, z. b. als südwestlicher grenzpunkt des bistums Freising bei $\mathrm{K}$. Roth, Beitr. 1,92 (in silua scarinza); von Veit Arnpeckh hg. von Deutinger, Beitr. zur gesch. des erzbistums München und Freising 3, 544 (pro restitutione certorum terminom silve Schernitz); als wilde waldgegend, in deren einsamkeit sich Welf, der schwiegervater Ludwigs des frommen, zurückzog, beim Annalista-Saxo, MG. SS. 6, 764 a. 1126 (juxta sitram que Scerenzerewald dicitur), s. auch K. Roth, Kozroh's Renner s. 19. 29. 104 und besonders die vielen beispiele bei Förstemann 2, 1233 und Schmeller-Fr. 2, 469. I as oben angeführte citat gehört $\mathrm{zu}$ den vielen ausschmückenden hyperbeln des gedichtes; das waldgebirge komnte dem verfasser durch eigene anschauung oder auch vom hörensagen bekannt sein: weitere schlüsse lassen sich aus seiner erwähnung nicht ziehen.

Ueber seine lebensumstände gibt der dichter keine auskunft. An einer stelle des letzten capitels scheint er aber auf seine person anzuspielen. Bei dem gericht der minne stellt die treue als letzte der klägerinnen ihren diener, einen edelknecht, vor mit der bemerkung, dass ihn und den der diz buoch getihtet hat ein und dieselbe mutter geboren habe (v. 4246 ff.). Führt er sich in der tat in dieser verkleidung selber ein, dann ist er wol von adligem stande, ein junker, gewesen.

Was sich über sein geistiges leben aus seinem werke entnelmmen lässt, bezieht sich auf seine künstlerischen fäligkeiten und auf seine bildung. Davon ist gelegentlich des stoffes und des stils die rede gewesen. 


\section{Schluss.}

Die Minneburg war eine der beliebtesten minneallegorien des 14. 15. jh.'s: das beweist die anzahl der hss., welche die der meisten verwanten gedichte übertrifft: es sind, einschliesslich der prosa und des auszugs bei der Hätzlerin, 8 hss. direct überliefert, andere lassen sich als zwischenglieder aus dem handschriftenverhältnis sowie aus Lassbergs mitteilung erschliessen; das beweist ferner die umarbeitung in prosa und die aufnahme der minnerede in das liederbuch der Hätzlerin. Die erhaltenen hss. zeigen, dass das gedicht von Ostfranken aus in Böhmen und in der Wetterau, besonders aber in Schwaben (hier auch die nachwirkung bei Sachsenheims nachahmer) verbreitung gefunden hat. - In Ostfranken ist die gattung der minneallegorien ausser durch die gedichte des meisters Fgen und die Minneburg noch durch den Spruch von der minne im garten, Cod. pal. germ. 358, bl. $74^{\mathrm{a}}-82 \mathrm{~b}$ (vgl. Karl Meyer. Meister Altswert s. 6) vertreten. I)ass auch dieses gedicht ostfränkisch ist, zeigen die reime deutlich: von dialektischen formen erscheinen nur die inf. olnne $-n$, diese sehr häutig. Auch das versmass ist glatt, die sprache nicht übertrieben. Diese allegorie steht künstlerisch in jeder beziehung höher als die Minneburg.

\section{Anhang I.}

Die aufstellung der mundartlichen erscheinungen s. $258 \mathrm{ff}$. und s. 288 ff. hat eine reihe charakteristischer eigenschaften des ostfränkischen ergeben, als deren hervortretendste das fehlen des $n$ im infinitiv und nur in diesem zu bezeichmen ist. Diese hat es zwar mit dem thüringischen und meissnischen (Heinrich von Krolewitz) gemein, es unterscheidet sich jedoch von ihmen durch den mangel anderer diesen eigenen besonderheiten. Fs fehlen den ostfränkischen überhaupt die hauptsächlichsten md. kennzeichen, denn unter len von l'aul in seines Nhd. glamm. $\$ \$$ 90-109 angeführten md. merkmalen sind nur or fïr $j$ und lie graplische verteretung von $a$ durch o hies heimisch. (ierade im letzteren fmokt mutersilheidet sich das ostfriblekehe vom thïringisehen mol moissnisehen.

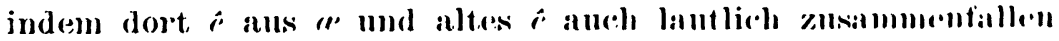

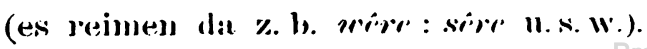


Auf nruud der oben festgestellten merkmale des ostfränkischun ist die heimat verschiedener mhd. gedichte anders oler genalter zu bestimmen als bisher geschehen. Behaghel hat jüngst in seiner rectoratsrede 'Schriftsprache und mundart' aut rinen merkwürdigen zufall in der ortsbestimmung mittelhoc:hdeutscher denkmäler aufmerksam gemacht, wonach so viele derselben in 'grenzgebieten' entstanden sein sollen. Gerade (Jstfranken wird oft als 'iibergangsgebiet' in anspruch genommen, wenn bairische und mitteldentsche, oder gar bairische und schwäbische und mitteldeutsche bestandteile in einem denkmal vereinigt vorzukommen scheinen. Es läuft dabei der irrtum unter, dass man dem ostfränkischen einen stärker ausgeprägten mu. charakter zuschreibt als wirklich der fall ist.

So lag nach Rosenhagen (Untersuchungen über Daniel vom blühenden tal s. 47) die heimat des Strickers 'etwa im östlichen Franken'. Mit recht bezweifelt Seemüller, dass aus den sprachlichen eigentümlichkeiten allein diese abgrenzung sich ergebe (Anz. fda. 19, 250). $o$ für $u$ in den praett. pl. si verlorn, si erkorn, si flogen, si enlogen, si engolten ist nicht ostfränkisch ; umgekehrt fehlen die infinitive olne $n$, die bei einem der mundart einigen spielraum gewährenden verfasser nicht gemangelt hätten.

Den in bruchstücken überlieferten roman von Blanschandin (hg. von J.Haupt, Germ. 14,68 ff.) sowie dessen hs. verweist Rosenhagen (a.a. o. s. 44) ebenfalls nach Ostfranken. Aber im gedichte passen.dazu nicht die bindungen sêre: wêre 3, 27, auch nicht in anbetracht der sonstigen genauigkeit der reime rîten : vermî̂den 3,88 . Die hs. vollends hat eine reihe vom ostfränkischen abweichender eigentümlichkeiten, so häufig $d$ für $t$, Iit für mit, ritterschaf, ginem 3,98; ginhalb 3,64 für jenem, jenhalb; simelichez 3, 107 für semelichez.

Als entstehungsgebiet von Herzog Ernst D nimmt Bartsch (H. Ernst s. Lvir) die grenze zwischen Baiern und Mitteldeutschland (etwa das heutige Mittelfranken) an, ebenso Ahlgrimm (Untersuchungen über die Gothaer hs. des ' $\mathrm{H}$. Ernst', diss. von Kiel 1890, s. 32) '), Weinhold Ostfranken (Mhd. gramm.² s. 106

1) Die ausgesprochen rheinfränk. hs. zeigt nach Ahlgrimm s. 23 'ein mischungsverhältnis md. und obd. dialektes, welches etwa auf das heutige Mittelfranken hinweist, wo md. und obrosprachgebiet zusammenstossen? 
und 1:35). Mitteldeutsche bestandteile sind allerdings vorhanden, aber gerade deshalb ist die heimat des dichters nicht in den drei bairischen Franken zu suchen. Freilich noch weniger in Baiern, denn dafür kann der einzige in betracht kommende reim $\hat{\imath}:$ ou in rum : zederboum, goum : rûm, goumen : versîmen nicht massgebend sein, zumal die diphthongierung von $\hat{u}: o u$ gerade vor $m$ am frühesten eingetreten $z u$ sein scheint (s.oben s. 272 f.).

Auch Otte's Eraclius gehört nicht nach Ostfranken, denn das $t$ der flexion in der 2. sg. praes. fehlt öfter und der schwund des $h$ ist ganz geläufig, auch neben consonanten (Gräf s. 24 f. Herzfeld, Zu Otte's Eraclius, diss. von Heidelberg 1884, s. 19 ff. E. Schröder, Gött. gel. anz. 1884, 565 anm.); umgekehrt kommen infinitive olıne $n$ nach Gräf nicht vor (oder doch nur ganz vereinzelt?).

Holz verlegt die bearbeitung A des Rosengartens (s. xcI seiner ausgabe) nach Ostfranken, Jänicke den Wolfdietrich C nach bair. Mittelfranken (Berliner heldenbuch 4, s. xxvil f.). Die reime geben für beide annahmen keine anhaltspunkte.

Der Trierer Aegidius zeigt nach Roediger 'md. bindungen', die von ihm Zs. fda. 21, 396 gesammelt sind; viele davon beweisen, dass das gedicht jedenfalls nicht ostfränkisch ist, wie Roediger ebda. s. 397 vermutet. Als heimat des schreibers des Trierer Silvester nimmt Kraus in seiner ausgabe, wo das mundartliche ausführlich behandelt ist, den nördlichsten teil Ostfrankens an (s. 43), wegen der for'm dit für diz, die im benachbarten Hessen gebräuchlich ist. Ws scheint mir eher eine nördlichere gegend, also Thüringen, anzusetzen zu sein.

Der Stricker und Otte, der verfasser des Blanschandin sowie der schreiber der hs., der dichter von Ernst J) und der des Trierer Aegidius haben ihre heimat in Rheinfranken. Für Otte werden daher die bestimmungen von (iräf und Herzfeld geltung behalten. Er mag eher noch etwas südlicher als in der Wetterau heimisch gewesen sein.

Ungekehrt sind ins ostfränkische zu verlegen:

I)ie erzählung Der vrouwen turnej (v.d. Hagen. (i.l. 1. 371-382) wegen der vielen $u$-losen infinitive (vorl. (irimm.

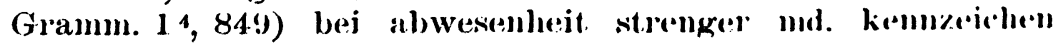


(der reim zutrahl : werhaft v. 1!) ist nicht dialektisch, sondern len unreinen reimen uveuoge: sucone 57, armuot: nôt $199 \mathrm{zu}$ zuresellen); und aus denselben griinden Des hundes not (vgl. Reissenberger s. 21; dass die 2. sg. praes. ind. im dialekt des dichters auf $-s$ ausgeht, ist nicht zu erweisen, da der reim singes: sucinges 11 bloss von dem schreiber eingeführt sein kann). l)ie mundart in der Klage Adams und Evas (v. d. Hagen, ( A A. 1, 5-16. H. Fischer, Germ. 22, 316-341, die reime s. ebda. s. 333) ist auf das ostfränkische $\mathrm{zu}$ beschränken.

Schliesslich noch eine bemerkung zum Mönch von Heilsbronn. Die ungenauigkeit seiner reime erschwert eine sichere ortsbestimmung. Jedenfalls aber zeigen sich md. formen, vgl. Wagner, QF. 15, 17 ff. (nachzutragen ist 2. sg. ind. praet. mehte im reim auf gebrehte und knehte im eingang und schluss des Fronleichnam), gemäss welcher er unmöglich in bair. Mitteltranken, wo das kloster Heilsbronn liegt, noch auch in Ostfranken zu hause gewesen sein kann. Da nun sehr häufig infinitive ohne $n$ begegnen (ausserdem wird flexions- $n$ nur nach nasalisch endendem stamm unterdrückt in den part. perf. vernomen : kom, drum : kumen, und in der 1. plur. wir lernen:stern, was als reimfreiheit aufzufassen ist), so muss die heimat des mönchs Thüringen gewesen sein. Dahin passt auch die 3. praes. ind. sêt 'er sagt' im reim auf gebet (Wagner s. 19. 21), vgl. H. Fischer, Zur gesch. des mhd. s. 29. Fr war also ein Thüringer, der in dem kloster Heilsbronn lebte. ') Die sprache seiner umgebung hatte einfluss auf ihn, und aus der damit entstehenden uneinheitlichkeit mögen sich viele der reimungenauigkeiten ergeben haben. - Auch die von Wagner (s. 3) zum vergleich mit dem dialekt des mönchs beigezogene Tristan-hs. aus Scheinsfeld (Kutschera, Zs. fda. 19, 76 ff.) ist zu sehr md. gefärbt, als dass sie dem ostfränkischen entstammen könnte, und hat überdies keine apokopierten infinitive.

Keine spuren ihrer ostfränkischen herkunft zeigen' die werke der guten zeit der mhd. dichtkunst, wie der Wigalois, Winsbeke, oder die lieder des grafen von Botenlouben. Erst

1) Ueber 'dialektmischung durch aufenthaltswechsel verursacht' $s$. Behaghel, Schriftsprache und mundart s. 29. 
die bürgerlichen dichter wie Ruprecht von Würzburg und Hugo von Trimberg nehmen die mundart auf, aber zunächst mit zurückhaltung. Um die mitte des 14. jh.'s ist sogar ein nachahmer der höfischen dichtung wie der verfasser der Minneburg, nicht mehr im stande, sich dem einfluss der mundart. zu entziehen.

\section{Anhang II.}

In der hs. $\mathrm{P}$ schliessen sich unmittelbar an die prosaische inhaltsangabe (s. oben s. 258) in nicht abgesetzten zeilen drei lyrische gedichte an, eingeleitet durch die worte vnd ditz buch hebet sich an mit dryn liedern vnd sprechen also (bl. 84a-85b):

1.

1 Die sinne wert an got ich wirlic brîse, wîse, die er îf minn geleget hât.

ez hât sîn rât

durch minne gunne uns schôn nâch im gebildet.

5 got mildet sich gen Moysê durch minn hie vor mit spîse.

Sin minn die wert hie her von anegenge strenge, wan er nam an sich menschlich wât, dar în er trat

durch menschlich kunne daz im daz was verwildet.

10 gezildet hât er âne wê uns zu der engel menge.

Hie got wol wert daz minne ist daz beste wan er durch uns gar veste

an des kriuzes este durch minne wart genegelt,

15 da mit uns wart verhegelt der helle brunne, ob sünden uns bevildet. ez gît der grîse sich uns zu spíse daz sîn minne ôf uns rîse;

20 sîn überflüzzic minnen runs gen uns ie minne gert.

2.

1 Nie bezzerz wart wan daz man got durchsinnet, ninnet, daz bringet êwiclichez heil. so machet geil

5 vor hie hs. 10 gezildet = gezilt. 11 wert =- 'bewiilurt', hs. Wwt.

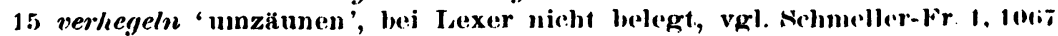

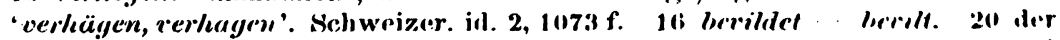

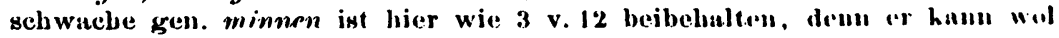
dem original angrehiren, obenso wirden 3 v. 18; vgl. olorll N. 2:44. 
der minne gluot. wo sio dir: hej\% enbrennet.

i sie trennet sorgen bint en\%wei wohin sie suoze rinnet.

l)er minne wnrt die machet trúric herzen

scherzen und bint sie an der fröuden seil.

sarr sunder meil

sie sanfte tuot wo man sie reht erkennet.

11) sie bennet mort und jâmers schrei und wendet allen smerzen.

Die mimn die wart ir dîrer vor untêten,

in wirlen orden treten

lêret sie ir stêten

und macht sie êren giric,

15 ir fröude stêt und wiric.

sie gibt dem muot der sie zn fronwen nennet.

die minne bringet

daz den gelinget,

der muot nâch irem willen ringet.

20 ir lêre snîdet sam ein grât, sie hât ie mezzers art.

3.

1 Sît minne leit so genzlich kan behûren, trûren, für wâr daz wil ich varen lân, wan ich mir hân

mit liebes bant ein liep in mich gestricket,

5 daz zwicket mir mîn sendez herz daz ich bî ir. muoz trûren.

Mîn herz ie leit grôz liep ûf sie gehiure

tiure, daz ich der lieb niht abe gân.

gar sunder wân

ich nie derkant kein wîp sô schôn geschicket.

10 sie blicket sam ein valkenterz $\hat{\mathbf{z}}$ heizer giiete fiure.

Strît ich ie leit von mîns gedanken witzen,

daz ich der minnen kritzen

ir nie torst ergitzen,

die mich gar hât bekreizt

15 und bî mir ist erbeizt,

daz ich empfant mîn herz alsô zerbicket.

wer kan durchloben

ir wirden kloben

und ouch ir lop daz unbestoben,

20 und kan durchwird daz sïeze wîp des lîp wît sunne treit.

4 starker plur. herz(e), des versmasses wegen. 10 bennet] hs. wendet. 11 'die minne bewahrt die ihr dauerhaft anhängenden vor untaten.' 15 wivic 'dauerhaft', bei Lexer nur zweimal belegt. 12 kritzen, 14 bekreizen, 16 zerbicken, 17 durchloben sind nur selten belegt, 13 ergitzen, 19 unbestoben, 20 durchwirden bei Lexer gar nicht. 
Tass diese lieder in der tat von dem dichter der Minneburg. verfasst sind, das beweist schon das sonst unbelegte crgitzen in 3,13, das auch in der Minneburg vorkommt und zwar dreimal, v. 1174 und 4933 im reim auf witzen, v. 4103 auf gesitzen; es ist $=$ er-gickezen und bedeutet 'stammeln, stotteru', vgl. Schmeller-Fr. 1, 884 gigken, gigkezen. Ebenso ist den liedern und der Minneburg gemeinsam die phrase der minnen livitzen lied $3,12=\operatorname{Mbg} .3302 \mathrm{f}$. die dồ der minnen kritzen lî̀rten wô sie wolten hin. Auch der schwülstige stil in den liedern trägt ganz die art des Minneburgdichters: hier ebenfalls die besonders in den reimen angebrachten, gesuchten wörter, die in form von subst. mit substantiv. genitiv ausgedrückten metaphern, deren mehrere in der Minneburg widerkehren. Die reime sind in den liedern verhältnismässig rein. doch begegnen auch hier kürzen auf längen gebunden: 1, 2. 3. 7. 8 hât, rât, wât, trat, 2, 11.12.13 untêten, treten, stêten. Die mundart kommt zur geltung in den apokopierten infinitiven gunne 1, 4 und im versinnern in durchwird(e) 3,20, wo beide male schon die hs. richtig $n$ weglässt. Gezilt, beriltt werden des reimes wegen zu gezildet, bevildet $1,10.16$ in folge falscher auf ungenügender sprachkenntnis beruhender etymologie nach dem muster von bint $=$ lindet etc.

In den lyrischen gedichten ist ein strenger rhythmus besonders auch hinsichtlich der einsilbigkeit der senkung regel. Nun herscht in diesen strophen dieselbe freie behandlung des schwachen $e$ wie in der Minneburg. Die apokopierten formen im reime mildet(c) 1,5, herz(e) 3,5 zeigen, dass es weggelassen werden kann, takte wie aine | génge 1, 6, värm | lán 3.2. dass es selbst nach mhd. kürze + nasal bez. liqu. als senkung verwendet werden darf. Iarum wird z. b. die 3. sg. praes. ind. sowol mit schwachem " gehraucht, wie machet 2. 3.6. als ohme (lasselbe, wie macht 2,14 . Die ans den freier gebanten versen der Nimneburg erschlossente regel (s.282) wird also durch diese lieder bestätigt.

HEIISLCBLR(i. GINTAV HHRINMANN. 